\title{
Guide to the identification of fish protozoan and metazoan parasites in stained tissue sections
}

\author{
D. W. Bruno ${ }^{1, *}$, B. Nowak ${ }^{2}$, D. G. Elliott ${ }^{3}$ \\ ${ }^{1}$ FRS Marine Laboratory, PO Box 101, 375 Victoria Road, Aberdeen AB11 9DB, UK \\ ${ }^{2}$ School of Aquaculture, Tasmanian Aquaculture and Fisheries Institute, CRC Aquafin, University of Tasmania, \\ Locked Bag 1370, Launceston, Tasmania 7250, Australia \\ ${ }^{3}$ Western Fisheries Research Center, US Geological Survey/Biological Resources Discipline, 6505 N.E. 65th Street, Seattle, \\ Washington 98115, USA
}

\begin{abstract}
The identification of protozoan and metazoan parasites is traditionally carried out using a series of classical keys based upon the morphology of the whole organism. However, in stained tissue sections prepared for light microscopy, taxonomic features will be missing, thus making parasite identification difficult. This work highlights the characteristic features of representative parasites in tissue sections to aid identification. The parasite examples discussed are derived from species affecting finfish, and predominantly include parasites associated with disease or those commonly observed as incidental findings in disease diagnostic cases. Emphasis is on protozoan and small metazoan parasites (such as Myxosporidia) because these are the organisms most likely to be missed or mis-diagnosed during gross examination. Figures are presented in colour to assist biologists and veterinarians who are required to assess host/parasite interactions by light microscopy.
\end{abstract}

KEY WORDS: Identification $\cdot$ Light microscopy $\cdot$ Metazoa $\cdot$ Protozoa $\cdot$ Staining $\cdot$ Tissue sections

\section{INTRODUCTION}

Classical keys are used extensively to assist with the identification of whole protozoan and metazoan parasites. However, such keys are of limited use for parasite identification in stained tissue sections as specific detail or features may not be present in sections, which are typically 3 to $5 \mu \mathrm{m}$ thick. References to these taxonomic keys are generally not cited in this manuscript. Although some groups of parasites possess unique features that enable a diagnosis of whole organisms to be made, many of these features may not be easily observed or identified in sections, and the degree of taxonomic detail available will vary between the major groups. For example, the presence of a good scolex for cestodes may allow identification to the order, whereas for nematodes it should be possible to identify to order, and often to suborder, by identifying the type of epithelial cells that compose the intestine. Generally, identification from sections relies on recognising morphological detail, and determining the life stage of the parasite in the fish. The size of a parasite can be crucial for identification, but shrinkage occurring after fixation may make measurements based on fresh specimens inapplicable to parasites in fixed material. The host specificity of particular parasites, the habitat (e.g. fresh water, brackish water or marine), along with water temperature and other environmental conditions, can also provide additional clues to the parasite's identity. The location of the parasite in or on the host is also important, as some parasites are only found in certain organs or tissues. For example, ectoparasites such as certain species of mobile peritrichous ciliates and monogeneans may only occur on the gills, whereas others parasitise the skin and fins as well as the gills. 
Infective agents often cause typical tissue responses that vary as the infection progresses from acute to chronic or disseminated phases. Characteristic pathological changes (or the lack thereof) associated with certain infestations can contribute to their identification. For example, the liver, gall bladder, kidney and gonads of fish may be grossly discoloured if infected with certain protozoa, microsporidia or myxosporea. Tissues may contain areas of consolidation, encapsulation, granuloma, inflammation, necrosis or repair associated with parasitic infection. When considered with relevant clinical information, the histological features can provide sufficient information to confine the search to a particular type of organism or even a specific entity. In amoebic gill disease (AGD), for example, amoebae are usually found along hyperplastic gill tissue forming characteristic lesions (Adams \& Nowak 2001). The condition of the parasite can also affect the host response. The host response to certain protozoa and to microsporidia that have dispersed from ruptured xenomas can be severe, as can the response to dead or deteriorating parasites. Conversely, a severe reaction of a host to a parasite can even obscure the presence of the parasite.

Additional descriptions for recognition of parasites in tissue sections, and the associated histopathological changes observed in fish and mammalian tissues infected with protozoan and metazoan parasites, are available in publications including Ribelin \& Migaki (1975), Ferguson (1989), Lom \& Dyková (1992), Bruno \& Poppe (1996), Gardiner et al. (1998), Kent \& Poppe (1998), Gardiner \& Poynton (1999), Roberts (2001), Nowak et al. (2002), and Woo et al. (2002). The present review features the appearance of finfish parasites in colour photographs of histological sections. Specialized terms used to describe morphological features and life cycle stages of parasites are defined in the sections describing specific parasite groups. For additional glossaries of parasitological and histopathological terms, the reader is referred to texts such as Chitwood \& Lichtenfels (1972), Lom \& Dyková (1992), Bruno \& Poppe (1996), Kent \& Poppe (1998), and Hoffman (1999).

\section{TECHNIQUES}

Fixation. Tissues begin to undergo autolysis rapidly after death and rapid fixation is essential. Small fish, less than $2.0 \mathrm{~cm}$ in length, can be preserved whole in a fixative such as $10 \%$ buffered formol saline, providing an abdominal flap has been cut and removed. This practice allows the fixative to penetrate the tissues. Individual tissues from larger fish must be dissected using a scalpel or pointed scissors and forceps, and carefully removed for fixation in formal saline. The demonstration of certain tissue components requires the use of an alternative fixative such as Bouin's solution. Poor handling before fixation can induce tissue changes; for example, the liver serosa in salmonids may show tissue changes as a result of handling with forceps including a localised necrosis or capillary dilatation.

Processing. Serial sections can provide further information for identification as diagnostic features used for parasite identification may not be visible in all sections. Ectoparasites and endoparasites that are not firmly attached to host tissues can easily be lost from the tissues during fixation and processing and require care during processing. In some cases orientation of the tissue is important; for example, longitudinal sections of gills are usually preferable for examination due to the 3-dimensional structure. Lastly, it is important to correlate findings whenever possible from both gross and histological examination.

Staining. A range of staining techniques is used for observing parasites in tissue sections and the most widely used is the standard haematoxylin and eosin stain, commonly called H\&E. This stain is often sufficient for identification of larger parasites such as helminths, leeches and crustacea. In the H\&E method the nuclei of cells are stained by the haematoxylin whilst the cytoplasm is coloured by the eosin. In addition, special staining techniques designed to demonstrate diagnostic features of organisms can be useful for identification (Table 1). For example, Giemsa staining is useful for a range of protozoan parasites and some metazoans (Table 1), particularly for distinguishing myxosporidian spores, as the polar capsules stain dark against a pale background. In addition, Feulgen's nuclear reaction for selective staining of DNA and the periodic acid-Schiff (PAS) reaction for staining of polysaccharides may be helpful for identifying a variety of parasites (Table 1). Gram staining or acid-fast staining (Ziehl-Neelsen) can be used to stain Microsporidian and Myxosporidian spores in tissue sections or smears. The latter technique is also used for observation of coccidian oocysts. A combination of H\&E-stained sections and other stains can help to identify some parasite structures. For example, to observe various features of amoebae in tissue sections, H\&E, Feulgen, and Giemsa stains are often used. Some selective staining methods have been developed, such as the method described by Sterba et al. (1989) for selective staining of hooks of echinococci, cysticerci and tapeworms in histological sections.

Immunohistochemical staining procedures and nucleic acid probes for in situ hybridisation have been developed for specific identification of some economically important fish parasites (see e.g. Bartholomew et al. 
Table 1. Examples of special stains used for identification of parasites in histological sections. PAS: periodic acid-Schiff

\begin{tabular}{|c|c|c|c|}
\hline Stain & Parasite group & Feature & Source \\
\hline Acetic acid /Alum carmine & $\begin{array}{l}\text { Platyhelminthes } \\
\text { Acanthocephala }\end{array}$ & & \\
\hline Alcian blue/PAS & Neoparamoeba sp. & Individual organisms & Zilberg \& Munday (2000) \\
\hline Feulgen nuclear reaction & $\begin{array}{l}\text { Flagellates, Kinetoplasts } \\
\text { Paramoebae }\end{array}$ & Parasome & \\
\hline Gram & $\begin{array}{l}\text { Microsporidia } \\
\text { Myxosporidia } \\
\text { Myxosporea and coccidia }\end{array}$ & $\begin{array}{l}\text { Spores (Gram-variable) } \\
\text { Polar capsules (Gram-positive) } \\
\text { Sporogonic stages (modified Gram stain) }\end{array}$ & $\begin{array}{l}\text { Franzen \& Müller (1999) } \\
\text { Schachner \& Holzer (2001) }\end{array}$ \\
\hline Giemsa & $\begin{array}{l}\text { Flagellates } \\
\text { Rosette agent } \\
\text { Myxosporidia } \\
\text { Metacercariae }\end{array}$ & $\begin{array}{l}\text { Nucleus } \\
\text { Individual organisms } \\
\text { Polar capsules } \\
\text { Cysts - blue/red }\end{array}$ & $\begin{array}{l}\text { Arkush et al. (1998) } \\
\text { Roberts (2001) }\end{array}$ \\
\hline Heidenhain's azur solution & Platyhelminthes & & Roberts (2001) \\
\hline Iodine or Best's carmine & Myxobolus & Spores & Desser \& Paterson (1978) \\
\hline Mallory's triple stain & Platyhelminthes & & Roberts (2001) \\
\hline Methylene blue & Myxosporidia & Polar capsules & \\
\hline PAS & $\begin{array}{l}\text { Ichthyophonus sp. } \\
\text { Rosette agent } \\
\text { Arthropods }\end{array}$ & $\begin{array}{l}\text { Polysaccharides in the wall of resting spore } \\
\text { Individual organisms } \\
\text { Chitin }\end{array}$ & Arkush et al. (1998) \\
\hline Warthin-Starry stain & $\begin{array}{l}\text { Rosette agent } \\
\text { Microsporidia }\end{array}$ & $\begin{array}{l}\text { Individual organisms } \\
\text { Pre-spores and spores }\end{array}$ & $\begin{array}{l}\text { Arkush et al. (1998) } \\
\text { Kent et al. (1995), }\end{array}$ \\
\hline Ziehl-Neelson (acid-fast) & $\begin{array}{l}\text { Coccidia } \\
\text { Microsporidia } \\
\text { Myxosporidia }\end{array}$ & $\begin{array}{l}\text { Oocysts } \\
\text { Spores } \\
\text { Spores }\end{array}$ & Franzen \& Müller (1999) \\
\hline
\end{tabular}

1990, Howard \& Carson 1993, Antonio et al. 1998, Muñoz et al. 1998, Morris et al. 2000, Kent et al. 2001, Cunningham 2002, Young \& Jones 2005). Because of the rapid and continuing development of these staining techniques for the identification of parasites, the reader is referred to sections on specific parasite groups in this review, and is advised search the current literature on specific parasites for the most up-to-date methodology.

\section{TAXA}

Flagellates. Flagellates represent an assemblage of different, divergent groups of small protozoa (cells often about $15 \mu \mathrm{m}$ in size or smaller). The trophozoites move by means of 1 to many flagella, and most have a single nucleus, but exceptionally some have more monomorphic nuclei. Most reproduce by longitudinal (symmetrogenic) binary fission. Sexual reproduction, which occurs in a few groups, is by syngamy (the union of 2 gametes to form a zygote) involving the fusion of haploid gametes. The group includes both autotrophs (organisms capable of synthesizing organic substances from inorganic compounds) with chloroplasts, and heterotrophs (organisms obtaining energy from organic substances produced by other organisms) without chloroplasts. Heterotrophs are often equipped with an elaborate buccal apparatus.
Dinoflagellates. Dinoflagellates are (unicellular) protists that exhibit a great diversity of form; this group includes gill and skin parasites that can cause serious disease of freshwater, estuarine, and marine fish (e.g. Amyloodinium, Piscinoodinium). Five genera are reported as parasites of fish (Noga \& Levy 1995). Gill infestations may be associated with epithelial hyperplasia, degeneration and necrosis, along with haemorrhage. Petechiae and inflammation may be observed in the skin.

In tissue sections, the trophonts are attached to gill or skin tissue, and may appear ovoid, pyriform or saclike, with a single eccentric nucleus but without visible flagella. Flagella are visible in the motile infective stages, gymnospores or dinospores). An attachment disc or holdfast organ (often attached to the trophont body by a short peduncle), with projections that adhere to, or penetrate, host cell membranes may be visible. Trophonts of photosynthetic species possess coloured chloroplasts; reserves are starch granules and fat droplets. Procedures for staining these features are available in texts such as Clark (1981).

Trypanosomatids (Trypanosoma). Trypanosomatids are transmitted to fish hosts by leech vectors, and can be detected in the peripheral blood of various freshwater and marine fish species. Infections may be chronic or acute; severe parasitaemia can result in anaemia and death. The body is leaf-like with a single 
nucleus. A disc-shaped or dish-shaped kinetoplast (an organelle consisting of an agglomeration of DNA fibres within the trypanosome mitochondrion) is present near which a single flagellum arises. The flagellum is directed anteriorly, running underneath the body surface and thus forming the outer margin of an undulating membrane extending along one side of the body. The free portion of the flagellum protrudes anteriorly. The nucleus and kinetoplast (often relatively small, but close to the origin of the flagellum-associated undulating membrane) may be visible in blood vessels in tissue sections stained by Giemsa, Janus green or Feulgen stains. However, in Giemsa-stained blood smears, characteristics such as the nucleus, kinetoplast, flagellum, and undulating membrane are more clearly visible than in sections. When stained with Giemsa stain, the cytoplasm stains blue, and the nucleus, kinetoplast, and flagellum stain red or violet. The exact differentiation of fish trypanosome species can be difficult even in smear preparations, and the appearance of the flagellates can be quite variable (Lom \& Dyková 1992).

Bodonids. Bodonids (e.g. Cryptobia, Ichthyobodo and Trypanoplasma) are flagellates with 2 unequal (heterodynamic) flagella originating from a deep broad surface invagination, termed the flagellar pocket. The kinetoplast is usually single, and extremely large.

Bodonid genus Cryptobia. Cryptobia species occur on gills of freshwater fish and occur on a wide range of fish in Africa, Asia, Europe and North America, and do not appear to be species-specific; in addition, some infestations of marine fish have also been reported. Most Cryptobia spp. are commensal and rarely pathogenic. The size range is 12 to $22 \times 3.5$ to $4.5 \mu \mathrm{m}$. Some intestinal Cryptobia spp. have been found in freshwater fish (cichlids) and in some marine fish; endozoic species may be more species-specific than ectozoic species. Cryptobia of the digestive tract are generally found in the lumen but occasionally spread to tissues, where they may occur intracellularly within macrophages. In heavy infections, the intestinal species $C$. iubilans provokes extensive inflammation characterised by oedema and infiltration of macrophages in the stomach and intestine of cichlid fishes, as well as necrosis of the liver and spleen.

Cryptobia are elongate to triangular protozoans with 2 flagella, one directed forward and the other (recurrent flagellum) originating anteriorly but running backward along the body and extending posteriorly from the body. This latter flagellum sometimes raises the pellicle to form a short, narrow undulating membrane. The kinetoplast is long and slender. The flagellates adhere to the host tissue with their recurrent flagella while feeding. Gill Cryptobia are not usually firmly attached and may become detached and lost during tissue processing. However, when they are pre- sent, the prominent elongated kinetoplast is often visible in preparations stained by Feulgen or Giemsa procedures.

Bodonid genus Ichthyobodo (=Costia). Ichthyobodo is an ectoparasite of surface tissues and all freshwater fish species are considered susceptible. Infestations have also been reported in marine fish. Historically, $I$. necator has been reported to lack host specificity, but morphological and genetic evidence suggests that parasites presently classified as I. necator may actually represent more than 1 Ichthyobodo species, with each species exhibiting some host specificity (Lamas \& Bruno 1992, H. A. Callahan, College of Veterinary Medicine, North Carolina State University, Raleigh, NC, USA, pers. comm.). Heavy infestations can cause epithelial hyperplasia (Fig. 1), exhaustion of mucous goblet cells, and dermal accumulations of macrophages, followed by oedema and sloughing of epidermal tissue.

The free-living form is 10 to $15 \mu \mathrm{m}$ in long and usually oval or kidney-shaped. It has 2 pairs of flagella and the 2 longer flagella are used to create movement which results in a jerky motion. The other flagella extend posterio-laterally and from a deep flagellar pocket. A long tubular mitochondrion contains numerous nucleoids so that there are many small kinetoplasts throughout the body. The stage attached to fish curls in a cuneiform or pear-like shape, with 2 flagella pointed away from the fish surface. The pellicle around the cytostome serves as an attachment plate, through which the cytostome and the associated cytopharyngeal canal protrude as a finger-like process into the host epithelial cell. In tissue sections, parasites are often attached to skin or gills, and the flagella are not generally visible (Fig. 1). The nucleus is usually discernible in routine sections stained by H\&E or Giemsa. Numerous dot-like kinetoplasts may be observed by Feulgen staining.

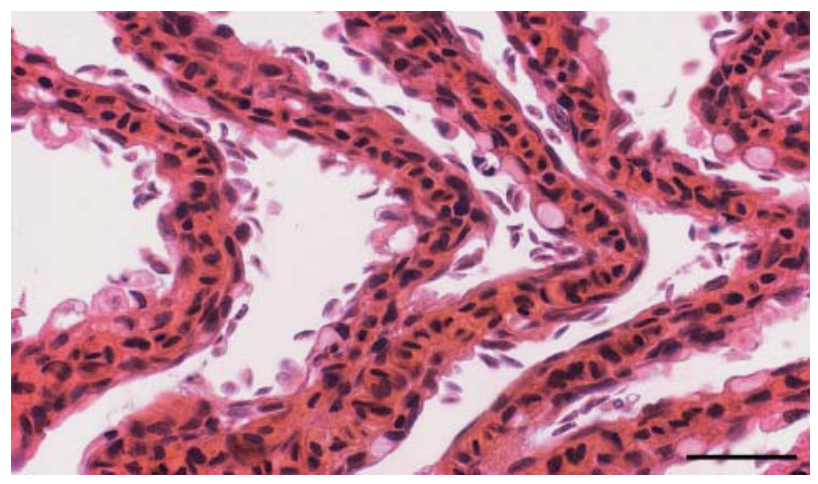

Fig. 1. Flagellate: bodonid. Ichthyobodo necator attached to the gill lamellae of rainbow trout Oncorhynchus mykiss. Heavy infestation of $I$. necator can cause marked hypertrophy and hyperplasia of lamellar epithelial cells. H\&E. Scale bar $=50 \mu \mathrm{m}$ 
Bodonid genus Trypanoplasma. Trypanoplasma species, especially $T$. boreli, T. bullocki and T. salmositica are known to cause disease and mortality in many fish species, both wild and cultured. They are parasites of the bloodstream and tissues of both freshwater and marine fish species. A particular species may have a broad host range. In some texts the protozoan $T$. salmositica is referred to as Cryptobia salmositica (e.g. Woo \& Poynton 1995, Kent \& Poppe 1998). Other texts distinguish the blood biflagellates of fish (Trypanoplasma), which normally have a 2-host life cycle (with a leech vector), from the ectoparasitic Cryptobia, which have a direct life cycle (e.g. Lom \& Dyková 1992, Hoffman 1999). The latter classification is followed here.

Severe infections of fish by some Trypanoplasma species can cause anaemia and organ changes in the host such as haemorrhagic foci, congestion of blood vessels and capillaries, oedematous kidney glomeruli, ulcerative lesions of the abdominal cavity and intestinal necrosis.

Trypanoplasma species appear similar to Cryptobia species, with a short anterior free flagellum, and long recurrent flagellum extending from the flagellar pocket at the anterior apex of the body. The recurrent flagellum forms a wavy undulating membrane, much wider than that of Cryptobia. The large, elongated, densely staining kinetoplast is often visible in preparations stained by Feulgen or Giemsa (Fig. 2). Morphological features such as the prominent undulating membrane are observed in smears stained by Giemsa. The pleomorphic nature of these parasites can make precise identification difficult, even in smear preparations; for example, $T$. salmositica can vary in size from 6 to $25 \mu \mathrm{m}$ long $\times 2$ to $4 \mu \mathrm{m}$ wide.

Diplomonadida. Diplomonads (e.g. Spironucleus) are found in various freshwater and marine fish and are spread via direct transmission. Trophozoites are

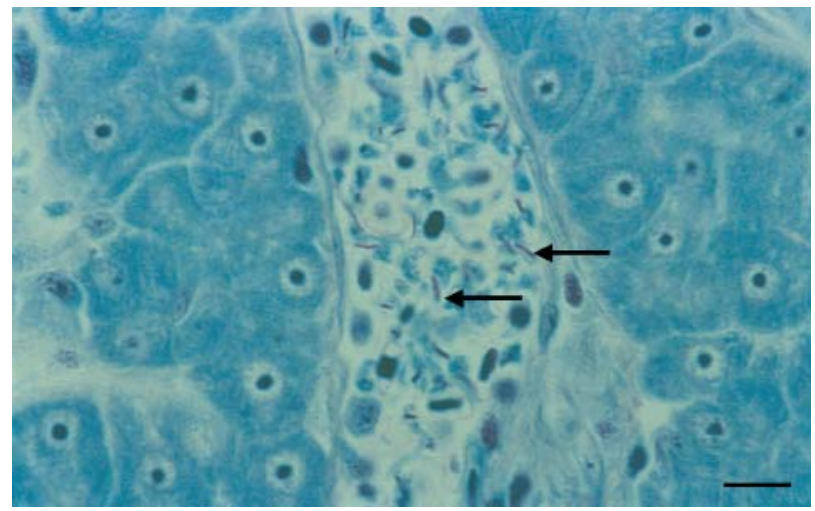

Fig. 2. Flagellate: bodonid. Trypanoplasma (Cryptobia) salmositica with prominent kinetoplasts (dark staining elongate structures at arrows) in the central vein of a juvenile chinook salmon Oncorhynchus tshawytscha. May-Grünwald Giemsa. Scale bar $=10 \mu \mathrm{m}$ frequently intestinal endocommensals, but they can spread to the gallbladder or other organs in cultured fish. Spironucleus spp. are oval or pyriform, flattened parasite measuring 7 to $12 \mu \mathrm{m}$ in length, with 3 pairs of anterior flagella and 1 pair of recurrent posterior flagella (Poynton \& Sterud 2002).

Fig. 3 shows trophozoites of Spironucleus salmonis in the central vein of juvenile rainbow trout Oncorhynchus mykiss. In this case, there is no degenerative or cellular reaction. However, in salmonids reared under adverse conditions infection by diplomonads in general can result in emaciation, enteritis, cholecystitis, extensive necrosis and a granulomatous response in affected organs. Outbreaks involving these parasites in hatchery reared salmonids appear to be related to poor husbandry including low oxygen and inadequate diet.

Histologically, Spironucleus spp. are primarily found in the intestinal crypts, and there are crypt and villous changes, such as the marked crypt hyperplasia and villous atrophy and inflammation. Occasionally crypt necrosis occurs.

Diplomonads are 'doubled' flagellates appearing as a fusion of 2 individuals. Each flagellate trophozoite thus consists of 2 units called karyomastigonts, with each karyomastigont including a nucleus and an adjacent group of 4 kinetosomes from which extend 3 anterior and 1 recurrent flagellum. Thus, each 'doubled' parasite has 8 flagella. The paired nuclei, which are important for diagnosis and flagella of trophozoites, may not be visible in routine tissue sections stained with $H \& E$, but features such as the capsules of the parasites are visible in preparations stained with iron haematoxylin, Feulgen or Giemsa. For example, axostyles (tube-like cytoskeletal structures which may

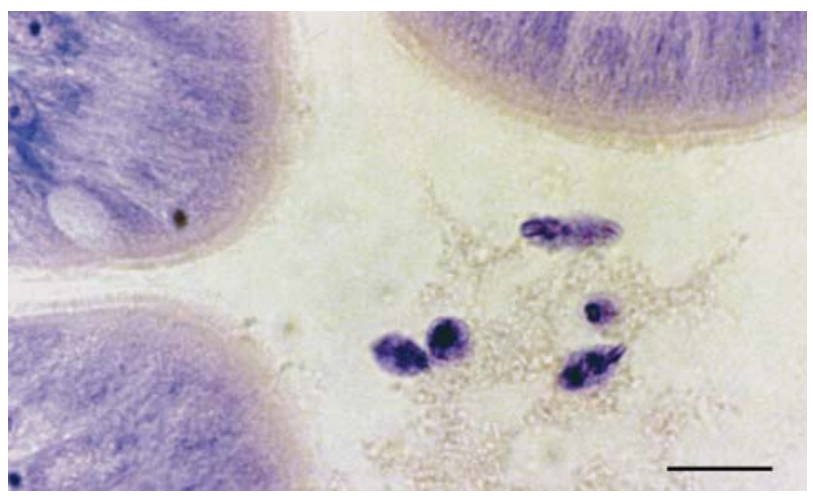

Fig. 3. Flagellate: diplomonad. Ovoid to pyriform diplomonad trophozoite, identified as Spironucleus (formally Hexamita or Octomitus) salmonis in the lumen of a pyloric caeca of a rainbow trout Oncorhynchus mykiss. Two nuclei are evident in the anterior (larger) end of some parasites, and a portion of the flagellar pocket can be seen in the posterior end, but no flagella are visible with this stain. May-Grünwald Giemsa. Scale bar $=8 \mu \mathrm{m}$ 
appear as a single fused rod) are often visible in preparations stained with iron haematoxylin, and nuclei can be demonstrated by Giemsa staining. The flagellar pockets often appear as 2 clear bands extending the length of the parasite in Giemsa-stained smear or imprint preparations. Overall, precise identification of diplomonads to genus and species requires transmission and scanning electron microscopy (Poynton \& Sterud 2002).

Amoebae. Amoebae represent a rather heterogeneous assemblage of protozoa that use pseudopodia or simple protoplasmic flow as their means of locomotion in the trophic stage. A few species of amoebae such as certain Entamoeba and Schizamoeba species are specific endocommensals in the digestive tracts of fish, and are associated with disease only when present in high numbers. Some species form protective cysts. Most amoebae infecting freshwater or marine fish are amphizoic species, i.e. free-living forms that can colonise fish under certain conditions. Some amphizoic species can cause severe disease (e.g. intestinal amoebiasis, systemic amoebiasis, and AGD) with high mortality. Severe infections of internal organs are often associated with granulomatous changes, whereas advanced cases of AGD are characterised by hyperplastic lesions resulting in fusion of gill lamellae and the formation of cavities (Fig. 4). Among the amphizoic species that have been identified from fish are species of the genera Neoparamoeba (= Paramoeba), Thecamoeba and Trinema from the gills, Naegleria from the intestine, and Acanthamoeba, Hartmanella, Vahlkampfia and Vexillifera from a variety of tissues. Fig. 5 shows trophozoites of Acanthamoeba sp. in the liver of carp Cyprinus carpio. The 'foamy' appearance of the cytoplasm is due to the presence of conspicuous vacuoles.

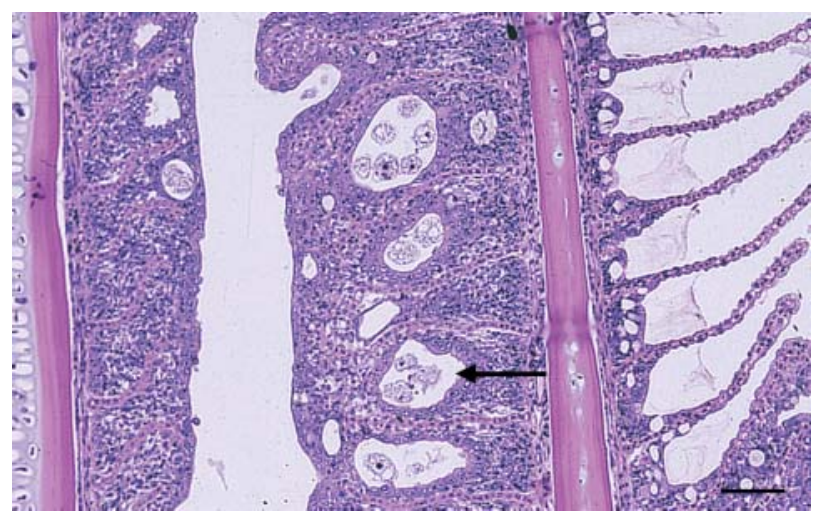

Fig. 4. Amoeba. Neoparamoeba sp. among the secondary lamellae of turbot Scophthalmus maximus (arrow). Trophozoites found on the gill are usually found along hyperplastic gill tissue showing increased mucous cells and fusion of gill lamellae forming characteristic 'cavity' lesions such as that seen at arrow. H\&E. Scale bar $=50 \mu \mathrm{m}$

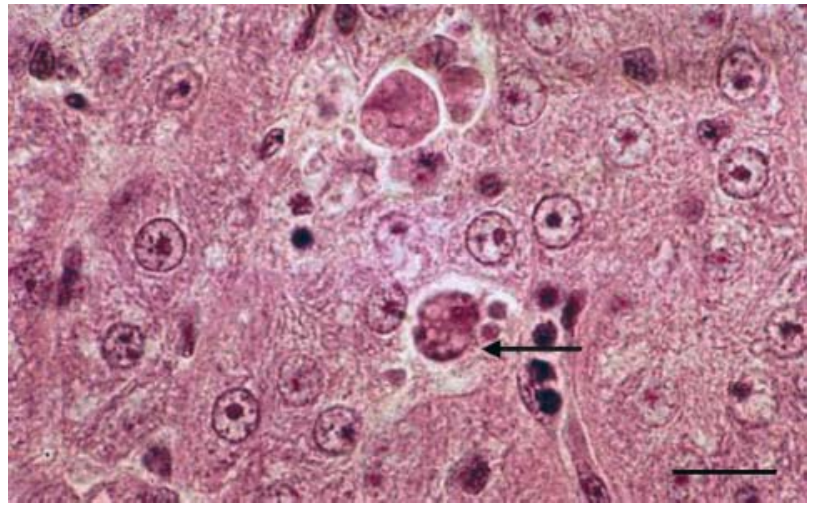

Fig. 5. Amoeba. Acanthamoeba sp. trophozoites in the liver of carp Cyprinus carpio. Cytoplasm contains conspicuous vacuoles, giving it a 'foamy' appearance (arrowed). H\&E. Scale bar $=25 \mu \mathrm{m}$

Identification of amoebae in tissue sections can be difficult because they often do not retain characteristic locomotive, feeding, and resting features after fixation and staining (Hoffman 1999). However, some features characteristic of amoebae may be visible, such as cytoplasmic vacuoles and certain features of the nucleus such as the size and location of the endosome (nucleolus). The distinctive ectoplasmic ridges and folds of the gill parasite Thecamoeba may be visible in tissue sections using Heidenhain iron haematoxylin, or Feulgen reagent with fast-green counterstain (Sawyer et al. $1974,1975)$. The prominent circular to ovoid parasome of AGD agent Neoparamoeba can often be observed adjacent to the nucleus in histological sections using Feulgen dyes. The parasome stains Feulgen-positive, and more than 1 may be present per amoeba. The parasome has been identified as a symbiotic organism, Perkinsiella amoebae (Dyková et al. 2000), and is found in a variety of amoeba species. Additionally Neoparamoeba has been shown to be Alcian blue positive (Zilberg \& Munday 2000). Immunofluoresce staining procedures have been developed for identification of this parasite in gill smears and sections (Howard \& Carson 1993).

Ciliates. Ciliates are highly organised protozoa, with the cell covered by a pellicle composed of a cell membrane subtended by flat pellicular alveoli (membranebound vesicles). These organisms typically possess cilia or compound ciliary organelles, which are used for feeding and locomotion, in at least 1 stage of the life cycle and a subpellicular infraciliature (a complex fibrillar network associated with ciliary basal bodies) is present even when cilia are absent. Somatic cilia may occur anywhere on the organism other than the oral region, where oral cilia occur. Two types of nuclei are normally present, with 1 to several generative diploid micronuclei, and 1 to several vegetative polyploid macronuclei. Ciliates typically divide by transverse 
binary fission, and rarely by budding or multiple fission. A contractile vacuole (osmoregulatory organelle) is usually present. Identification of ciliates requires the observation of important ciliate features, such as oral and somatic cilia and macro-and micronuclei, in live as well as stained specimens. For stained specimens, staining with nuclear stains and impregnated by Klein's dry silver method can be used, or with protargol for ciliature and nuclei of whole specimens (Lom \& Dyková 1992).

Suctorian ciliates. Capriniana (= Trichophrya) are ectocommensals on a variety of freshwater fish species. Other genera such as Erastophrya (freshwater) and Endosphaera (freshwater and marine) parasitise other ciliates (peritrichs) that are ectocommensals on fish. Adult suctorians are sedentary, without cilia, and are equipped with few to many suctorial tentacles for ingestion of prey. The suctorians are attached to the host surface either directly, or by means of a noncontractile stalk. Internal or external budding produces offspring, and the migratory stage (daughter individual) is equipped with rows of cilia for locomotion.

In sections, Capriniana $(\sim 20 \mu \mathrm{m})$ are usually observed as variably shaped sac-like elongated organisms attached ('glued') to the secondary lamellae of gills by a flattened broad attachment surface (scopuloid) (Fig. 6). The most distinctive feature is the presence of apical suctorial tentacles projecting from the cytoplasm. A large macronucleus is often visible and digestive vacuoles and melanin granules may be visible in some individuals.

Vestibuliferan ciliates. The vestibuliferan ciliate Balantidium is ellipsoidal or oviform in shape and, although normally commensal, has been observed to cause the disease balantidiosis in a variety of fresh-

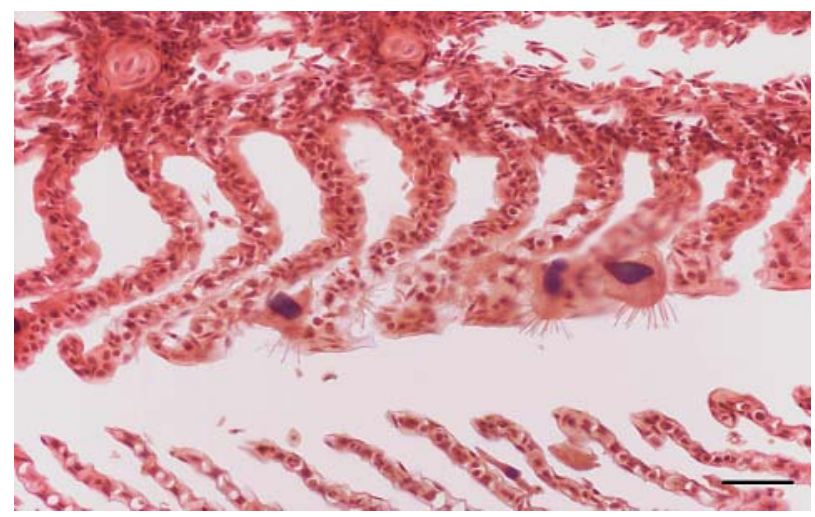

Fig. 6. Ciliate: suctorian. Capriniana (= Trichophrya) attached to the secondary gill lamellae of a rainbow trout Oncorhynchus mykiss. An oval macronucleus and characteristic rod-shaped suctorial tentacles are evident on some parasites. Suctorians are ectocommensals and usually elicit little host response. H\&E. Scale bar $=20 \mu \mathrm{m}$ water and marine fish. This single cell organism is either ellipsoidal or oviform in shape and about 40 to $140 \times 25$ to $115 \mu \mathrm{m}$ in size. Some species appear to be host-specific, whereas others parasitise fish in different genera. Balantidium species are endocommensals in the intestine, but can become histophagous parasites. These ciliates are uniformly covered with longitudinal ciliary rows and have a cytostome (buccal apparatus) preceded by a vestibular cavity lined with distinctive vestibular kineties (a kinety is a row of cilia basal bodies and their kinetodesmose, a compound fibre that joins cilia into rows). Silver or protargol impregnation of smears is necessary to reveal characteristic patterns of the kineties.

In tissue sections, ovoid parasites may be visible in the intestinal lumen or between intestinal mucosal folds, or may be associated with intestinal ulcers and penetrate into the sub-epithelial tissues (although the severity of infestation, clinical signs and histological appearance of infection are different for each species). The parasites may adhere to the intestinal mucosa by their cytostomes. Parasites have a single macronucleus, which may be ovoid, bean-shaped, or irregularly shaped, and several fragments of the macronucleus may be visible in a ciliate in section. Large cytoplasmic vacuoles may also be present. Histological changes in severe cases may include intestinal desquamation and extensive ulceration, and granuloma formation in deep tissues.

Hypostomatan ciliates. These ciliates possess a ventral cytostome with an elaborate and often curved cytopharyngeal apparatus. Chilodonella is a skin and gill ectoparasite of freshwater, estuarine and brackish water fish. Most freshwater fish are considered susceptible to chilodonellosis, and an infestation can cause fish to secrete excessive mucus. The body of Chilodonella measures 40 to $70 \mu \mathrm{m}$ in length and is dorsoventrally flattened and ovoid, with or without an indentation at the posterior end. The single macronucleus is oval, there is a single micronucleus, and the parasite has no posterior adhesive organelle. The ventral ciliature is reduced to 2 longitudinal belts close to the body margins. Gill lesions include hyperplasia, fusion of lamellae, impaired gill function and necrosis. Respiratory failure due to gill hyperplasia is considered to be the primary cause of fish mortality.

Brooklynella is ectoparasitic on the gills of marine fish (particularly stressed fish) in mariculture and aquaria. Brooklynella measures approximately 40 to $80 \mu \mathrm{m}$ in length, has a flattened, ovoid body with a posterior indentation, and the ventral side of the body is equipped with an elevated posterior adhesive organelle. The entire ventral surface is covered by kineties, except where the adhesive organelle is located. There is a single macronucleus but many small 
micronuclei. Like Chilodonella, Brooklynella can cause high mortality.

These ectoparasites may be lost during histological processing. The body shape of the parasites observed in histological sections will vary depending on the plane of section. The ovoid macronucleus is often visible in sections stained with H\&E. Silver or protargol impregnation of smears clearly reveals the patterns of the kineties on the ventral side of the body.

Hymenostomatan ciliates (and colpodid ciliate Cryptocaryon). The buccal ciliature of hymenostomatan ciliates such as Ichthyophthirius, Tetrahymena and Uronema and the colpodid ciliate Cryptocaryon is inconspicuous, and the body is mostly covered with uniform somatic ciliature. The cytostome at the bottom of the buccal cavity opens into an inconspicuous cytopharynx.

Tetrahymena. Tetrahymena spp. have been reported from a variety of freshwater fish species, and can cause serious disease and mortality in both tropical and temperate species. Infection may cause general debilitation, skin haemorrhage and exophthalmia. These simple ciliates range in size from 30 to $55 \mu \mathrm{m}$ and are pyriform, with a radially symmetrical body covered with ciliary rows, and 1 macro- and 1 micronucleus. Certain species are polymorphic. Tetrahymena does not form cysts. Some studies have suggested that the parasite invades the host through the integument, especially through sites of injury. Tetrahymena may be present in a variety of organs and tissues such as scale pockets, muscle (especially between muscle fibres), abdominal cavity, intestine, liver, eye socket, cranial cavity and spinal cord and may destroy the surface tissue and also internal organs. For example, T. corlissi occurs in the muscle fibres of guppy Poecilia reticulata (Fig. 7).

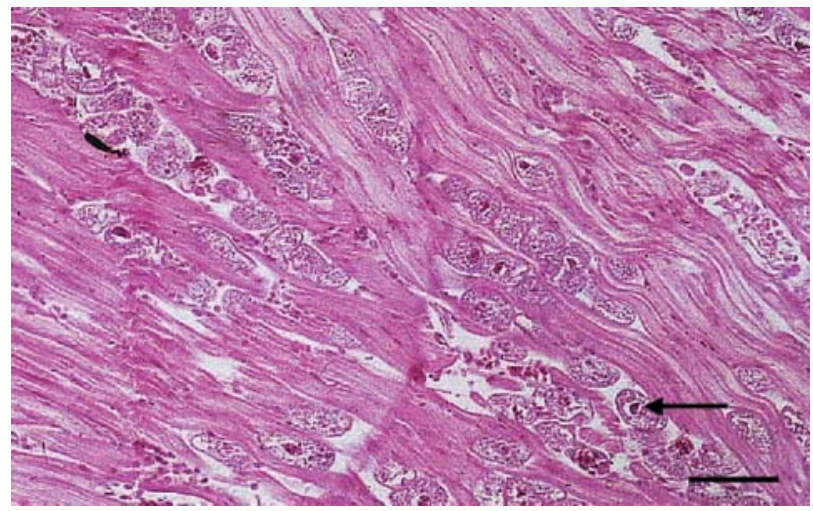

Fig. 7. Ciliate: hymenostomatan. Tetrahymena corlissi between muscle fibres of the guppy Poecilia reticulata. Some of the parasites show the characteristic pyriform shape, whereas others are distorted by crowding into tissue. Oval macronucleus is visible in some organisms (arrow). H\&E. Scale bar $=50 \mu \mathrm{m}$
In tissue sections some Tetrahymena show the characteristic pyriform shape or appear ovoid, but they also may be distorted when numerous parasites are crowded in a tissue. The prominent oval macronucleus is usually visible in H\&E-stained sections. Silver or protargol impregnation procedures of smears are usually used to view patterns of the kineties and other features such as the oral cavity.

Ichthyophthirius multifiliis. Ichthyophthirius multifiliis is a common freshwater (protozoan) ciliate that normally infects the gills and skin and causes 'Ich' or white spot disease. The life cycle includes the theront ('swarmer'), a small migratory stage that initially infects the fish; the trophont, a feeding and growing stage in the skin and gills of the fish; the tomont, an encysted stage that develops on a convenient substrate after the trophont has matured and escaped from the host; and tomites, which are produced by division from the tomont within the cyst. The tomites break through the cyst wall to become theronts and infect a host.

The spherical to ovoid trophonts may reach $1 \mathrm{~mm}$ or more in diameter, have short cilia covering the entire surface, and have a single horseshoe-shaped macronucleus (Fig. 8) and a single round or oval micronucleus. Trophonts live in surface tissues of fish, including the epidermis of the skin, the gills, and the lining of the oral cavity, causing characteristic 'white spot' disease. Most of the parasites are situated on or above the basal lamina, but occasionally may be found in deeper tissues when infections are extremely heavy. Infections may be associated with epithelial hyperplasia (especially in the gills), mucous cell hyperplasia, and skin erosion.

The trophonts are readily identified in tissue sections of skin or gills by their large size $(0.5$ to $1.0 \mathrm{~mm}$ diameter in sections) and the horseshoe-shaped macronucleus (which may not be apparent in all sections). The trophont may be irregularly shaped in stained

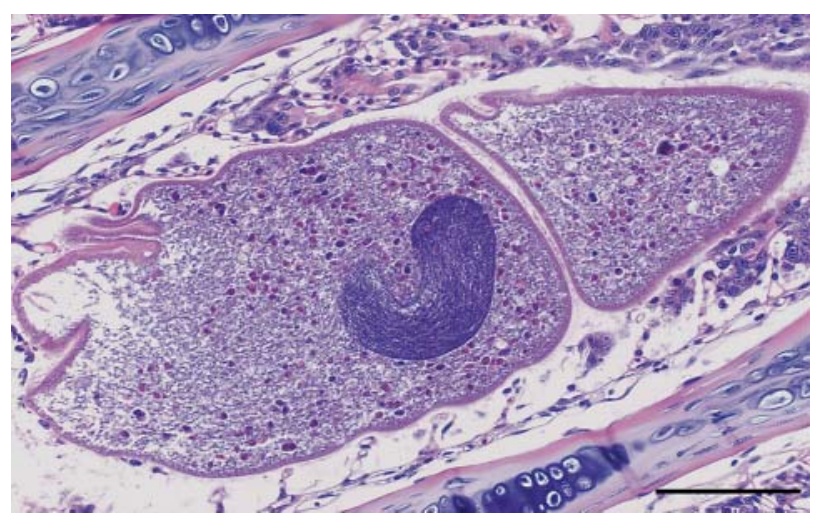

Fig. 8. Ciliate: hymenostomatan. Ichthyophthirius multifiliis trophonts in the gills of rainbow trout Oncorhynchus mykiss. One parasite shows the characteristic crescent-shaped macronucleus; cilia are not easy to distinguish in stained sections. H\&E. Scale bar $=200 \mu \mathrm{m}$ 
tissue sections. H\&E staining is useful, although cilia are not always visible.

Uronema. Uronema is a facultative parasite that can infect many marine species over a wide range of temperatures (at least $8^{\circ}$ to $28^{\circ} \mathrm{C}$ ) and salinities (20 to 31). Uronema parasitizes fish predisposed by environmental stress, and can cause high mortality. It is a small $(20 \times 40 \mu \mathrm{m})$, ovoid, sparsely ciliated form with a flat uniciliated anterior pole, a long caudal cilium, a long buccal area, a scutica (hook-like field of kinetosomes associated with the posterior end of the paraoral membrane), a single macronucleus, and a single micronucleus. Uronema can cause heavy infection of gills, skin, viscera and somatic musculature of most fish species, and also nervous tissue in southern bluefin tuna Thunnus maccoyii. Uronema is considered the marine equivalent of Tetrahymena, although it is classified in a different order within the Subclass Hymenostomata.

In histological sections, Uronema is most commonly observed in the skeletal muscle (particularly the highly vascularised 'red' muscle) with associated tissue destruction, but may occur in other tissues. The parasites may appear ovoid in tissue sections, with the single macronucleus often visible. The ciliate cytoplasm often contains ingested blood cells. Protargol or silver impregnation techniques of smears are used to view patterns of kineties and other morphological features.

Cryptocaryon. This parasite is the agent of marine 'white spot' disease, playing a similar pathogenic role in the marine environment as freshwater Ichthyophthirius. Cryptocaryon chiefly affects the skin and gills of warm-water $\left(17^{\circ} \mathrm{C}\right)$ marine fish, but the organism has been found parasitizing fish at temperatures as low as $12^{\circ} \mathrm{C}$. With the exception of elasmobranchs, Cryptocaryon appears to infect fish indiscriminately, given suitable temperatures and salinity $(>20)$, and can cause high mortality. Cryptocaryon was formerly grouped in the Order Hymenostomatida, Class Oligohymenophora, with Tetrahymena and Ichthyophthirius, but recent gene sequence and ultrastructural data suggest that Cryptocaryon has a closer affinity to the Order Colpodida, Class Colpodea.

The life cycle is similar to that of Ichthyophthirius, with theronts (infective stage), trophonts (feeding stage in fish tissues), tomonts (encysted stage on substrate) and tomites (formed by division of a tomont). The large ovoid trophont (180 to $700 \mu \mathrm{m}$ in diameter) has 4 ellipsoid macronuclei that are often connected by a fibril to form an open ' $U$ ', and 4 to 7 micronuclei. The large trophonts are readily apparent in tissue sections of skin and gills, and may be located above or beneath the basal lamina. In addition, portions of the 4 macronuclei may be apparent. Infections of gills and skin may be associated with marked epithelial cell and mucous cell hyperplasia.
Sessile peritrichs. Sessile peritrichs are filter-feeding ciliates that can be found attached to the skin and gills of fish. Some genera such as Apiosoma, Epistylis and Propoxydium are found on freshwater fish, Ambiphyra species are found on freshwater and brackish water fish species, Riboscyphidia is found on freshwater and marine fish, and Caliperia is found on marine fish species. The epizoic species found on fish are essentially ectocommensals or symphorionts that use their hosts as a moving substrate that allows them greater access to food particles (organic debris or waterborne bacteria). They are specifically adapted to life on the surface of certain species of fish. The presence of high numbers of sessile peritrichs on the host surface is uncommon, and most often occurs in fish predisposed by debilitating environmental or infectious factors, or both.

As with all peritrichs, sessilines have a conspicuous buccal ciliature encircling the apical (oral) pole, and the antapical (aboral) pole is equipped with a holdfast organelle, the scopula. Sessilines may have noncontractile stalks (secreted by the scopula) or contractile stalks. The stalk may bear 1 ciliate, or if branched, it may bear multiple ciliates (or zooids) and form a macroscopic colony. To move to another host, the zooid transforms into a disc-shaped telotroch or migratory stage, with an equatorial locomotory fringe of pectinelles (fused cilia). Sessilines can also form protective cysts.

Sessile peritrichs are recognised in tissue sections as conical or urn-shaped protozoa (in longitudinal-section through zooids) attached to the surface of the skin or gills, with minimal associated histopathological changes in host tissues. For colonial species, stalks bearing more than 1 zooid may be visible. The macronucleus, which can be ovoid to horseshoe-shaped or ribbonshaped depending on the species, may be visible (either as a whole or pieces thereof). Giemsa is useful to stain the cilia and nuclei in tissue sections; protargol staining can be used to view these features in whole organisms. Observation of living ciliates is desirable for accurate description of morphological features.

Mobile peritrichs. Mobile peritrich ciliates (e.g. Hemitrichodina, Trichodina, Tripartiella, Vauchomia) attach only temporarily to the substrate while feeding, and have been found on (or in) both freshwater and marine fish. Some species appear to be host-specific, whereas others are common to many different hosts. Mobile peritrichs may be ectozoic or endozoic. Some ectozoic species occur only on the gills or show a preference for the gills (e.g. Trichodinella and Tripartiella species), but others occur indiscriminately on the gills and skin (e.g. some Trichodina species), and only live on the skin (e.g. some Trichodina species). Endozoic mobile peritrichs usually live in the urinary tract; how- 
ever, species inhabiting the intestine or the reproductive tract of marine fish are also known. The mobile peritrichs of fish are essentially commensal, feeding on waterborne particles and bacteria, as well as detritus and particles from the fish surface. They may become numerous, particularly in stressed or debilitated hosts, and heavily infested fish may exhibit epithelial hyperplasia, excessive mucus secretion, and/or epidermal sloughing. In severe infestations, normally ectozoic trichodinids may penetrate into the gill or skin tissue, and may be found in the rectum and cloaca.

The body of these protozoa is usually discoidal to bonnet-shaped, although the shape may vary widely in live organisms. The ciliates attach temporarily to the substrate by means of a slightly concave adhesive disc at the antapical pole (aboral pole); this disc is reinforced by a system of proteinaceous skeletal elements. Above this disc are 3 ciliary wreaths, 2 of them locomotory and 1 consisting of tactile immobile cilia. The buccal (adoral or peristomial) ciliary spiral at the apical (oral) pole may form one-half turn to 3 turns, depending on the species. After attachment the sharp rim of the border membrane bites into epithelial cells resulting in irritation.

Depending on the orientation of the parasites in sections, Trichodina appear as saucer-shaped, hemispheric, dumbbell-shaped, and sac-like or flattened cylindrical organisms in cross-section, or as round discs in oral or aboral view, measuring approximately $50 \mu \mathrm{m}$. The taxonomy of these ciliates is based largely on the structure of the buccal ciliature, and the appearance and constituents of the adhesive disc (e.g. denticulate ring). This ring consists of refractile denticles, indicating a hard structure. The horseshoe-shaped macronucleus may be visible (Fig. 9). Some elements of the ciliary wreaths and adhesive disc may also be apparent (Fig. 10).

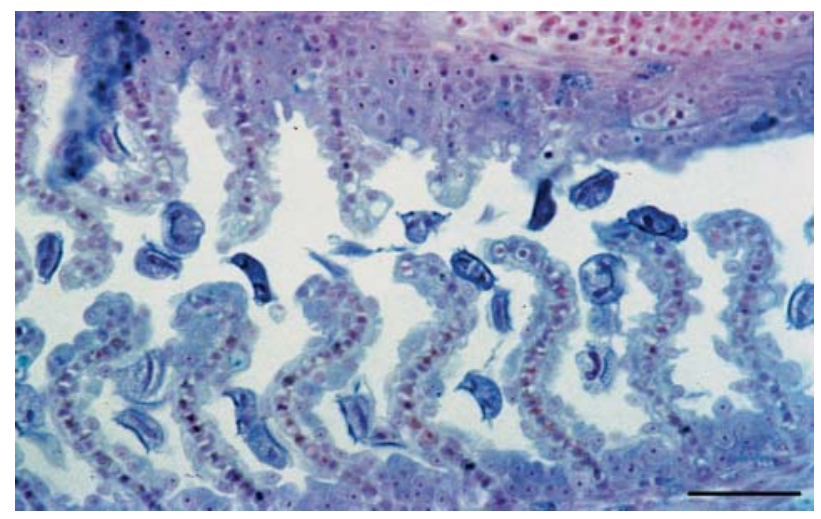

Fig. 9. Ciliate: mobile peritrich. Trichodinids on the gill of a rainbow trout Oncorhynchus mykiss. Horseshoe-shaped macronucleus and refractile structures of the adhesive disc (portions of the denticulate ring) are visible in some parasites (arrows). Giemsa. Scale bar $=50 \mu \mathrm{m}$

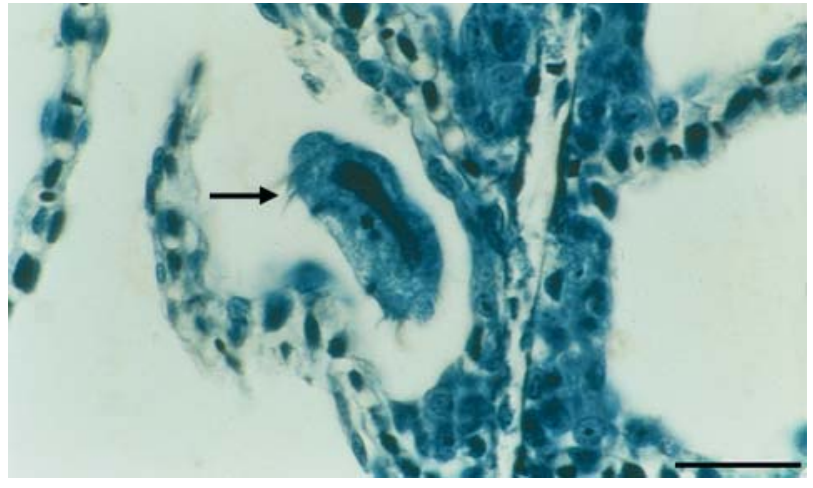

Fig. 10. Ciliate: mobile peritrich. Cross-section of a trichodinid on the gill of a Pacific salmon Oncorhynchus spp. showing the domed shape and the slightly concave aboral adhesive disc. The dark-staining macronucleus is visible, and cross-sections of adoral ciliary wreaths can be seen adjacent to the adhesive disc (arrow). Iron haematoxylin. Scale bar $=15 \mu \mathrm{m}$

Features of the adhesive disc are revealed by silver impregnation (Klein's technique) of smear preparations, and protargol impregnation of smears is used to show buccal ciliature.

Apicomplexans. Apicomplexans are parasitic protozoans equipped with a special set of organelles, the apical complex, which are used to penetration into host cells. The apical complex, located at the apex of the cell of some stages, can only be visualised using transmission electron microscopy. Apicomplexans of fish are exclusively intracellular parasites, and the life cycle often requires 2 hosts. These parasites feed by osmotrophy uptake of nutrients through the cell surface by absorption), pinocytosis (engulfment of fluid droplets), through a cytostome, or by a combination of these methods. As a rule, apicomplexans of fish have a fixed sequence of asexual proliferative generation(s) (merogony), sexual generation (called gametogony, gamogony, or gametogenesis), and spore-forming stages (sporogony). The infective stages are mobile, elongate sporozoites (which are protected by sporocysts) and oocysts. In Eimeria and Isospora spp. unsporulated oocysts are passed in the faeces; sporulation may occur endogenously but in most species they sporulate exogenously.

Upon entering a host cell, the sporozoite begins to grow (first becoming a feeding, growing, non-dividing trophozoite), then transforms into a large meront (schizont), which divides by multiple fission (or rarely by budding or binary fission) to produce several to many elongated cells, merozoites. The merozoites enter other host cells and may repeat merogony once or twice more, with the various merogony generations generally showing morphological differences. The final generation of merozoites initiates gametogony after entering another host cell. Some merozoites grow 
and differentiate into large oocyte-like macrogametes. Other merozoites differentiate into male gamonts (microgamonts), which divide to produce either 1 to 4 non-flagellated microgametes, or many slender flagellated microgametes. Macrogametes are fertilised by microgametes, and the resulting zygote initiates sporogony. The zygote divides and secretes a protective envelope, the oocyst wall, and becomes an oocyst. Each oocyst contains 2 to many sporozoites, which are enclosed within separate shells called sporocysts.

Haemogregarina. Haemogregarina species infect fish blood cells and are mostly found in marine fish, although some species occur in freshwater fish. In haemogregarines, merogony and transformation of merozoites into gamonts occur in blood cells of fish, whereas differentiation of gamonts into gametes, zygote production, and sporulation resulting in oocyst formation occur in leech vectors. The dividing stages of Haemogregarina occur in both leucocytes and erythrocytes, whereas non-dividing gamonts are found only in erythrocytes.

Apicomplexans infecting fish blood cells are usually observed and identified in Giemsa-stained blood smears rather than tissue sections, but heavy infections may be detectable in blood cells in tissue sections. In sections, enlarged erythrocytes containing meronts of haemogregarines can appear to be extracellular parasites. In Giemsa-stained blood smears, Haemogregarina gamonts are elongate or crescent-shaped, frequently with one end tapered and the other rounded, and are often as long as the erythrocyte. Meronts in erythrocytes or leucocytes are rounded or worm-like, and each meront can produce from 2 to 36 oval to crescent-shaped merozoites.

Many Haemogregarina infections are mild and chronic although some haemogregarines may be serious pathogens. An example is $H$. sachai infection of turbot Scophthalmus maximus, which can cause nodular lesions of haematopoietic tissue and other organs; lesions are characterised by a fibrous capsule, parasitecontaining macrophages in varying stages of degeneration, and liquefying necrosis at the centre (late stage lesions).

Babesiosoma and Dactylosoma. Babesiosoma and Dactylosoma species have been found in freshwater and marine fish (e.g. turbot and the Atlantic mackerel Scomber scombrus). For dactylosomatids (Babesiosoma and Dactylosoma), merozoites and presumptive gametocytes have been identified from fish erythrocytes (not leucocytes), but the supposed leech vectors have not been identified. Most life stages of Babesiosoma and Dactylosoma in fish have not been well studied; however, it is known that Dactylosoma merogony produces 3 to 8 merozoites in erythrocytes, often in a fan-like arrangement, whereas Babesiosoma mero- gony produces not more than 4 merozoites in rosettes or a cross-shaped arrangement.

Eimeriida. Many species of 'true' coccidia (e.g. Calyptospora, Cryptosporidium, Eimeria, Epieimeria, Goussia and Isospora) have been identified in fish, with infections occurring in both freshwater and marine fish species. 'True' coccidia are exclusively intracellular tissue parasites. Although many coccidian species develop in intestinal epithelial and subepithelial cells of the fish host, extra-intestinal infection are also common including the gonads. This is a very important problem in the carp and goldfish culture. However, among species that infect extra-intestinal sites no strict organ specificity may be observed.

Direct transmission has been demonstrated for some piscine coccidia, whereas evidence indicates that another host might be involved in the life cycles of certain other piscine coccidians. In most piscine coccidia oocysts show endogenous sporulation while still in the fish host tissue. Both thin- and thick-walled oocysts are described. The thin oocyst wall easily breaks to release the sporocysts, which are often found free. As a rule, merogony gametogony, and sporogony take place within the same tissue at the same site. Eimeria oocytes in the lamina propria of a sea bass Dicentrarchus labrax are illustrated in Fig. 11.

Heavy infections of intestinal coccidians, such as Goussia carpelli in the intestine of common carp, can cause severe enteritis. Also occurring in carp in Europe is G. subepithelialis, which causes a nodular coccidiosis of the small and posterior intestine (Fig. 12). Goussia species infecting extra-intestinal sites can cause significant inflammation and necrosis in affected tissue.

Various developmental stages of coccidians can be observed in histological sections. The parasite is located within a host membrane-bound parasitophorous vacuole within the host cell. Fish eimeriids

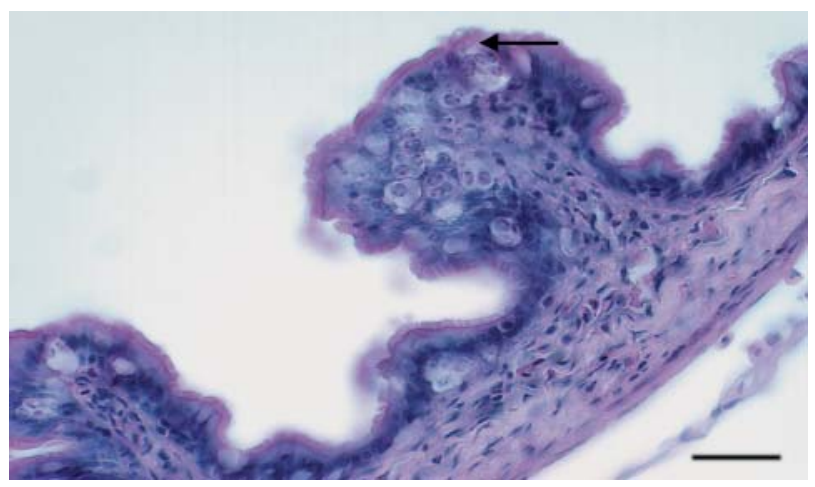

Fig. 11. Apicomplexa: 'true' coccidian. Several oocysts of Eimeria spp. in the lamina propria of a sea bass Dicentrarchus labrax. Note: release of unsporulated oocysts into lumen (arrow). H\&E. Scale bar $=30 \mu \mathrm{m}$ 


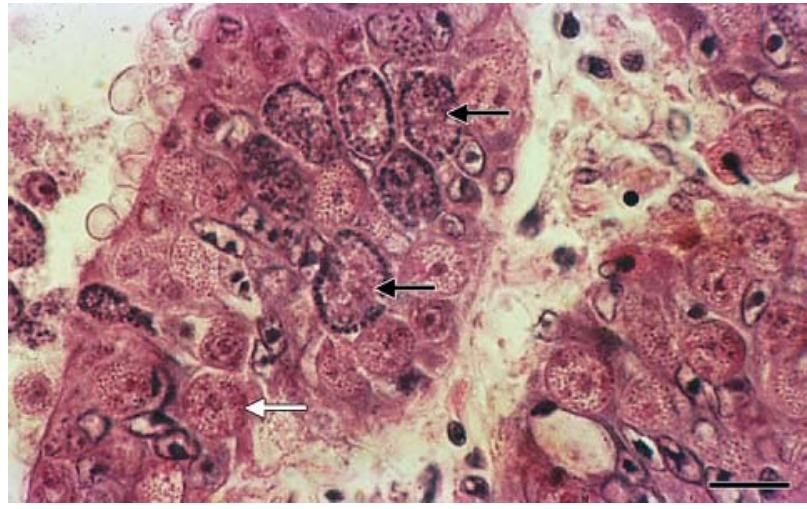

Fig. 12. Apicomplexa: 'true' coccidian. Macrogametocytes and microgametocytes (sexual phase of the life cycle) of Goussia subepithelialis in the intestinal epithelium of carp Cyprinus carpio. Macrogametocytes (recognised by their prominent central nucleus and cytoplasmic amylopectin granules; white arrow) outnumber microgametocytes (characterised by numerous small peripherally located nuclei; black arrows). H\&E. Scale bar $=15 \mu \mathrm{m}$

can be located either deep in the cytoplasm of a cell or just beneath the host cell membrane. In some species or genera (Epieimeria, Goussia), this submembrane location (appearing 'epicellular' or 'epicytoplasmic') is of diagnostic value (Fig. 13).

Meronts are single and membrane-bound, and mature merozoites appear in rosettes, in tightly packed bundles, or at random. Merozoites are often described as sausage- or banana-shaped, and often show basophilic staining in H\&E stained sections. Macrogamonts (macrogametocytes) have a large, centrally located nucleus and a cytoplasm containing numerous amylopectin granules and a few lipid droplets (Fig. 12). Macrogamonts often show eosinophilic staining in

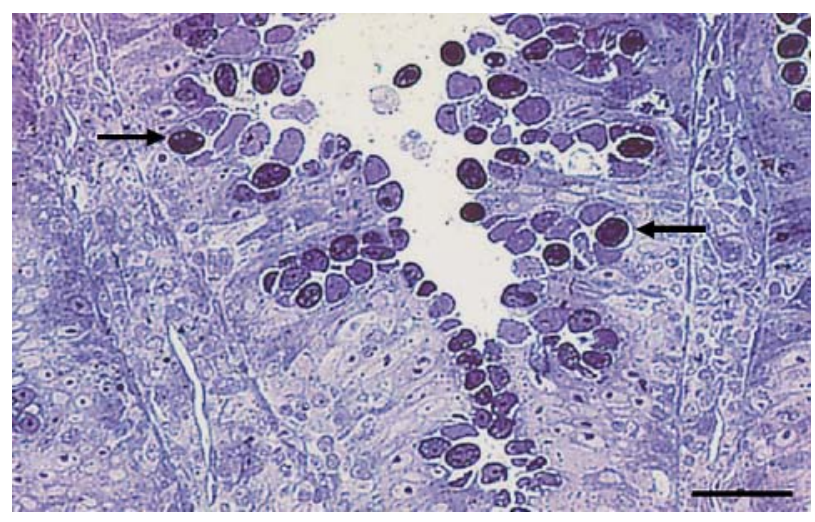

Fig. 13. Apicomplexa: 'true' coccidian. Goussia janae in the intestine of dace Leuciscus leuciscus. Coccidia are localised immediately beneath the plasma membrane within the microvilli of the intestinal epithelial cells (arrows). In this submembrane position (called 'epicytoplasmic' or 'epicellular'), the parasites appear to be extracellular. Semi-thin section, toluidine blue. Scale bar $20=\mu \mathrm{m}$
H\&E-stained sections, and the amylopectin granules also stain PAS-positive. The less numerous microgamonts (microgametocytes) have a great number (100 or more) of peripherally located nuclei, and stain more basophilic than macrogamonts by H\&E (Fig. 12).

Oocysts in various stages of maturity may also be observed. Sporulated oocysts of most piscine coccidians enclose 2 to 8 thick-walled sporocysts containing ellipsoidal, club-shaped or sausage-shaped sporozoites, which sometimes are flexed to fit in the sporocyst. Acid-fast staining is often used for demonstration of sporozoites within oocysts in tissue sections (Fig. 14). A residual body (sporocyst residuum) mainly containing PAS-positive amylopectin granules may also be visible inside each sporocyst. Oocyst and sporocyst structure is important for taxonomy of these parasites. Oocysts of Cryptosporidium contain 4 'naked' sporozoites, without sporocysts. Oocysts of many Eimeria and Goussia species infecting the intestinal epithelium are enclosed in 'yellow bodies' which appear as a thin layer coating the oocyst wall, or as large amorphous bodies containing 1 or more oocysts (or occasionally no oocysts, suggestive of an abortive evolution of the oocyst). The 'yellow bodies' are remnants of completely degraded cells originally invaded by the macrogamont, and contain lipofuscin or ceroid (products of cell degradation), and sometimes amylopectin granules.

Mesomycetozoea (Ichthyosporea). Ultrastructural and molecular studies have indicated that Dermocystidium salmonis, Ichthyophonus hoferi, and the salmonid 'rosette agent' Sphaerothecum destruens (Arkush et al. 2003) belong to an unusual group of protists placed evolutionarily between fungi and animals (Ragan et al. 1996). Cavalier-Smith \& Allsopp (1996) assigned this group to a new class (Ichthyosporea) within the Subphylum Choanozoa. Recently, the Class Ichthyosporea has been renamed as the Class

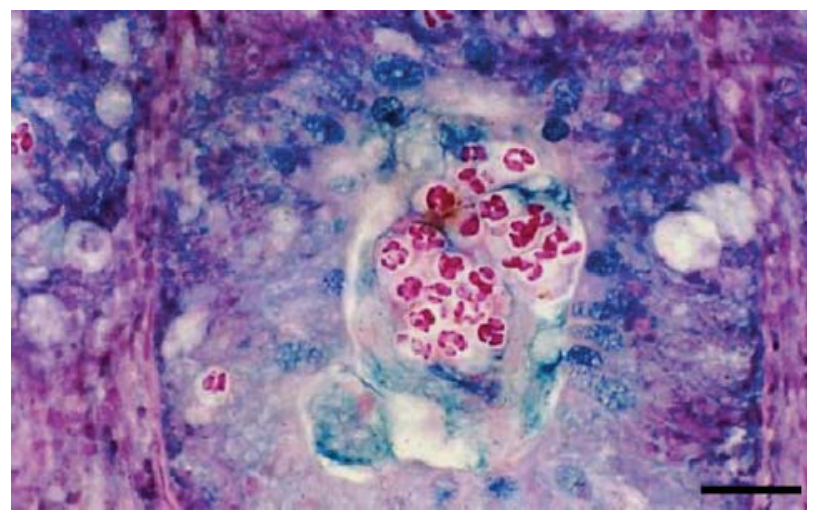

Fig. 14. Apicomplexa: 'true' coccidian. Goussia carpelli in the intestine of carp Cyprinus carpio showing acid-fast-stained sporozoites, within sporocysts, within oocysts. Ziehl-Neelsen. Scale bar $=20 \mu \mathrm{m}$ 
Mesomycetozoea (Mendoza et al. 2002). These parasites are considered members of the Kingdom Protozoa in the six-kingdom classification scheme devised by Cavalier-Smith (1998a) on the basis of ultrastructural and molecular studies (Cavalier-Smith 1998b), but are discussed with fungi in some texts. This novel phylogenetic group has been referred to as the DRIP clade (an acronym of the original members: Dermocystidium, rosette agent, Ichthyophonus and Psorospermium) (Ragan et al. 1996) or Mesomycetozoa clade (Herr et al. 1999).

Dermocystidium. Currently the taxonomic status of many members of the catch-all genus Dermocystidium remains unclear. The genus Dermocystidium has been used for various pathogenic organisms that infect aquatic animals including amphibians and a variety of freshwater fish, including cyprinids, salmonids, centrarchids, eels, northern pike Esox lucius, stickleback Gasterosteus spp., smelt Hypomesus pretiosus, and perch Perca fluviatilis. Dermocystidium spp. have in common spherical stages, designated as spores that have some morphological similarities. The organisms have often been relegated to unspecified groups of lower fungi, and formation of hyphae in $D$. koi has been suggested as evidence of the possible fungal nature of this parasite. The branching hyphae have a thick homogeneous wall. D. salmonis has recently been placed in the new Class Ichthyosporea (now Mesomycetozoea) within the Subphylum Choanozoa (phylum Neomonada) in the Kingdom Protozoa (Cavalier-Smith 1998b).

The species infecting fish locate either in epithelial tissue of the skin, fins and gills or in visceral organs. The infections often appear as small round, oval or elongate white nodules or cysts in the affected tissue.

In histological sections, species assigned to the genus Dermocystidium are characterised by a spheri-

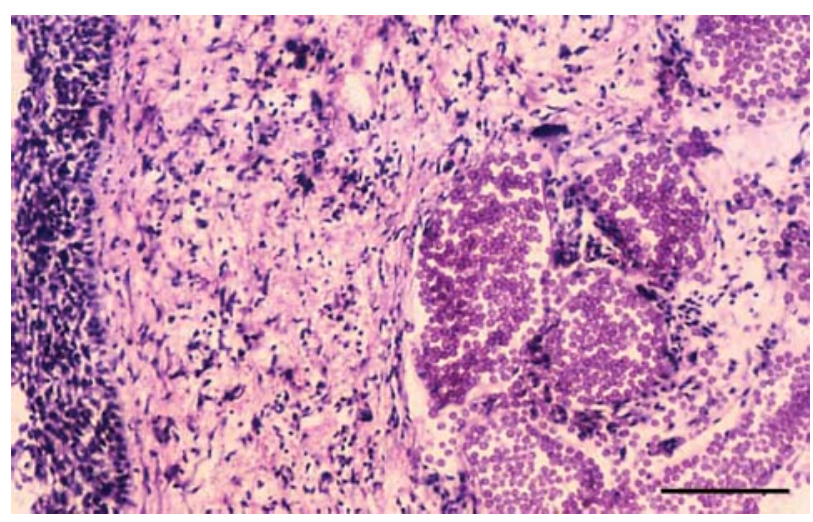

Fig. 15. Mesomycetozoea. Accumulation of spherical spores of Dermocystidium koi in the skin of a koi carp Cyprinus carpio. This species develops in, and can destroy, the skin and subdermal tissues of koi carp and goldfish. H\&E. Scale bar $=200 \mu \mathrm{m}$ cal spore stage (Fig. 15) with a large central vacuole or a solid refractile body and the cytoplasm with the nucleus restricted to a narrow peripheral layer (Fig. 16). Species infecting the skin and gills form spores containing a solid central refractile, PASnegative body (vacuoplast, Fig. 16), whereas the viscera-infecting species form spores with a large central vacuole instead of a refractile body. In most species the spores are of relatively uniform size (3 to $12 \mu \mathrm{m}$ in size, depending on the species), but in $D$. koi the spores vary greatly in size $(6.5$ to $15 \mu \mathrm{m})$.

In the developmental cycle of most skin- and gillinfecting species that have been studied, a small multicellular plasmodium grows, becomes confined within a distinct hyaline cyst wall, and then fragments into uninucleate spores, which divide into 2 sporoblasts that mature into spores. In some species (e.g. Dermocystidium cyprini) the fragmentation of plasmodia is associated with the formation of small compartments, whereas in others (e.g. D. branchiale), this is not reported. The development of the visceral Dermocystidium species does not include the growth of large plasmodia, and the small plasmodia may not be confined within capsule walls. In the skin pathogen D. koi, a web of aseptate hyphae is formed. Within the hyphae, multinucleate cytoplasmic contents segment into multinucleate and uninucleate cells that eventually transform into a large number of variablesize spores (Fig. 17). The formation of flagellated zoospores within spores has been observed in the gill pathogens $D$. cyprini and D. salmonis; these have been shown to be an infective stage in $D$. salmonis.

Granulomatous inflammation is often observed in association with Dermocystidium infections in Atlantic salmon Salmo salar. Within the spleen and liver, loose granules containing uninucleate spores can be observed with associated compression of adjacent tissue.

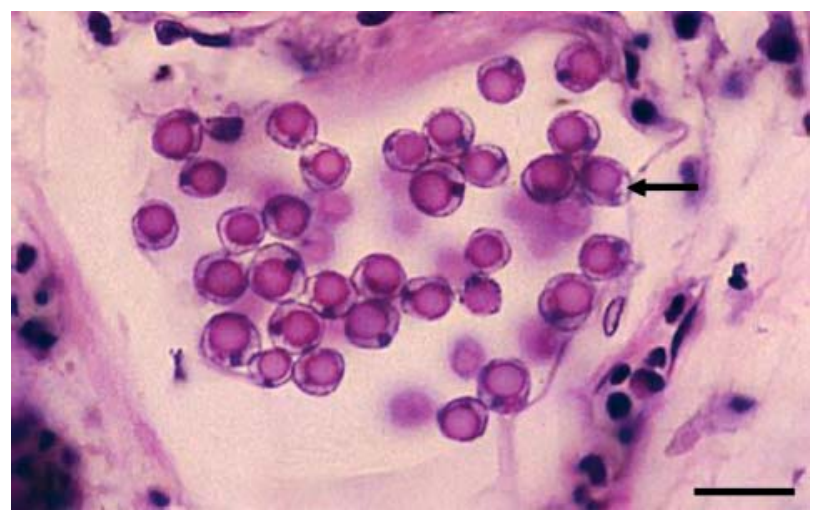

Fig. 16. Mesomycetozoea. Spores of Dermocystidium koi showing a large central inclusion (vacuoplast) (arrow) and the cytoplasm and nucleus restricted to a narrow peripheral area. The spores of $D$. koi are variable in size. H\&E. Scale bar $=50 \mu \mathrm{m}$ 


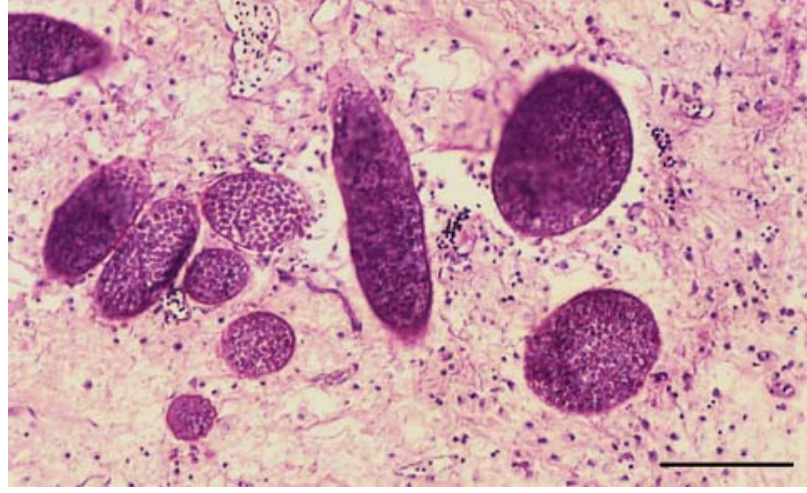

Fig. 17. Mesomycetozoea. Spores of Dermocystidium koi developing within hyphae in subcutaneous tissues of a koi carp Cyprinus carpio. Hyphae grow and segment into multinucleate and uninucleate cells, which later transform into spores. H\&E. Scale bar $=200 \mu \mathrm{m}$

Necrotic areas occur centrally in the granulomas. In the kidney, some free blood may be observed within the haematopoietic tissue, along with an increase in number of melanomacrophages (Fig. 18). Epithelial hyperplasia and fusion of gill lamellae are common in gill infections. H\&E, Gram and PAS staining methods are useful for staining Dermocystidium infection (Bruno 2001).

Ichthyophonus hoferi. Ichthyophonus hoferi is a common parasite of many species of freshwater and marine fish over a wide geographic range. Many organs can be infected. In salmonids, the heaviest infections are frequently found in the heart, skeletal muscle, liver, kidney, and spleen, and are often characterised by the appearance of whitish nodules in these organs. Severe infections of the brain and central nervous system have also been observed in salmonids and topminnows Poeciliopsis sp. Significant mortality has been reported in both marine and freshwater fish

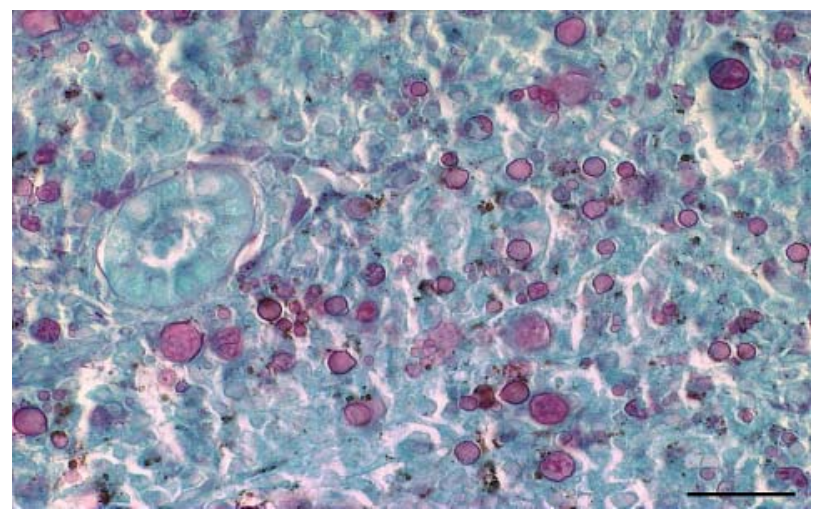

Fig. 18. Mesomycetozoea. Dermocystidium sp. in the kidney of farmed Atlantic salmon Salmo salar. Variable sized spores occur throughout the haematopoietic tissue and the outer spore wall stains strongly periodic acid-Schiff (PAS)-positive. PAS. Scale bar $=50 \mu \mathrm{m}$ with herring Clupea spp., and plaice Pleuronectes platessa being particularly susceptible.

Fish presumably become infected with Ichthyophonus by ingestion of spores. Based on culture and microscopy studies, and analysis of previous work, Spanggaard et al. (1995) have proposed a life cycle in which the thick-walled, spherical, multinucleated spores germinate in the stomach in response to low $\mathrm{pH}$. The branching aseptate hyphae penetrate the digestive tract, and when they reach a blood vessel (neutral $\mathrm{pH}$ ), the hyphae rupture, releasing uni- and binucleate bodies or amoeboid cells or both. These small cells are easily transported in the blood vessels, and spread in organs highly vascularised with blood (heart, kidney, liver, muscle and spleen), where they develop into multinucleate spores (Fig. 19). Soon after the death of the host, the spores germinate (Fig. 20).

The stage most commonly observed in tissue sections is the multinucleate 'resting spore' (Fig. 19), which appears roughly circular, can measure from 10 to over $300 \mu \mathrm{m}$ in diameter, and has a thick fibrous wall that stains PAS-positive (Fig. 20). A severe granulomatous response around the spores is characteristic, although sometimes individual spores may evoke minimal host response. The presence of hyphae protruding through the outer spore wall is a definitive characteristic (Fig. 20).

Rosette agent (Sphaerothecum destruens). The rosette agent is an obligate intracellular parasite that causes morbidity and mortality in salmonid fish. Infection with the 'rosette agent' results in a chronic inflammatory disease in Atlantic salmon Salmo salar, chinook salmon Oncorhynchus tshawytscha, brown trout Salmo trutta and rainbow trout O. mykiss. Infections have been detected in fish held in fresh water and seawater.

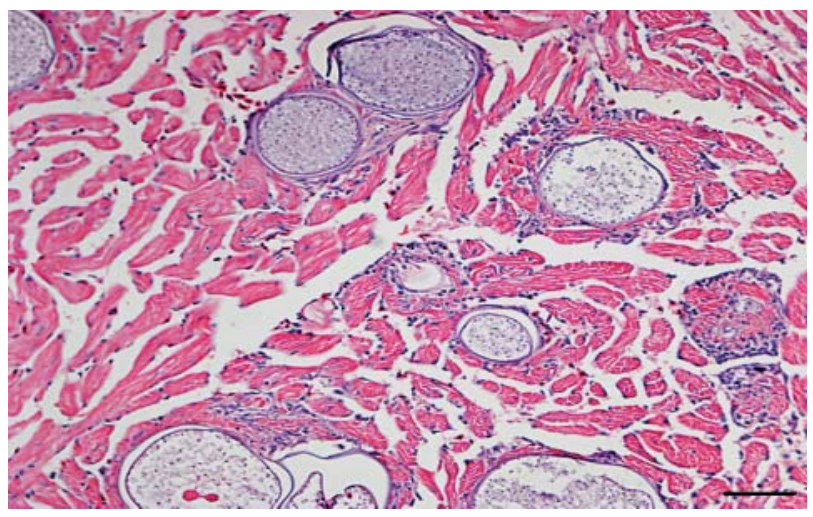

Fig. 19. Mesomycetozoea. Ichthyophonus sp. in cardiac muscle (ventricle) of an adult chinook salmon Oncorhynchus tshawytscha. Organisms are multinucleate resting spores. Most spores have elicited minimal host response, although chronic inflammation and fibrosis are visible in some areas. $\mathrm{H} \& \mathrm{E}$. Scale bar $=50 \mu \mathrm{m}$ 


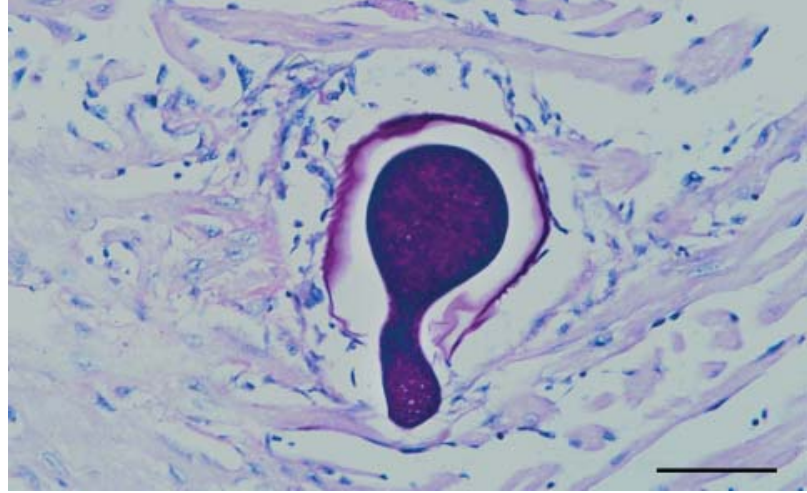

Fig. 20. Mesomycetozoea. Ichthyophonus sp. germinating body in the heart of an adult chinook salmon Oncorhynchus tshawytscha. Germinating bodies first produce single then branched hyphae. Resting spores and germinating bodies stain PAS-positive. PAS. Scale bar $=50 \mu \mathrm{m}$

Two stages or forms of the organism have been identified. The dividing stage is characterised by partitioning of the mother cell cytoplasm and its organelles to generate 2 or more daughter cells. The non-dividing stage is smaller than the dividing stage. Evidence suggests that potential sources for transmission of the organism include shedding in bile or urine, shedding from the gut epithelium and perhaps the gills and skin, or shedding in ovarian and seminal fluids.

Two forms of infection have been described: disseminated and nodular (Arkush et al. 1998). In disseminated disease, parasites can be found in both intraand extracellular locations in a variety of tissues, forming aggregates of small numbers of closely apposed organisms ('rosettes') along with associated necrotic cellular debris but with minimal host inflammatory cell response. Intracellular organisms may be located in haematopoietic, epithelial, or mesenchymal cells of the host. In nodular disease, aggregates of the rosette agent are found in the central zones of well-demarcated granulomas occurring predominantly in the kidney, liver and spleen. The parasites often appear as clusters ('rosettes') within and between macrophages (Fig. 21). In H\&E-stained sections, the rosette agents are deeply eosinophilic spheres, about 2 to $4 \mu \mathrm{m}$ in diameter for the non-dividing stages, and 4 to $6 \mu \mathrm{m}$ in diameter for the dividing stages. The rosette agent stains Grampositive, strongly PAS-positive, argyrophilic (WarthinStarry and Grocott's methenamine silver), and basophilic after Giemsa staining, but does not stain acid-fast (Arkush et al. 1998). The agent can also be detected in Gram-stained or Giemsa-stained tissue imprints.

Microsporidia. The microsporidia are obligate parasites found in members of all animal phyla, and are characterized by infectious spores with unique organelles involved in their invasion of a host and causing

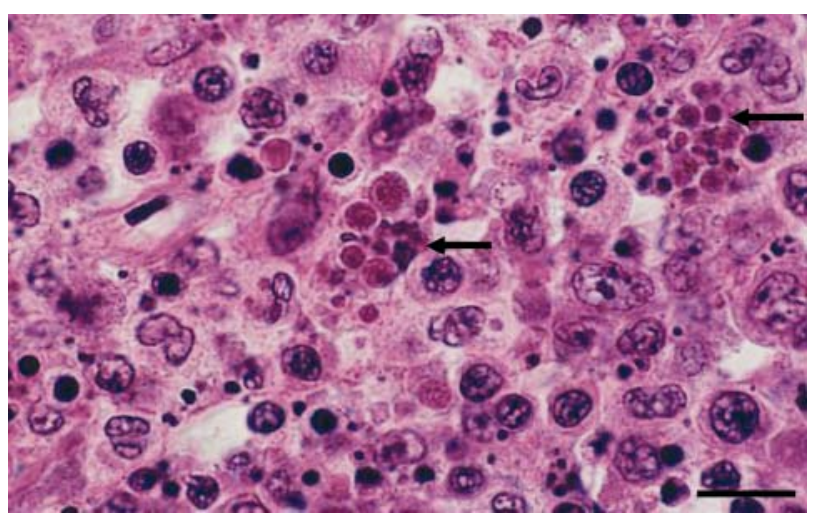

Fig. 21. Mesomycetozoea. Rosette agent (Sphaerothecum destruens) in kidney interstitial tissue of a salmonid. In sections, the rosette agent parasites (arrows) appear as clusters of spherical eosinophilic organisms within and between macrophages and are associated with multifocal necrosis and chronic inflammation. H\&E. Scale bar $=20 \mu \mathrm{m}$

infections of varying severity. This group are now considered to be highly derived fungi (Subkingdom Eumycota) rather than protozoans (Van de Peer et al. 2000 ), but are often grouped with protozoa in practical keys or texts. Microsporidia are strictly intracellular parasites with unicellular spores with an imperforate 1-piece chitinous wall containing 1 sporoplasm and an elaborate hatching apparatus. The principal part of the hatching apparatus is an extrusive hollow polar tube (coiled in the intact spore), which serves for injection of the sporoplasm into the host cell. Most microsporidian stages are small, with spores ranging from about 3 to $10 \mu \mathrm{m}$ long and plasmodial stages about 20 to $30 \mu \mathrm{m}$ long.

Fish become infected with microsporidia by ingestion of spores. After ingestion, the polar tube is extruded from the spore under the appropriate stimulus in the digestive tract, and the sporoplasm is injected through the tube into an intestinal epithelial cell. There the sporoplasm may initiate an infection, or may enter an appropriate target cell (such as a macrophage or other leukocyte), and thus reach the final target site elsewhere in the body. The developmental cycle of microsporidia has a proliferative stage, termed merogony (or schizogony), and a spore-forming stage, termed sporogony. During merogony, the parasites grow and undergo repeated binary or multiple divisions, filling host cells with increasing numbers of meronts (round, oval or elongated). In some microsporidia (such as Pleistophora), meronts may be encased within a thick amorphous wall that later develops into the sporont wall (see below); in other microsporidia, the wall may grow more extensively to enclose many merogony and later sporogony stages, becoming the sporophorocyst. Meronts eventually transform into sporonts, which in the sporogony phase of the devel- 
opmental cycle produce sporoblasts, which in turn differentiate directly into mature spores. In most microsporidian genera, a special envelope is produced at the surface of each sporont; this detaches from the parasite during subsequent sporogony stages to seal the parasite from host tissue. The entire formation is called a sporophorous vesicle (formerly called a pansporoblast), and may comprise a firm wall (e.g. in Pleistophora) or a fragile membrane (e.g. in Glugea). No sexual reproductive processes or indirect transmission have been demonstrated for fish microsporidia.

Criteria used in taxonomy of microsporidia include spore structure (much of which is only visible by electron microscopy), the presence or absence of sporophorous vesicles and of diplokarya (2 nuclei in spores), details of merogony and sporogony, and the structure of xenomas, if present. Feulgen staining can be used to demonstrate the DNA in microsporidian developmental stages and spores. Molecular approaches are also being used for phylogenetic analysis (Whipps et al. 2004, Abollo et al. 2005). A review of molecular and non-molecular diagnostic methods for detection, species differentiation and phylogenetic analysis of microsporidia (including methods applicable to tissue sections) has been prepared by Franzen \& Müller (1999).

The groupings below do not have taxonomic significance but are based on the appearance of the parasites in tissues. Recent information on phylogeny and classification of microsporidia has been reviewed by Nilsen $(2000,2003)$ and Lom \& Nilsen (2003).

Intranuclear microsporidia. The intranuclear microsporidian Nucleospora (= Enterocytozoon) has been observed in various salmonid fish species in both freshwater and marine environments. Nucleospora infects the nuclei of haemoblasts (particularly lymphoblasts or plasmablasts). It has been associated with anaemia. In addition, proliferating plasmablasts of fish suffering from plasmacytoid leukaemia (associated with a retrovirus) are often also infected with $N$. salmonis; the microsporidian may be a co-factor in the disease.

Nucleospora are very small microsporidia in which multinucleate merogony and sporogony stages are in direct contact with the host cell karyoplasm. Identification of the microsporidia in tissue sections requires careful examination of the nuclei of haemoblasts. In H\&E-stained sections, Nucleospora parasites appear as spherical eosinophilic bodies (2 to $4 \mu \mathrm{m}$ ) in the host cell nuclei, surrounded by a rim of basophilic host cell chromatin. Detection of the parasite in tissue sections can be enhanced by use of the Warthin-Starry stain combined with H\&E (Kent et al. 1995). By this procedure, pre-spore stages stain brown or black, and spores stain an intense black. The characteristic spores can also be detected in Gram-stained kidney or eye imprints. The bean-shaped spores stain Gram-positive and measure about $2 \times 1 \mu \mathrm{m}$. In Giemsa-stained imprints, the spores or pre-spore stages appear as clear spheres in host cell nuclei, although confusion with artefacts is possible.

Xenoma-inducing microsporidia. A xenoma is a hypertrophied host cell that contains spores and other developmental stages of microsporidia. Xenoma-inducing microsporidia (e.g. Loma, Ichthyosporidium, Microfilum, Microgemma, Nosemoides, Spraguea, Tetramicra, and most Glugea) are widely distributed in teleosts in freshwater, estuarine and marine habitats. Some xenoma-forming microsporidia infect multiple fish species, whereas others are only known from 1 host species, although the data are incomplete to claim strict host specificity in these cases.

Some xenoma-inducing microsporidia infect numerous organs of fish, whereas other species have a more restricted organ distribution. These microsporidia develop in the cytoplasm of host cells, usually in connective tissue cells or cells of mesenchyme origin. The microsporidian stimulates the infected host cell to enormous hypertrophy (up to $14 \mathrm{~mm}$ diameter); these hypertrophied cells (xenomas, Figs. 22 to 24) are often grossly visible as whitish nodules or corpuscles. Xenoma-inducing microsporidia have been associated with severe disease in both cultured and feral fish populations.

In an intact xenoma, the altered host cell and the parasite are physiologically and morphologically integrated to form a separate entity. This offers some benefits to both the parasite and host: optimum growth conditions, protection from host cell attack for the parasite within the xenoma, and limitation of the spread of

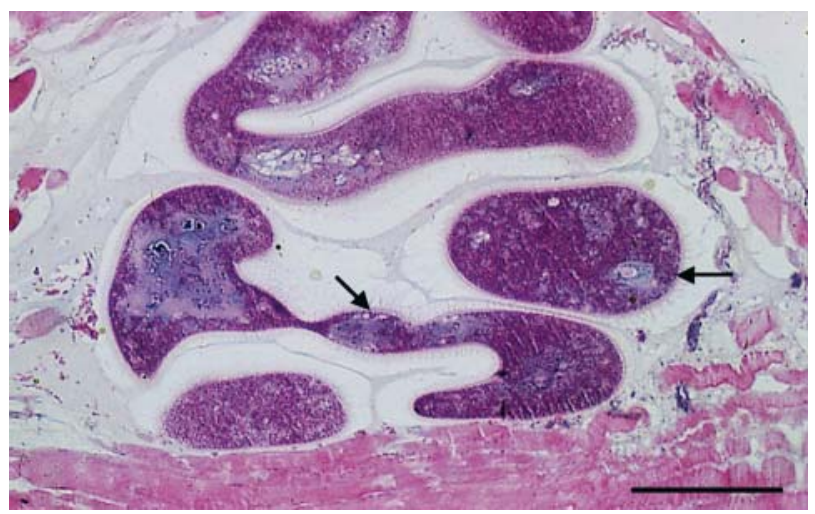

Fig. 22. Microsporidia (xenoma-inducing). Xenomas of Tetramicra brevifilum in muscle tissue of turbot Scophthalmus maximus. Xenomas up to $0.2 \mathrm{~mm}$ in diameter aggregate to form whitish nodules several $\mathrm{mm}$ in size, which are visible through the skin and are associated with muscle degeneration. Each xenoma has a central reticulate nucleus and microvillous, membrane-bound surface projections (arrows), by which several xenomas can interlock in aggregates. H\&E. Scale bar $=100 \mu \mathrm{m}$ 


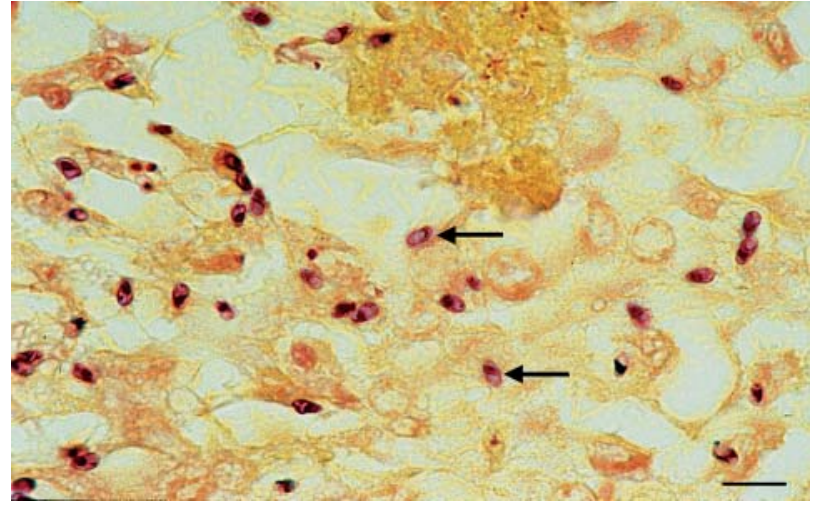

Fig. 23. Microsporidia (xenoma-inducing). Pyriform spores of Loma salmonae (arrows) dispersed in a granulomatous lesion in the cardiac ventricle of a coho salmon Oncorhynchus kisutch. In routine H\&E stained sections, the cause of this granulomatous lesion would be difficult to discern. Gram stain. Scale bar $=10 \mu \mathrm{m}$

the parasite by confinement to the xenoma. The structural changes of the host cell involve fragmentation of the nucleus or both, changes in cytoplasmic organelles, and special adaptations of the plasmalemma covering the surface of the xenoma (Fig. 22).

Dyková \& Lom (1980) presented a review of tissue reactions in fish to xenoma-inducing microsporidia. The tissue reaction to these microsporidia starts from the initial weakly reactive stage (primarily pressure atrophy), through the productive stage (proliferative inflammation and replacement of the fully developed xenoma by a granuloma) to granuloma involution directed toward the isolation of the parasite. This frequently results in complete destruction of spores with

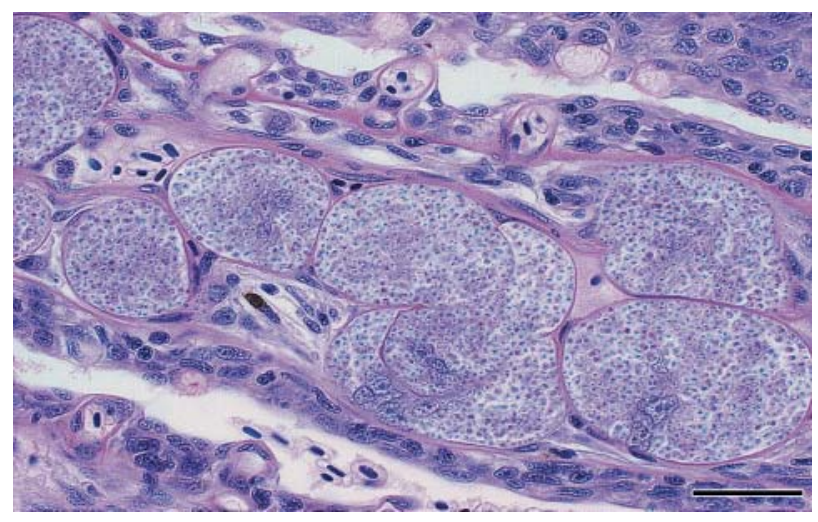

Fig. 24. Microsporidia (xenoma-inducing). Infection of Loma salmonae in gill lamellae of rainbow trout Oncorhynchus mykiss showing xenomas surrounded by a thin epithelium. Each xenoma is surrounded by a thin epithelium and is located at or near the pillar system or the blood vessels in the gill filament. There was little evidence of fibrosis, inflammatory infiltrate or apparent increase in mucous cell activity around the secondary lamellae, although some inflammation and congestion was recorded in the primary lamellae. H\&E. Scale bar $=30 \mu \mathrm{m}$ tissue repair. Thus, histological sections in which microsporidian spores have been eliminated by phagocytosis may not show the original cause of granulomatous lesions. If a few spores remain, these may be detectable in tissue sections by Gram or acid-fast staining. Care must also be exercised to avoid mistaking a parasitic focus encapsulated by host connective tissue for a xenoma.

Spores of most fish microsporidia are usually eggshaped or ellipsoid. For most species, spores are of a uniform shape and size, and have a large posterior vacuole (seen in fresh preparations). Microsporidian spores stain Gram-positive (Fig. 23) or Gram-variable, acid-fast, and are also stained by Giemsa in sections or smears. The polar capsule, into which the polar tube is inserted, stains as a red granule (polar granule) by PAS. Characteristics of the xenoma such as the hypertrophied or fragmented host cell nucleus or certain features of the xenoma surface (e.g. the thickened refractile xenoma wall of Loma) may be visible in tissue sections (Fig. 24).

The differences in host reaction that may be observed in infections by xenoma-forming microsporidia under different circumstances can be illustrated by gill infections of Loma in salmonids. Loma infections in gill lamellae of rainbow trout show xenomas surrounded by a thin epithelium and located at or near the pillar system, or in the filament blood vessels (Fig. 24). There is little evidence of fibrosis, inflammatory infiltrate or apparent increase in mucous cell activity around the secondary lamellae, although some inflammation and congestion occurs in the primary lamellae (Bruno et al. 1995). L. salmonae infections in gills of coho salmon Oncorhynchus kisutch held in fresh water are also characterised by intact xenomas with minimal associated host response (Kent et al. 1989). A few presporogonic stages of the parasite can be found in the heart endothelium prior to xenoma formation in the gills (Kent \& Speare 2005). Loma spores stain PAS-positive and weakly to strongly Gram-positive (Kent et al. 1989, Bruno et al. 1995). After the fish are transferred to seawater, however, rupture of xenomas is common, and is accompanied by subacute to chronic vasculitis and perivasculitis (Fig. 25), and characterised by engorgement of the branchial vessels with a mixed inflammatory infiltrate. The parasites are most pathogenic during this phase of the infection.

Non-xenoma-inducing microsporidia. Microsporidia which infect sarcocytes of the trunk musculature are represented by several genera, Heterosporis (Fig. 26), Pleistophora (Fig. 27), and Kabatana = Kabataia (Fig. 28), and infection does not generally induce xenoma formation. However, $H$. finki is reported to induce xenoma formation when it infects connective tissue cells of the oesophagus, but not when it infects myocytes of trunk musculature. These microsporidia 


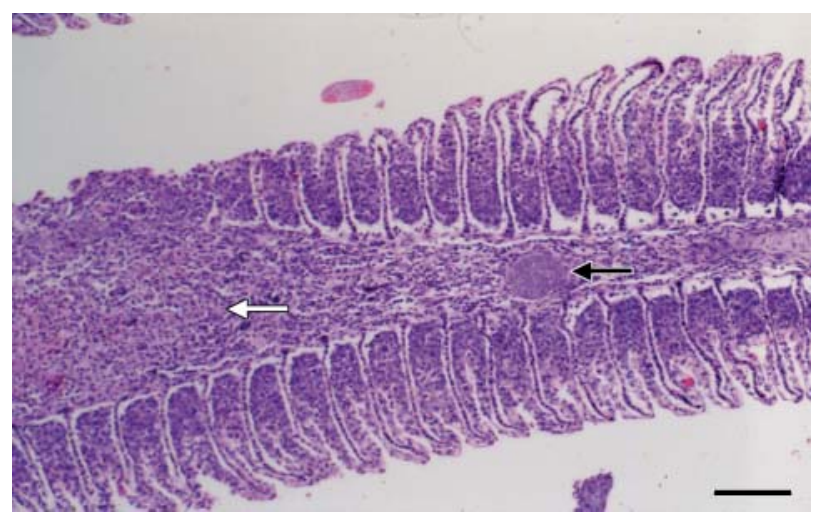

Fig. 25. Microsporidia (xenoma-inducing). Loma salmonae infection in the primary gill lamellae of coho salmon Oncorhynchus kisutch in seawater. An intact xenoma is visible (black arrow) and is associated with minimal host response. In contrast, a nearby ruptured xenoma (white arrow) with dispersed spores has elicited marked vasculitis and perivasculitis in the gill filament tissue. Ruptured xenomas of $L$. salmonae are commonly seen in coho salmon in seawater, but not in fresh water. H\&E. Scale bar $=80 \mu \mathrm{m}$

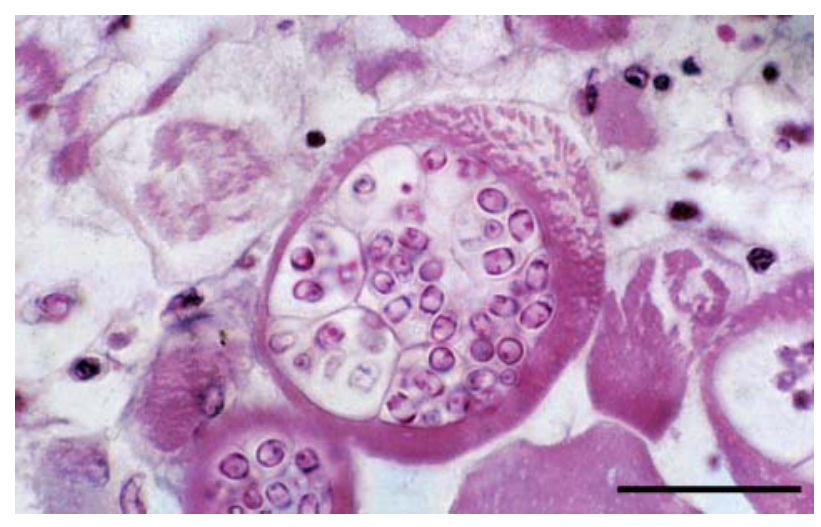

Fig. 26. Microsporidia (non-xenoma-inducing). Heterosporis anguillae (= anguillarum) in muscle tissue of a Japanese eel Anguilla japonica. A sporophorocyst enclosing sporophorous vesicles containing spores is visible in the centre of the photomicrograph. Both microspores and macrospores are produced, and spores have large posterior vacuoles. H\&E. Scale bar $=40 \mu \mathrm{m}$

infect a wide range of freshwater, estuarine, and marine teleost fish hosts. Some of the microsporidia infect multiple fish species, whereas others have been found in only 1 host species, though insufficient data exist to confirm strict host specificity for these parasites. Some of these microsporidia can cause severe disease in cultured and wild fish.

Despite low organ specificity exhibited by Pleistophora priacanthicola, most Pleistophora species infect muscle tissue, oocytes in ovaries, or epithelial cells in the seminiferous canaliculi in the testes. Heterosporis species mostly develop in trunk muscle (although 1

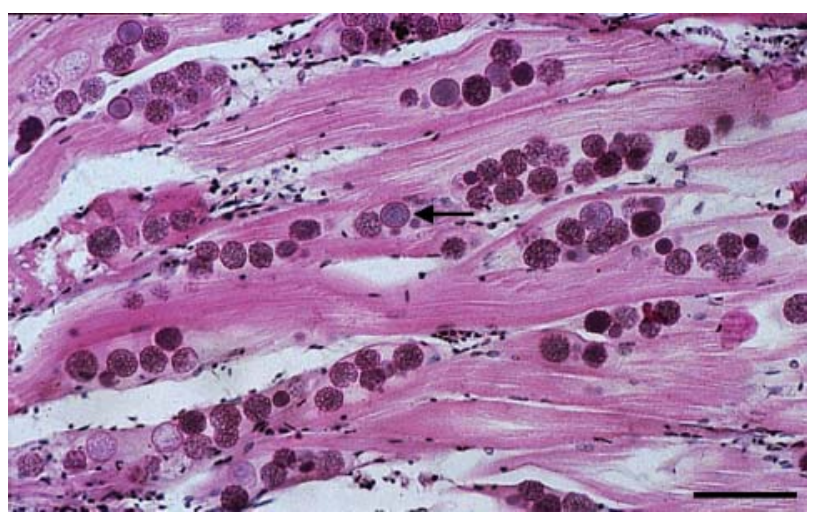

Fig. 27. Microsporidia (non xenoma-inducing). Pleistophora hyphessobryconis in skeletal muscle of a neon tetra Paracheirodon innesi. Thick-walled sporophorous vesicles (formerly pansporoblasts) predominate in this photomicrograph (arrow); heavy infections may be grossly visible as whitish patches under the skin, as parasites replace muscle fibres. H\&E. Scale bar $=100 \mu \mathrm{m}$

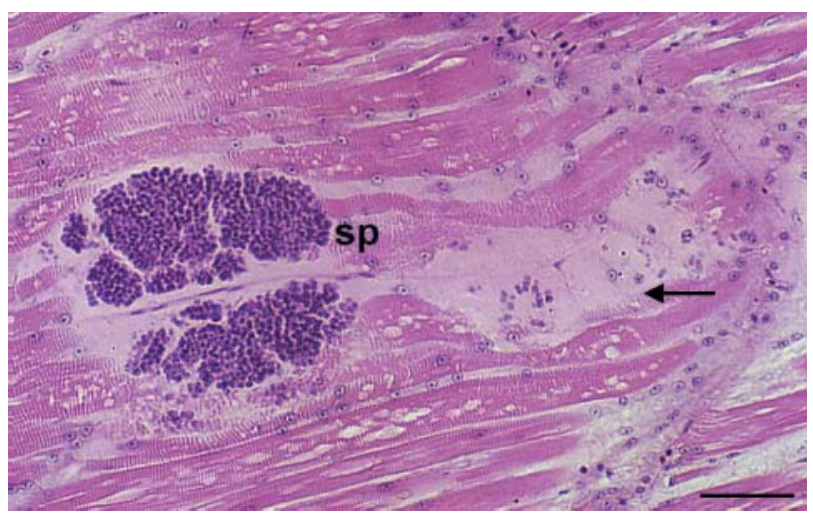

Fig. 28. Microsporidia (non xenoma-inducing). Kabatana arthuri (formerly Microsporidium arthuri and Kabataia arthuri) infecting trunk muscles of striped catfish Pangasiupols sutchi which may be visible grossly through the skin as white patches. Microscopically, foci of infection appear as aggregates of oviform (but variable-shaped) spores apparently free in the musculature (sp), with disintegrated sarcoplasm extending some distance from the spores (arrow). H\&E. Scale bar $=100 \mu \mathrm{m}$

species can develop in oesophageal connective tissue), and Kabatana species infect trunk muscle tissue. (Note: $K$. arthuri and $K$. takedai were formerly included in the collective genus Microsporidium). For most of the species, spores are formed in sporophorous vesicles localised directly in the tissue. In Pleistophora, the sporophorous vesicles are free in the tissue but each has a firm wall containing 6 to about 200 spores, depending on the species. The key feature for Heterosporis is the presence of a sporophorocyst which encloses all developmental stages of the parasite (i.e. meronts, sporonts and sporophorous vesicles with 
sporoblasts and spores). Clusters of sporophorocyst with sporophorous vesicles containing spores are shown in Fig. 26. Thick-walled sporophorous vesicles of Pleistophora hyphessobryconis predominate in skeletal muscle of neon tetra Paracheirodon innesi (Fig. 27). Heavy infections may be grossly visible as whitish patches under the skin, as parasites replace muscle fibres. The genus Ovipleistophora was established for Pleistophora mirandellae-like microsporidia from roach Rutilus rutilus and ruffe Gymnocephalus cernuus following ultrastructural and molecular analysis studies on merogony of the developmental stages. Unlike Pleistophora, Ovipleistophora has a thick additional envelope around the meront. This envelope breaks open to release the cells into the host cell cytoplasm. The cells, becoming multinuclear sporogonic plasmodia, already have a surface coat that transforms into the sporont wall and eventually into the sporophorous vesicle wall.

During development of Kabatana, no sporophorous vesicles are formed; proliferating $K$. takedai occur in cytoplasmic masses (without host cell nuclei) within cyst-like structures in the musculature. $K$. arthuri infects trunk muscles of striped catfish Pangasius sutchii, and foci of infection appear as aggregates of oviform (but variable-shaped) spores apparently free in the disintegrating sarcoplasm (Fig. 28).

The non-xenoma-forming microsporidia destroy and replace the contents of an infected cell or syncytium without inducing hypertrophic growth of that cell or syncytium. The host response to these microsporidia, studied mainly in Pleistophora spp. infecting muscles and oocytes, may be minimal until late stages, when mature spores are released from disintegrated muscle fibres or ruptured oocytes and are ingested by phagocytic cells. The formation of large granulomas is a prominent feature of infections with some of these microsporidian species but not others. The host reaction may not isolate the developmental stages of the parasites and thus may permit dissemination of the infection in the host (Dyková \& Lom 1980).

Another non-xenoma-forming microsporidian for which the pathology has been studied is Kabatana (formerly Microsporidium) takedai, which is highly pathogenic and specific to the Salmonidae. Several species of salmonids are known to be susceptible and include sockeye Oncorhynchus nerka, pink O. gorbusha, chum $O$. keta, and masou salmon $O$. masou, rainbow $O$. mykiss and brown trout Salmo salar and Japanese charr Salvelinus leucomaenis. All reports of this microsporidian occur in freshwater salmonids from Japan, although other species occur in seawater fish. A seasonal prevalence of this parasite is recognised with the initial outbreak during the summer at water temperatures around $15^{\circ} \mathrm{C} . K$. takedai infection results in whitish, spindle-shaped, cyst-like lesions within the musculature including the heart. In chronic cases the heart shows an extreme hypertrophy and deformation of the tissue with inflammatory oedema. Acute cases result in a high mortality and are characterised by a massive occurrence of cysts within the musculature. The tissue response is similar to that observed in the heart muscles. Within each cyst numerous ovoid proliferating microsporidia are seen which measure 2.5 to $4.0 \mu \mathrm{m}$ when mature. Provisional identification is based on dissection and gross examination of the musculature, and confirmed by subsequent microscopical examination of the cysts.

The general appearance of the spores and their staining reactions are the same as for xenomainducing species. However, Pleistophora and Heterosporis spores may show size variation (microspores, macrospores, and intermediate-sized spores), and mature spores of some Kabatana species may be variable in shape (rounded pyriform or curved). Histological examination will not reveal the presence of xenomas (exception discussed above) but can show other features such as sporophorous vesicles. The rapid detection of Pleistophora spores in sections can be achieved with a metachromatic blue stain containing $0.1 \%$ toluidine blue, $0.1 \%$ methylene blue and $1.0 \%$ sodium borate (Summerfelt \& Warner 1970). This preparation is poor for cytological detail of host tissue, but $P$. ovariae spores infecting ovary tissue are described as staining light to dark blue, with a dark band in the middle and dark blue at the end. Mallory's aniline blue stain (Clark 1981) is highly differential for distinguishing cytological detail of developing fish oocytes, and is also excellent for differentiating meronts (schizonts), sporoblasts and spores of $P$. ovariae from the cytoplasm and yolk of the oocytes.

Myxosporidia. Myxosporidia are multicellular organisms and among the most important pathogenic parasites of fish, both as spores, but more importantly as vegetative stages, and their importance has dramatically increased with the extraordinary expansion of aquaculture. In the infected cell of the fish host, microsporidia may either cause serious degradation of the cytoplasm and demise of the cell, or they may elicit host cell hypertrophy, producing a parasite-hypertrophic host cell complex, the xenoma. Cavalier-Smith (1998a) placed myxosporidians in the Phylum Myxosporidia within the Subkingdom Myxozoa of the Kingdom Animalia, rather than the Kingdom Protozoa, with vegetative unicellularity secondarily derived as a result of parasitism (Smothers et al. 1994). Many species of myxosporidia have been identified from freshwater and marine fish and although not all myxosporidian species are strictly specific with regard to host species, others seem to be specific for certain hosts. 
Myxosporidia are obligate parasites characterised by spores comprised of several cells configured into 1 to 7 spore shell valves, 1 to 2 amoeboid infective germs, with 2 to 7 nematocyst-like polar capsules, each of which contains a coiled extrudible filament with an anchoring function. The life cycle of myxosporidia is complex and not fully understood for most species. Although direct fish-to-fish transmission may occur in some species, development in an alternate invertebrate host (an oligochaete, polychaete, or bryozoan) is required to complete the life cycle of many myxozoan species (Kent et al. 2001). In the fish host, after the invasive sporoplasm has hatched from the spore, and its 2 haploid nuclei have fused (autogamy), it reaches the target organ and grows into a trophozoite. The trophozoite nucleus divides repeatedly, producing 1 or more primary (vegetative) nuclei, 1 or more inner secondary (generative) cells enclosed within the primary cell in membrane-bound vacuoles, and, sometimes, tertiary cells enclosed within the secondary cells. It is always the inner generative cell (secondary or tertiary) that represents the next generation of the myxosporidian. The trophozoites may vary greatly in dimension and shape, from small $(10 \mu \mathrm{m})$ pseudoplasmodia that have a single vegetative nucleus and produce a single spore, to large (up to $2 \mathrm{~cm}$ ) plasmodia that comprise many nuclei and specialised cells and produce a mass of spores. At this stage the main proliferation takes place where trophozoites can undergo purely proliferative cycles and (usually) proliferative cycles coupled with sporogony. The trophozoites may be either coelozoic trophozoites which have cytoplasmic holdfast outgrowths or moving pseudopodia, or, in contrast, histozoic trophozoites which are rounded and immobile, and firmly encased in the host tissue. The culmination of the myxosporidian life cycle in the fish host is usually the formation of multicellular spores. However, certain species, especially some that develop in the kidney, do not regularly produce spores and can be difficult to identify (e.g. Hoferellus carassii and Sphaerospora cyprini). Vegetative stages of myxosporidia often have no distinctive features important for classification, so taxonomy is largely based on the size, shape and structure of fresh spores (to avoid changes caused by shrinkage of fixed spores). Lom \& Arthur (1988) prepared guidelines for the description of myxosporidian spores (as well as vegetative stages).

Certain species seem to be specific for certain tissues, whereas others infect various locations in a host. Coelozoic myxosporidia live in body cavities such as the gall bladder and bile ducts, or in the urinary tract up to the renal corpuscles. They may be attached to the walls of the cavity or float freely in the cavity fluid, usually without the formation of macroscopically visible cysts. Infrequently they may occupy other sites such as the pericardium. In some myxosporidian species, the entire development takes place inside a single cell, whereas in others, early intracellular developmental stages are followed by intercellular or coelozoic stages. Some species also have blood stages. Histozoic myxosporidia are considered more advanced evolutionarily than coelozoic species, live in various tissues, mostly intracellularly, but often intracellularly. Infections of histozoic species may be grossly visible as small white 'cysts' (host connective tissue sheath surrounding parasites).

Various developmental stages of myxosporidia may be visible in histological sections. Myxosporidian spores are often weakly stained with H\&E, but are strongly acid-fast, with stain intensity increasing as spores mature. The polar capsules of spores stain intense blue or blue-black in Giemsa-stained sections or smears, stain with methylene blue, and also stain Gram-positive in sections or smears. Important taxonomic characters such as the shape of the sutural line and precise spore size are usually not discernible in tissue sections. However, information concerning spore shape, the presence of appendages, and location of the spores in the host and host-parasite interactions can be obtained from sections, often enabling presumptive identification. Immunohistochemical techniques are available for detection and identification of some myxosporidia (reviewed by Kent et al. 2001). In addition, molecular phylogeny has been developed for taxonomic studies of certain myxosporidian species in fish (Kent et al. 2001). These procedures can be particularly useful for diagnosis of infections when spores are not present.

Although the vegetative stages may not show definitive diagnostic features, characteristics visible in routine sections (e.g. size, morphology, location in the host, and host reaction) can provide clues for identification. Both H\&E and Giemsa stains are frequently used for observation of trophozoite stages.

Myxosporidian infections can cause all categories of regressive and progressive pathological changes in the host, including atrophy, dystrophy, hypertrophy, hyperplasia, necrosis and inflammation (usually proliferative). Nevertheless, most myxosporidian species cause minimal tissue damage; relatively few species are known to cause serious or fatal infections. Phagocytosis by macrophages of small trophozoites or of mature spores released into tissue spaces is important for host control of myxosporidian infections. Publications such as El-Matbouli et al. (1992), Lom \& Dyková (1992), and Feist (1997) describe the types of host reactions characteristic of infections by various myxosporidia, and such descriptions are also available in publications concerning the histopathology of infections by individual myxosporidian species. Characteristics of a few 
groups of fish myxosporidians, particularly those that have been associated with pathological changes in fish, are described in the following paragraphs.

Myxidiidae. Coccomyxa, Myxidium and Zschokkella possess spores that are spindle-shaped, sigmoid, or crescent-shaped, with 2 polar capsules (1 in Coccomуха) at opposite ends of the spore, and a longitudinal straight, curved or sigmoid sutural line. The distinction between the species of Myxidium and Zschokkella is sometimes difficult (e.g. the polar capsules of Myxidium are not always exactly pyriform, and Zschokkella polar capsules are not exactly spherical and they do not always discharge in the described direction).

Most of these myxosporidia are coelozoic in marine or freshwater fish, but a few species are histozoic. Certain species can cause tissue damage. For example, Myxidium minteri, which has been found in the renal tubules and gall bladder of salmonids in western North America, can cause renal tubular degeneration. Similarly, cysts of $M$. rhodei in roach Rutilus rutilus develop in the Bowman's spaces of the renal corpuscles resulting in renal hypertrophy (Fig. 29). The plasmodia of $M$. truttae from Atlantic salmon can develop in the bile duct of the liver and typically there is little inflammatory response (Fig. 30). Spores and plasmodia of $M$. giardi brought into various organs of eels Anguilla spp. by blood circulation can elicit focal granulomatous reactions. Heavy infections of plasmodia of some coelozoic Zschokkella spp. can result in distension of hepatic ducts, epithelial atrophy, and other regressive changes such as atrophy of liver tissue (Fig. 31).

Ortholineidae. Ortholineidae (e.g. Ortholinea, Neomyxobolus, Triangula) have spherical to irregular ellipsoidal spores that are bilaterally symmetrical along a straight sutural line, with 2 polar capsules set wide apart in the sutural plane. Most are coelozoic in the urinary tracts of marine or freshwater fish, but Triangula is

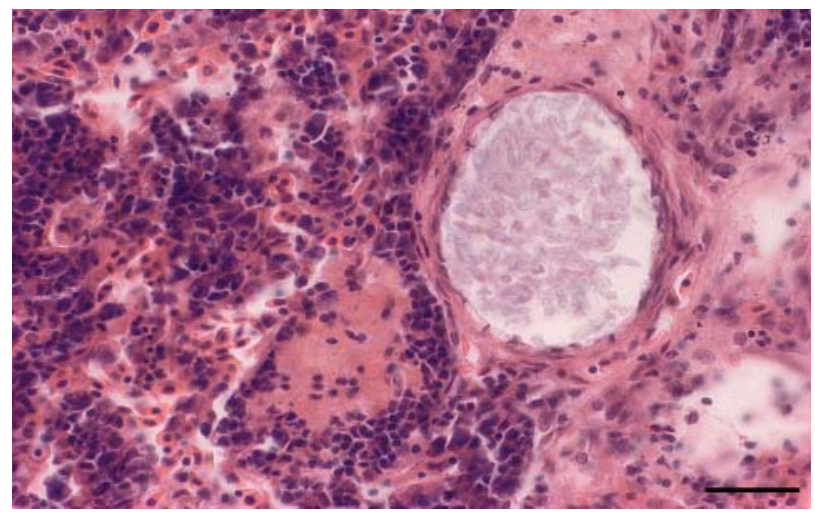

Fig. 29. Myxosporidia: Myxidiidae. Cysts of Myxidium rhodei in roach Rutilus rutilus developing in the Bowman's space of the renal corpuscles resulting in renal hypertrophy. H\&E. Scale bar $=40 \mu \mathrm{m}$ histozoic. T. percae infections in the brain of yellow perch Perca flavescens can provoke spinal deformities. The coelozoic sporogonic plasmodia (trophozoites) of Ortholinea fluviatilis attach to epithelial cells of renal tubules by means of pseudopodia-like projections (Fig. 32).

Ceratomyxidae. The spores of Ceratomyxa and Leptotheca have valves elongated or drawn out to an enormous length in the direction perpendicular to the straight central transverse suture; the 2 shell valves may be asymmetrical. The spherical to subspherical polar capsules are close to the sutural line in a plane perpendicular to it. The trophozoites are mono- to polysporic, mostly disporic. These parasites are coelozoic in marine fish and rarely histozoic in freshwater fish.

Perhaps the best known example is Ceratomyxa shasta, a pathogen of west coast North American

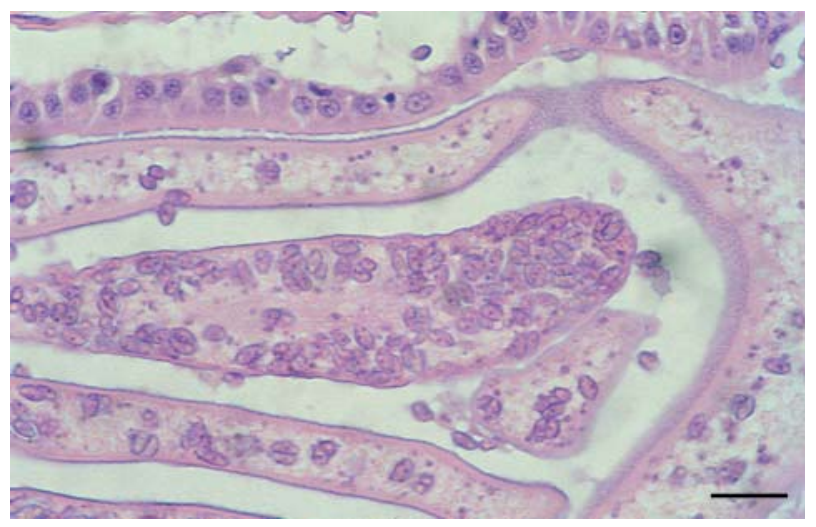

Fig. 30. Myxosporidia: Myxidiidae. Plasmodia of Myxidium truttae from wild Atlantic salmon Salmo salar developing in the bile duct of the liver; typically there is little inflammatory response. H\&E. Scale bar $=40 \mu \mathrm{m}$

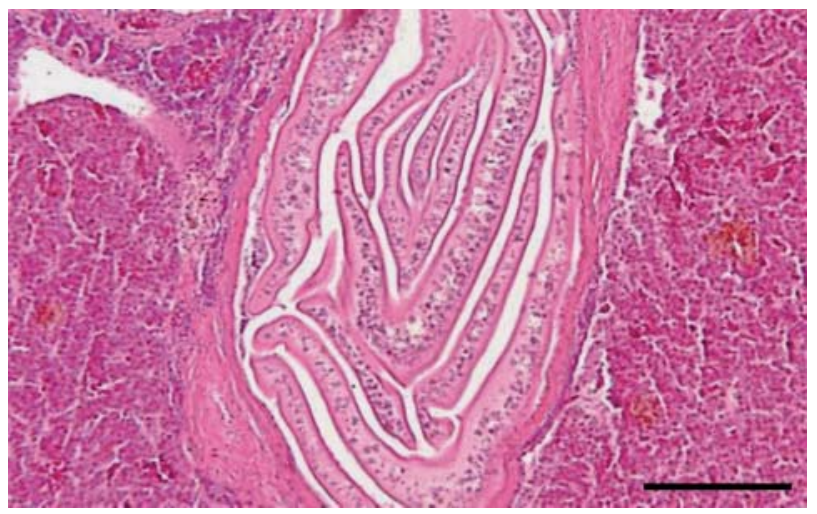

Fig. 31. Myxosporidia: Myxidiidae. Large plasmodia of Zschokkella sp. in the bile duct of a surfperch Cymatogaster aggregata. Bile ducts can be distended by masses of plasmodia, and surrounding liver tissue may show atrophy in heavy infections of coelozoic Zschokkella sp. H\&E. Scale bar $=100 \mu \mathrm{m}$ 


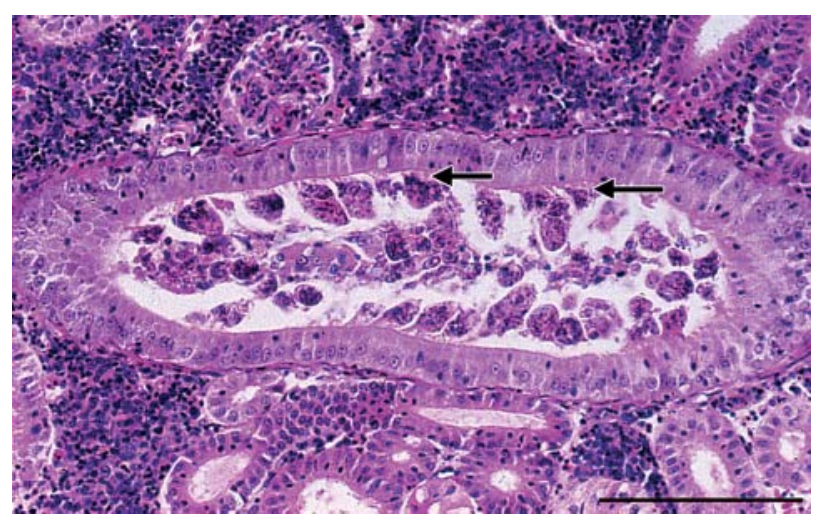

Fig. 32. Myxosporidia: Ortholineidae. Plasmodial (trophozoite) stages of Ortholinea fluviatilis in the kidney of the marine pufferfish Tetraodon fluviatilis. Coelozoic sporogonic plasmodia of this myxosporean use pseudopodia-like projections (arrows) for attachment to epithelial cells of renal tubules. H\&E. Scale bar $=200 \mu \mathrm{m}$

anadromous salmonids, which is transmitted to fish in fresh water. The parasite manifests itself in the gut, liver, spleen and muscle causing abdominal distension due to production of spore-containing fluid causing extensive tissue destruction and mortality. This parasite infects all layers of the entire digestive tract wall where tissue reactions may include hyperplasia, leucocytic infiltration, and necrosis, and the infection can also be disseminated to other organs (Fig. 33). In Giemsa-stained sections the multicellular trophozoites stain light blue and the nuclei show a dark staining karyosome surrounded by a clear halo. An immunohistochemical procedure has been developed for specific detection of C. shasta trophozoites in tissue sections (Bartholomew et al. 1990).

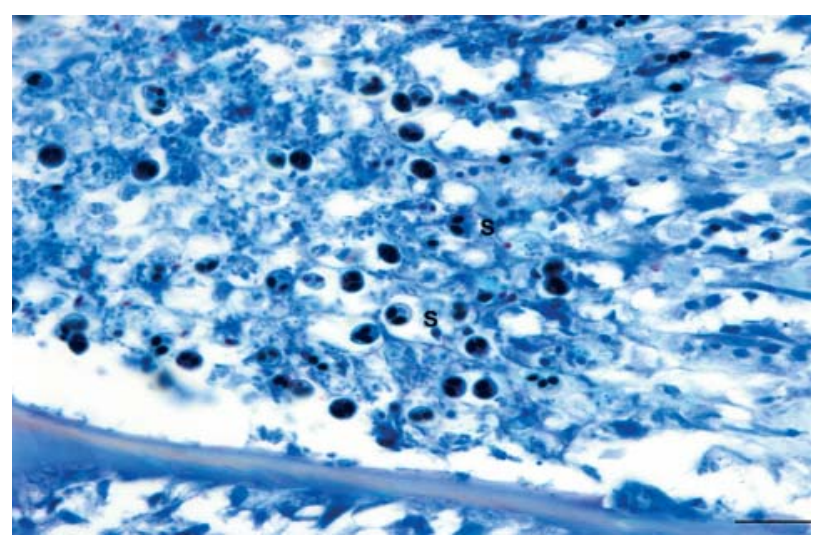

Fig. 33. Myxosporidia: Ceratomyxidae. Ceratomyxa shasta in the viscera of a chinook salmon Oncorhynchus tshawytscha. The elongated shell valves give the spores (s) a 'boomerang' or a 'kidney bean' shape; the 2 dark-staining polar capsules are located near the sutural line at the anterior pole of the spore. May-Grünwald Giemsa. Scale bar $=20 \mu \mathrm{m}$
Sphaerosporidae. The family Sphaerosporidae includes the genera Hoferellus, Myxobilatus, Palliatus, Sphaerospora and Wardia. The spores of these parasites are spherical, rounded pyramidal with a tapering anterior end, or elongated, often with appendages. The 2 polar capsules open at the anterior tip and are located in a plane perpendicular to the straight sutural line. The trophozoites are mono- to polysporic, and the parasites are mostly coelozoic (sometimes histozoic) in marine and freshwater fish.

Several Sphaerospora species are associated with disease in fish. Prominent among these is Sphaerospora renicola, which can be a serious pathogen in cultured carp Cyprinus carpio in Europe and Israel, with damage to renal and swimbladder tissues and impairment of their function. Sporogonic stages in the renal tubules may be associated with tubular dilation, and atrophy and necrosis of the epithelium. Renal corpuscles may be affected by fibrosis or granuloma formation. Intracellular 'dead-end' stages of $S$. renicola in the tubular epithelium elicit formation of granulomas with necrotic centres and extensive layers of connective tissue. Certain stages of $S$. renicola may undergo necrosis, and deposits of calcium salts are common in the necrotic mass. The development of swimbladder stages in young carp can result in severe proliferative inflammation with haemorrhage in this tissue. S. molnari infects gill epithelium and the skin of the head of juvenile carp with significant mortality reported in Europe (Fig. 34). The parasites elicit epithelial hyperplasia, and masses of parasites may replace host tissue, ultimately resulting in local circulatory disorders and necrosis. Other Sphaerospora species that have been associated with lesions in European fish include: $S$. tin-

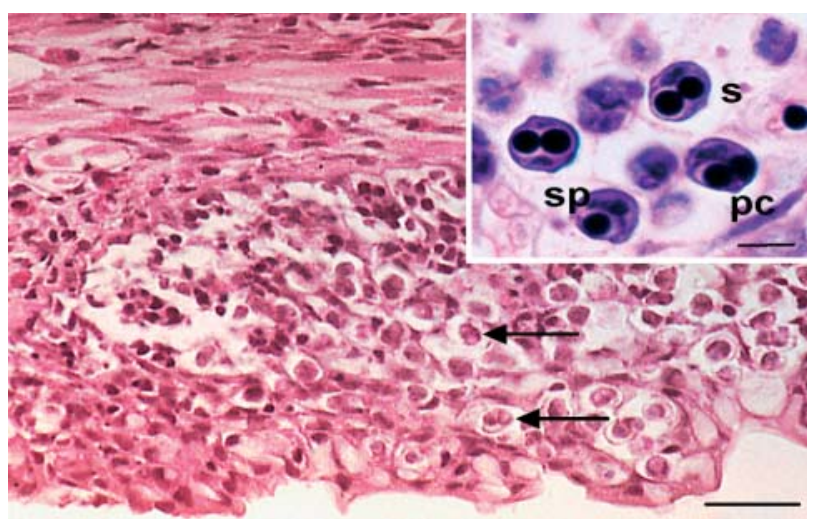

Fig. 34. Myxosporidia: Sphaerosporidae. Sphaerospora molnari in gills of carp Cyprinus carpio (arrows). This parasite infects the multilayered epithelium of the gills and head, and a heavy infection can result in significant epithelial hyperplasia, replacement and necrosis of host tissue, circulatory dysfunction and death. H\&E. Scale bar $=30 \mu \mathrm{m}$. Inset: $S$. molnari. Subspherical spores with prominent sutures (in cross-section; s), 2 subspherical polar capsules (pc) and sporoplasms (sp) can be seen in this preparation. Giemsa. Scale bar $=10 \mu \mathrm{m}$ 
cae in the pronephros of tench Tinca tinca, S. truttae in renal tissues of brown trout Salmo trutta, and S. pectinacea in renal tubules of perch Perca fluviatilis. In the United States $S$. ictaluri is associated with gill lesions in channel catfish Ictalurus punctatus.

A few Hoferellus species have been reported to be pathogenic to fish. H. carassii infections of the epithelial cells of renal tubules of goldfish Carassius auratus can cause papillary cystic hyperplasia and serious fish losses. The kidney parasite $H$. cyprini is mildly pathogenic to carp and causes destruction of renal tubular epithelial cells and focal inflammation of the interstitium. Masses of coelozoic plasmodia can result in atrophy of the tubular epithelium.

Chloromyxidae. Chloromyxidae (e.g. Caudomyxum, Chloromyxum) have spherical, subspherical or elongated spores bisected by a straight meridional suture. The spore valves may be smooth or have surface ridges, and the spores of some species bear caudal appendages. Four polar capsules, which may be unequal in size, are located at the apex of the spore. The trophozoites may be small (monosporic) to mediumsized (polysporic), and the parasites are coelozoic (rarely histozoic) in freshwater and marine fish. The gall bladder parasite Chloromyxum truttae can cause serious disease in salmonids, with emaciation, jaundice, and hypertrophy of the gall bladder reported. Infection with the kidney parasite $C$. majori can result in destruction of glomerular capillaries in salmonids. The (usually) endocommensal gall bladder parasite $C$. cristatum can invade the liver and induce necrosis in carp.

Parvicapsulidae. The spores of Neoparvicapsula and Parvicapsula are asymmetrical and thin-walled, elongated roughly in the sutural plane, with unequal valves meeting in a curved suture. Two to 4 conspicu-

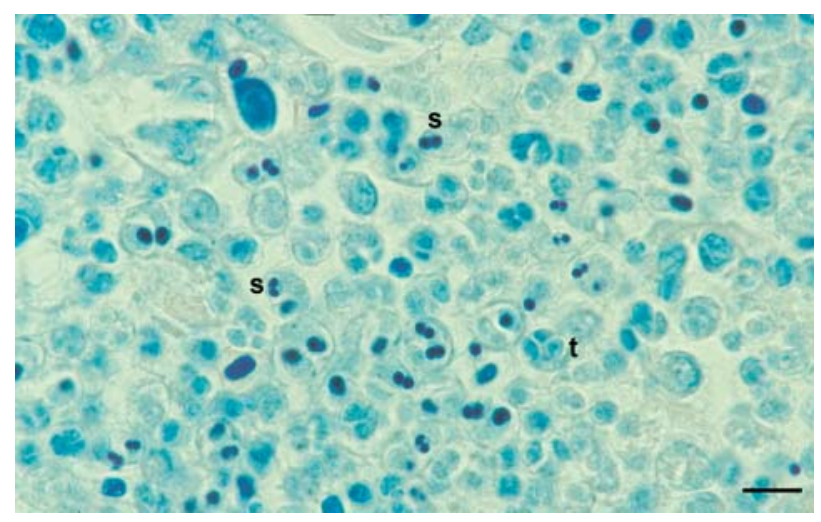

Fig. 35. Myxosporidia: Parvicapsulidae. Parvicapsula sp. in the pseudobranch of a juvenile coho salmon Oncorhynchus kisutch. Both spores (s) and trophozoites (t) can be readily observed in this Giemsa-stained section; spores are thin-walled and asymmetrical with 2 small polar capsules at the anterior end. Giemsa. Scale bar $=10 \mu \mathrm{m}$ ously small polar capsules are located in the spore apex of Parvicapsula (Fig. 35). The trophozoites are disporic to tetrasporic, and the parasites are usually coelozoic in the urinary system or gall bladder, and histozoic in kidneys of marine and anadromous fish. $P$. minibicornis occurs in the glomeruli and tubular lumina in renal tissue of a variety of Pacific salmon species Oncorhynchus spp. on the Pacific coast of North America. (Jones et al. 2003, 2004); severe infections in sockeye salmon can result in glomerulonephritis, tubular epithelial necrosis, and death. An unidentified Parvicapsula sp. has also been associated with mortality in netpen-reared salmonids on the Pacific coast of North America. Trophozoites of this parasite develop in the renal tubular epithelium, and the mature spores produced pass into the tubular lumina, to be discharged from the urinary bladder. Infection can result in destruction of renal tubular epithelium and proliferative nephritis. Infections by Parvicapsula involving the pseudobranch have also been observed in sea-farmed coho salmon on the Pacific coast of North America (Yasutake \& Elliott 2003; their Fig. 35), and recently in farmed Atlantic salmon in Norway (Karlsbakk et al. 2002, Sterud et al. 2003); the species in Atlantic salmon has been named P. pseudobranchicola (Karlsbakk et al. 2002).

Myxobolidae. Members of this family, which includes the genera Henneguya, Myxobolus, Theohanellus and Unicauda among others, possess spores that are flattened parallel to the straight sutural line. The suture forms an elevated ridge on the spore and may be drawn out into long caudal projections of the spore shell (e.g. Henneguya). One of the 2 polar capsules may be smaller (or missing as in Thelohanellus, Fig. 36). As a rule, these parasites form large histozoic trophozoites ('cysts') with

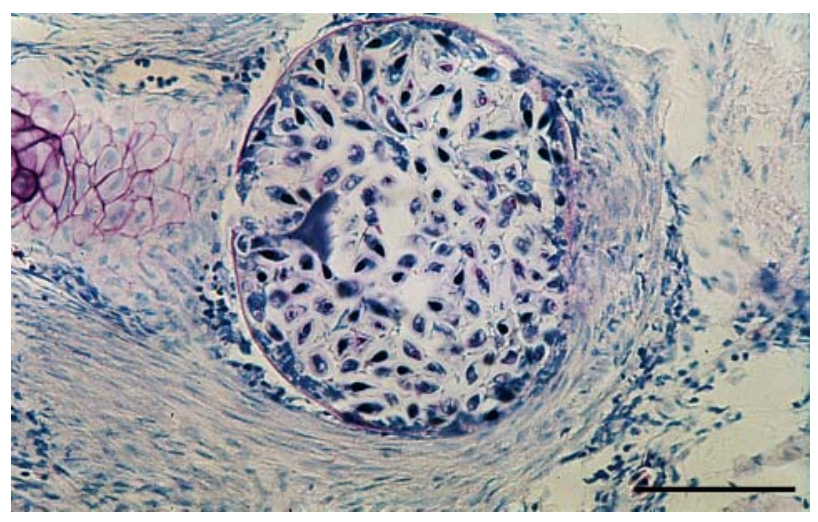

Fig. 36. Myxosporidia: Myxobolidae. Plasmodium of Thelohanellus pyriformis in the gills of tench Tinca tinca growing in the blood vessels of the gill filaments. The large plasmodia (up to $600 \mu \mathrm{m}$ ) elicit massive hypertrophy of one of the blood vessel endothelial cells, which becomes surrounded by the plasmodium. Spores are a curved teardrop shape with a single polar capsule. Giemsa. Scale bar $=200 \mu \mathrm{m}$ 
numerous spores, and infect mostly freshwater fish, although some species infect marine (primarily estuarine) fish. Most species have an iodinophilous vacuole.

A number of species of Myxobolidae can cause serious disease in fish. For example, Myxobolus (= Мухоsoma) cerebralis, the agent of whirling disease in salmonids, destroys head and vertebral column cartilage of juvenile salmonids by enzymatic lysis, which can result in misshapen skulls and twisted spines and inflict heavy losses. $M$. cerebralis is the only myxosporean found in the cartilage of salmonids (Fig. 37). The spores of $M$. cerebralis are typically oval, measuring $8 \times 10 \mu \mathrm{m}$ and the 2 polar capsules are normally of equal size, measuring $3 \times 4 \mu \mathrm{m}$. A direct fluorescent antibody test has been used to identify spores of $M$. cerebralis in tissue sections (Bartholomew et al. 1990, Thoeson 1994). More recently, an in situ hybridisation procedure has been developed to identify various life stages of this parasite in tissue sections from both fish and oligochaetes (Antonio et al. 1998).

Another fish pathogenic Myxobolus species, M. encephalicus, infects the central nervous system of carp resulting in locomotory disorders. Plasmodia in brain blood vessels cause dilation of the vessels and capillaries, impaired circulation, and localised oedema, whereas mature spores released from the plasmodia may induce severe granulomatous inflammation in brain tissue. $M$. kisutchi occurs in the central nervous system (medulla oblongata and spinal cord) of juvenile coho salmon and chinook salmon (Fig. 38), but often causes minimal host reaction. The preserved spores (formalin) have 2 polar capsules, are 7 to $8 \mu \mathrm{m}$ in diameter, appear uniform in shape and contain an iodinophilous vacuole. This parasite is sometimes observed in fish head samples taken for $M$. cerebralis detection, although $M$. kisutchi resides in nervous tissue rather than cartilage.

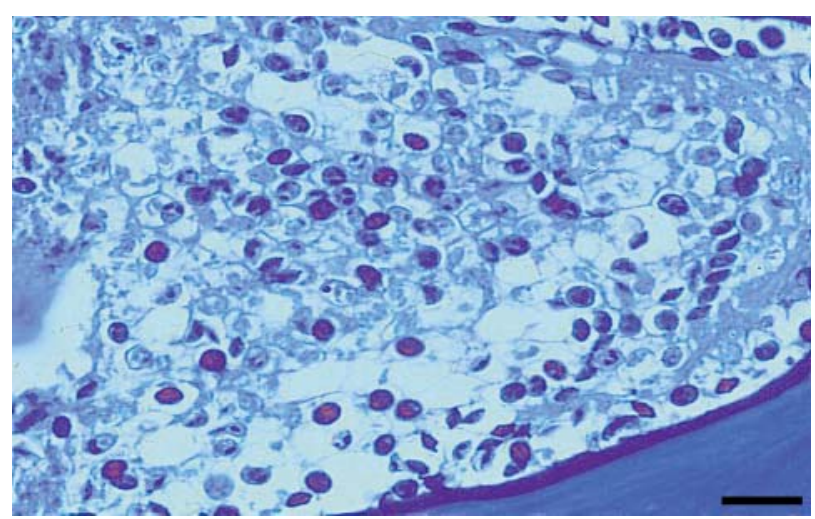

Fig. 37. Myxosporidia: Myxobolidae. Myxobolus cerebralis spores in the cartilage of rainbow trout Oncorhynchus mykiss. The agent of salmonid 'whirling disease' infects head and vertebral cartilage; the variable oval to spherical spores contain 2 polar capsules. Giemsa. Scale bar $=80 \mu \mathrm{m}$
Some Henneguya species are common in the gills of perch and northern pike in Europe and can cause deformation of gill tissues and granuloma formation; certain species also cause mortality. The early plasmodial stage of $H$. psorospermica in the gills of northern pike is shown in Fig. 39. H. exilis, a gill pathogen of channel catfish, causes 'interlamellar disease' associated with severe interlamellar tissue proliferation and heavy losses of fish. H. zschokkei infects muscle tissue of salmonids and coregonids; the large encapsulated plasmodia can make the flesh unmarketable. Thelohanellus pyriformis (Fig. 36), common in the gills of cyprinids in Eurasia, can cause massive endothelial hypertrophy of blood vessels in the gills, and has been implicated in mortality.

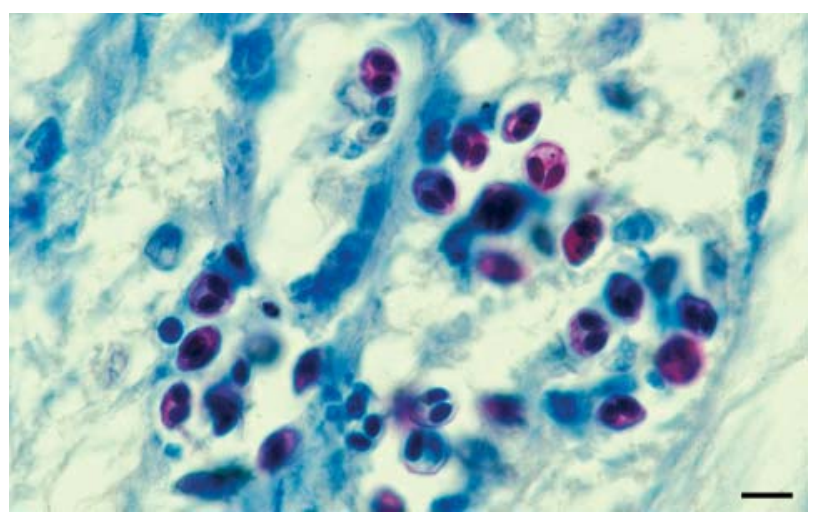

Fig. 38. Myxosporidia: Myxobolidae. Myxobolus kisutchi in the medulla oblongata of a juvenile chinook salmon Oncorhynchus tshawytscha. The subspherical spores with 2 pyriform polar capsules are clearly visible in this preparation. These parasites are sometimes observed in fish head samples taken for M. cerebralis detection in western North America, but $M$. kisutchi infects nervous tissue rather than cartilage. Ziehl-Neelsen. Scale bar $=10 \mu \mathrm{m}$

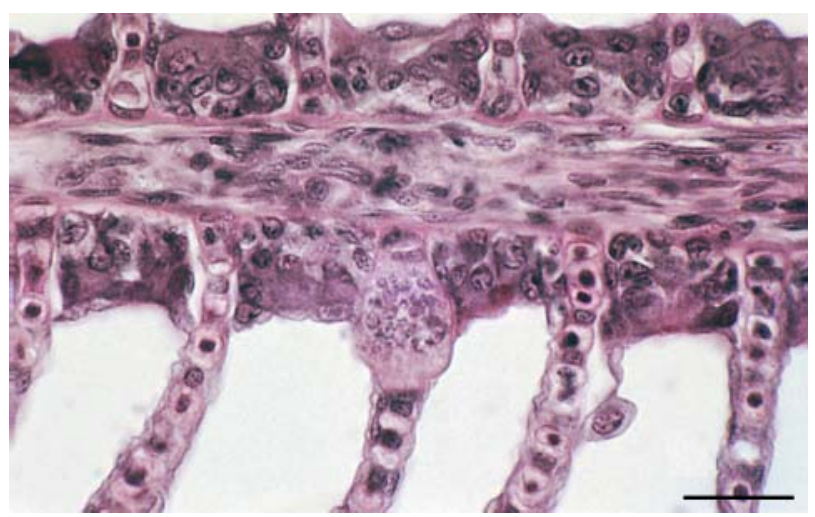

Fig. 39. Myxosporidia: Myxobolidae. Early plasmodial stage of Henneguya psorospermica in the gills of northern pike Esox lucius. Intralamellar plasmodia can result in deformation of lamellae and fusion of adjacent lamellae, reducing the respiratory surface. A granulomatous inflammatory reaction may occur after the spores have matured. H\&E. Scale bar $=30 \mu \mathrm{m}$ 
Kudoidae. Fish species around the world are parasitized by myxozoans of the genus Kudoa, several of which infect and cause damage of commercial importance. In particular, $K$. thyrsites can infect the myocytes of certain cultured fish species causing postmortem myoliqufaction, making the fish unmarketable. Parasite-produced proteolytic enzymes can induce post-mortem liquefactive degradation of the flesh. Kudoa spores have 4 shell valves, each of which contains one polar capsule (Fig. 40). In Kudoa the spores are stellate, quadrate or rounded quadrate in apical view with the suture lines often indistinct, and with pyriform polar capsules. In some Kudoa sp. not all polar capsules are the same size as each other. The trophozoites may be small (producing 1 to 7 spores) or large and polysporic. Kudoa species infect marine fish and are histozoic, mostly intracellular in muscles; exceptionally they are coelozoic. Immunofluorescence procedures have been used for detection and identification of Kudoa species in tissue sections (Yokoyama et al. 2000, Chase et al. 2001).

Some other members of the Order Multivalvulida (e.g. certain Hexacapsula, Trilospora and Unicapsula species) are also histozoic in the musculature of marine fish, and are associated with muscle degeneration or post-mortem liquefaction of muscle. The shell of the radially symmetrical spores of multivalvulids is composed of 3 to 7 valves meeting in 3 to 7 sutures. The polar capsules ( 1 per valve) are grouped together at the apex of the spore. Thus, Trilospora has 3 elongated shell valves with 1 spherical polar capsule per valve, and Hexacapsula has 6 valves with 1 polar capsule per valve. The exception is Unicapsula (Trilosporidae), which has subspherical spores with 3 unequal shell valves; 1 small valve contains a single spherical polar capsule, and 2 larger bilaterally symmetrically arranged valves contain 2 capsular rudiments that are difficult to distinguish by light microscopy.

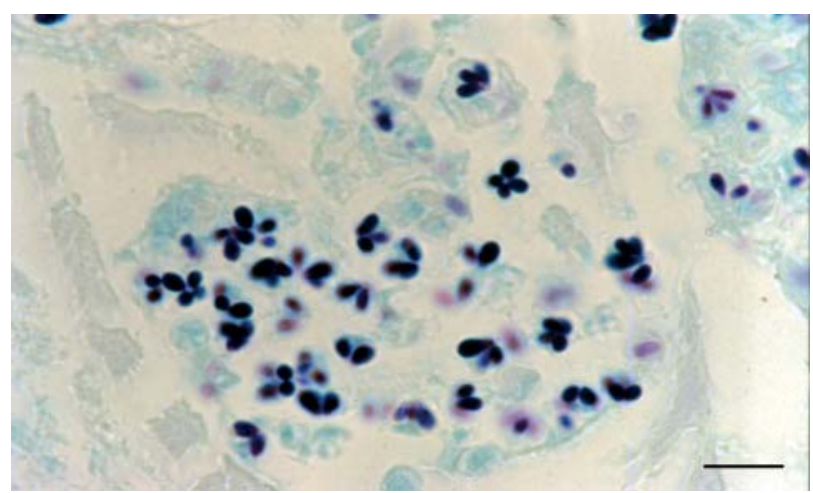

Fig. 40. Myxosporidia: Kudoidae. Multivalvulid myxosporean Kudoa thyrsites in the skeletal muscle of an Atlantic salmon Salmo salar. In this genus there are 4 polar capsules (each associated with a separate spore valve). May-Grünwald Giemsa. Scale bar $=30 \mu \mathrm{m}$
Saccosporidae. Proliferative kidney disease (PKD) is recognized as an economically important disease of salmonid culture in Europe and North America and the causative agent of salmonid fish, the PKX organism, has been described as Tetracapsuloides bryosalmonae (Canning et al. 2002). Earlier names for this parasite include Tetracapsula bryosalmonae (Canning et al. 1999) and Tetracapsula renicola (Kent et al. 2000). An initial stage of PKD characterised by haematopoietic hyperplasia is followed by diffuse, chronic inflammation. The parasites may be surrounded by coalescing whorls of inflammatory cells (primarily macrophages). Sporogenesis occurs in the renal tubules, resulting in monosporous pseudoplasmodia. The fully formed cryptic spores in the tubular lumina were once thought to be immature. The spores are ovoid $(12 \times 7 \mu \mathrm{m})$ with indistinguishable valves and 2 spherical polar capsules at the anterior end. In addition to the kidney, T. bryosalmonae may infect other well-vascularised organs such as the gills, liver, pancreas and spleen, causing changes similar to those observed in the kidney. In blood vessels, parasites adhere to the vessel walls causing a necrotising vasculitis.

Histopathological examination of H\&E-stained sections has regularly been used to diagnose PKD caused by Tetracapsuloides bryosalmonae. The PKX trophozoite in the renal interstitium is amoeboid and 5 to $20 \mu \mathrm{m}$ in diameter. It has eosinophilic and often foamy cytoplasm (Fig. 41), 1 to 3 vegetative nuclei with prominent endosomes (nucleoli) in the primary cell, usually 1 to 7 dense secondary cells, and sometimes 1 or more tertiary cells within the secondary cells. Intensely stained inflammatory cells are often attached

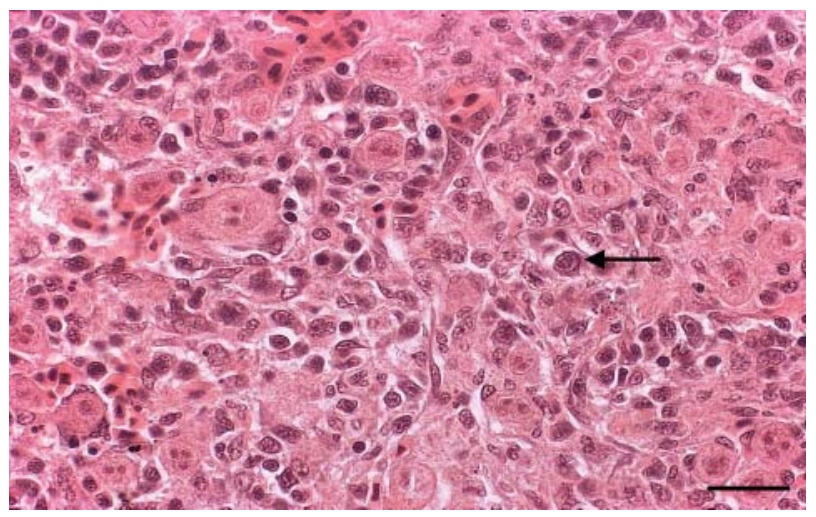

Fig. 41. Myxosporidia: Saccosporidae. Proliferative kidney disease (PKD) in rainbow trout Oncorhynchus mykiss, caused by Tetracapsuloides bryosalmonae. In H\&E sections, extrasporogonic stages in the kidney interstitium appear as amoeboid parasites characterised by eosinophilic, often foamy cytoplasm. Inflammatory cells surround, and are attached to, the parasites (arrowed). At higher magnification, features such as the primary cell nuclei with eosinophilic endosomes (nucleoli), secondary cells, and tertiary cells can be distinguished. H\&E. Scale bar $=40 \mu \mathrm{m}$ 
to the parasite and may surround it. The ovoid spores of this species, if present in the tubular lumina, usually show 2 prominent capsulogenic cell nuclei posterior to the spherical polar capsules in H\&E-stained sections. Immunohistochemical staining (Morris et al. 1997) and in situ hybridisation (Morris et al. 2000) procedures have been used for detection of various life stages of T. bryosalmonae in fish tissue sections.

Metazoa (except myxosporidians). The most important characteristics for identification of most metazoan parasites in histological sections include: integument or cuticle, musculature, body cavity, digestive system, reproductive system and special glands or other structures (Chitwood \& Lichtenfels 1972).

Monogenea. Parasites belonging to the Class Monogenea (platyhelminths) are monogenetic flukes characterised by a posterior attachment organ, the haptor (opisthaptor). Monogeneans are hermaphroditic and parasitise both freshwater and marine fish. Their life cycle involves 1 host, and infestation occurs directly, usually by a ciliated, free-swimming larva, the oncomiracidium. The Class Monogenea is traditionally divided into 2 Subclasses, the Monopisthocotylea (Fig. 42), which possess a haptor comprising a single attachment unit, and the Polyopisthocotylea (Fig. 43), members of which have a complex haptor with multiple attachment units, including suckers, clamps, or both. The mouth of monogeneans is at the opposite end of the body from the haptor.

Monopisthocotyleans are tissue grazers that generally inhabit the external surfaces and gills of their hosts (Fig. 42). Heavy infestations may elicit epidermal hyperplasia due to disruption by parasite attachment and feeding; increased mucus production may also

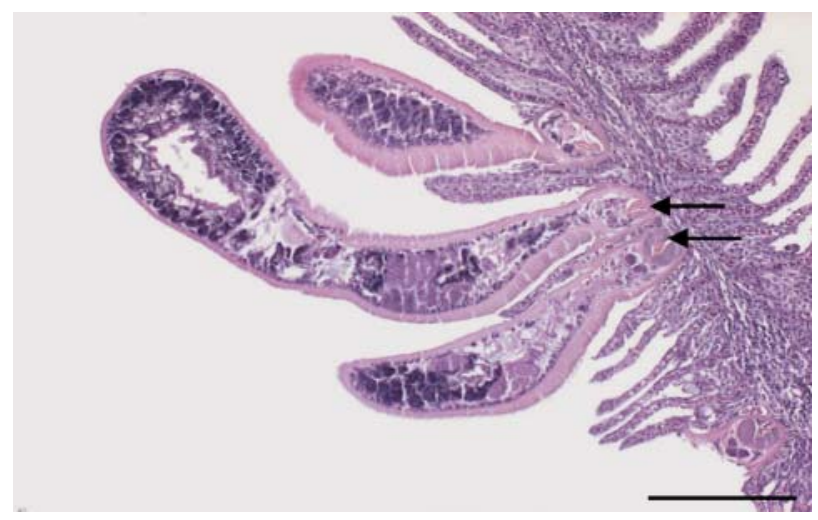

Fig. 42. Monogenea. Longitudinal section of several monopisthocotylean monogeneans attached to the primary gill lamella of a sea bass Dicentrarchus labrax. Posterior attachment organ (haptor) is visible, including portions of the refractile sclerotised hamuli (hooks or anchors) (arrows). Outer body wall consists of several layers of a thin acellular integument, beneath which are musculature; no muscle tissue is present in the inner parenchyma. No host reaction is apparent. H\&E. Scale bar $=100 \mu \mathrm{m}$

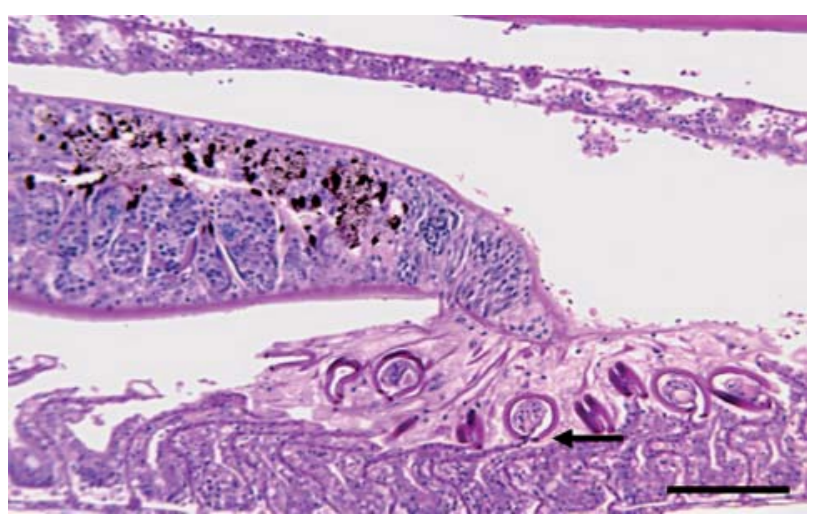

Fig. 43. Monogenea. Longitudinal section of a polyopisthocotylid monogenean on the gills of a marine fish. The haptor of adult polyopisthocotyle monogeneans is complex and often subdivided, with sucker-like attachment organs or clamps (arrow) replacing marginal hooks of the larval haptor. H\&E. Scale bar $=25 \mu \mathrm{m}$

occur. Secondary infections by protozoa, bacteria and fungi often ensue and can cause dermal erosion and haemorrhage. In severe infestations, death occurs, usually due to loss of osmotic regulation.

Monopisthocotyleans important in fish pathology include the Families Capsalidae (Benedenia and Neobenedenia), Dactylodyridae (including Dactylogyrus spp.), various members of the Diplectanidae, and Gyrodactylidae (Gyrodactylus spp.). They are mostly epidermal skin grazers and possess an opisthaptor armed with hooks. The Capsalidae can inhabit both the skin and gills and are recognisable in sections by their cup-shaped haptor, dorso-ventrally flattened body and large size as adults (generally $2 \mathrm{~mm}$ or more in length). Members of the Dactylogyridae generally inhabit gills of fish of the Family Cyprinidae and are small (often under $1 \mathrm{~mm}$ total length). The group is morphologically diverse and identifying them precisely in sections is often impossible. In contrast, sections of diplectanids often show the squamodisc, a sessile or subsessile disc on the haptor, covered with concentric rows of scale-like spines or lamellae. Gyrodactylus spp. inhabit the external surfaces and gills of their hosts and are unusual among the monogeneans in that they bear live young. Sections of gyrodactylids often show a developing embryo inside the uterus of the parent worm, a distinctive feature of the family.

In the Order Polyopisthocotylea the opisthaptor is armed with hooks and suckers or clamps. Polyopisthocotyleans usually inhabit the gills and are sanguinivorous, causing tissue compression and some hyperplasia of the gill tissues. Pathogenesis results from feeding and blood loss, which is reflected in decreased haematocrit in heavily infected fish hosts. Heavy infections cause death through compromised oxygen uptake; the haematological condition is compounded by inter- 
ruption of gill function caused by physical disruption where the parasites attach and by the host's tissue reaction. Some polyopisthocotylean genera relevant to fish pathology include Diplozoon, Microcotyle and Sparicotyle.

The hamuli (large hooks or anchors) and other sclerotised parts of the haptor may be present in tissue sections of fish tissue (Fig. 43). Additional features characteristic of monogeneans may also be observed, including the acellular cuticle subtended by several layers of body musculature, anterior adhesive organs (head organs, suckers, or pseudosucker, a muscular pharynx and bifurcated (usually) intestinal caeca, reproductive organs (a single ovary and 1 or more testes) and yolk glands (vitellaria). Internal organs are embedded in loose parenchyma consisting of cells and fibrils. Although such features can assist with the morphological identification of the taxonomic group to which an individual parasite belongs, identification of these parasites to genera relies on observations of whole animals. Both H\&E and PAS staining are useful procedures for observing monogeneans in sections.

Digenea. Trematodes are commonly found in all species of vertebrates. Members of the Class Trematoda most frequently encountered in fish are the Digenea, although some species of Aspidogastrea are also endoparasites of fish. Adult digeneans are mainly parasites of the digestive tracts (including the intestine, liver, and bile ducts) of fish and other vertebrates, although they can be endoparasitic in other organ systems. Digenea are usually hermaphroditic, the exception being schistosomes infecting humans. Digenea generally have either a 2-host or 3-host life cycle, although there are a variety of life cycle patterns. For most Digenea, molluscs (snails or bivalves) are the first intermediate host. In life cycles with a second intermediate host, this host may be an invertebrate or a fish. The final host is a vertebrate. Fish may serve as intermediate or final hosts for Digenea.

Trematodes are flat and leaf-shaped and frequently twisted upon themselves in histological sections, so that discerning the relationship among their internal organs is often difficult. The digenean body is limited by a thick elastic integument that may contain spines. When present, integumental spines are often on the anterior portion of the organism. In addition, some digeneans, such as the echinostomes, have large spines around the muscular anterior oral sucker, which surrounds the mouth. In addition to the oral sucker, digeneans have ventral suckers or terminal suckers on the posterior end. Digenea lack the chitinous hooks found in Monogenea. The muscle fibres of the suckers are usually arranged radially. The mouth gives rise to a muscular pharynx, and in turn, to paired intestinal caeca (rarely only 1 caecum). The caeca are blind and end in the posterior portion of the body and often contain a brown to black pigment associated with the breakdown of erythrocytes. This 'blood pigment,' when extruded from the body of the parasite, can also be found in the tissues. Both adult and larval trematodes have no body cavity and are filled with parenchyma.

Metacercariae are the digenean larval stages most commonly observed in fish. Cercariae liberated from a mollusc intermediate host actively penetrate and migrate into tissues of the fish intermediate host and encyst as metacercariae. The resistant surrounding cyst wall, suckers and paired caeca can identify metacercariae. These appear morphologically similar to adults but lack a developed reproductive system.

Nanophyetus salmincola metacercariae are common parasites in the skeletal muscle of juvenile chinook salmon (Fig. 44) and other fish; the adults are intestinal parasites of Carnivora and humans. The host reaction to these parasites ranges from a minimal response to a granulomatous reaction. Heavy infections of metacercariae have been shown to increase fish susceptibility to viral infections, resulting in higher morbidity and mortality. In addition, a rickettsia carried by Nanophyetus can cause serious disease in canids that eat infected fish.

Metacercariae of several digeneans found in the skin, fins and gills of freshwater and marine fish cause a condition known as 'black spot disease.' Melanophores in the host capsule cause grossly visible black spots that give the disease its name. The metacercariae of the trematode Posthodiplostomum cuticola causing black spot disease in freshwater fish is illustrated in Fig. 45. Wittrock et al. (1991) reported that the host capsule surrounding metacercariae of the black spot trematodes Uvulifer ambloplitis and Neascus pyriformis stained positively for proteins, and neutral and

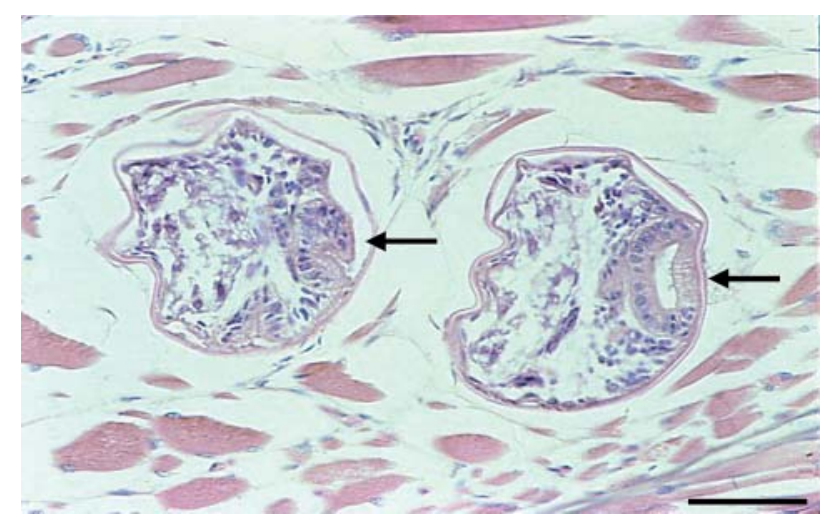

Fig. 44. Digenea. Encysted Nanophyetus salmincola metacercariae in skeletal muscle of a juvenile chinook salmon Oncorhynchus tshawytscha showing suckers with radially arranged musculature (arrows). Host reaction to the parasites in this section is minimal. H\&E. Scale bar $=100 \mu \mathrm{m}$ 


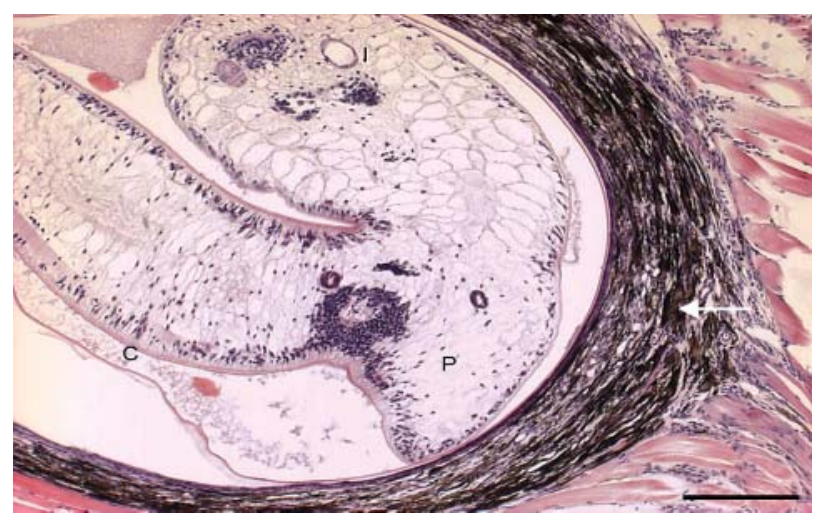

Fig. 45. Digenea. Metacercariae of Posthodiplostomum cuticola causing black spot disease in freshwater fish. An elastic integument (c), a body cavity filled with parenchyma (p), and the thin-walled paired intestinal caeca (seen in cross-section; i) are visible. Thick host capsule surrounding the parasite contains many melanophores (white arrow), giving rise to grossly visible black spots. H\&E. Scale bar $=200 \mu \mathrm{m}$

acid mucopolysaccharides. Cryptocotyle lingua is a black spot metacercariae commonly found in several marine fish species and salmonids during their saltwater phase. A proliferation of melanocytes occurs just beneath the epidermis and is generally visible macroscopically. Sometimes, the metacercariae may also be found in other organs such as the eyes, heart and peritoneum. The presence of circular black spots $(0.2 \mathrm{~mm}$ diameter) in the skin and other organs help with the identification of this parasite.

Diplostomum spathaceum is generally a seasonal debilitating condition of rainbow trout, although a large number of species have been reported to be infected. Metacercariae of the genus Diplostomum establish themselves in the anterior chamber, retina, vitreous body and lens causing cataracts leading to varying degrees of blindness (Fig. 46). The site of entry is marked by tiny capsular perforation through which

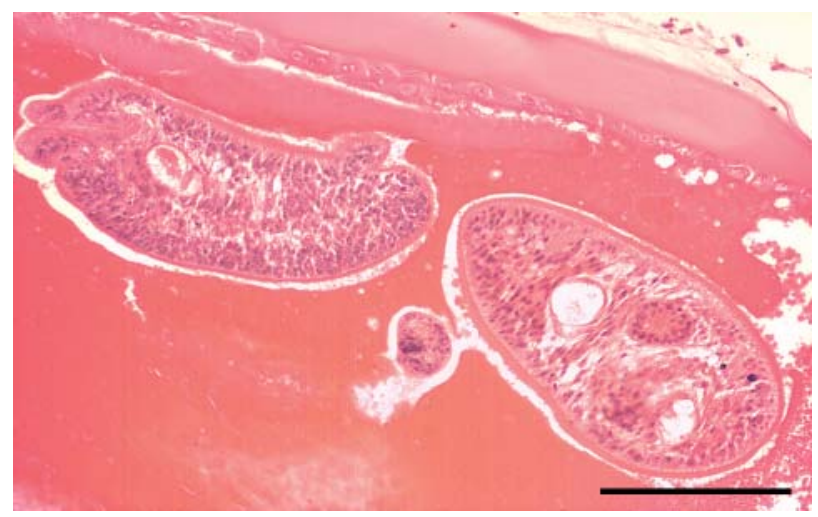

Fig. 46. Digenea. Metacercariae of Diplostomum spathaceum in the dorso-ventral band of the lens of rainbow trout Oncorhynchus mykiss. H\&E. Scale bar $=50 \mu \mathrm{m}$ cortical lens fibres exude. Occasionally, the perforations lead to lens rupture and severe endophthalmitis, followed by a generalised cortical liquefaction as flukes migrate to the anterior cortex with proliferation of the lens epithelium.

Certain adult digeneans reside in locations other than the intestines of fish, for example, the urinary bladder, gall bladder, ovary, or swim bladder. One of the most important of these is the blood fluke Sanguinicola, which occurs in blood vessels (especially those in the gills and kidneys) of various fish species. Embryonated eggs and developing miracidia of Sanguinicola in the gill of a rainbow trout are shown in Fig. 47. The adult Sanguinicola may cause little host damage, but in cultured fish, the miracidia escaping from the gills can cause severe disease.

The reproductive organs of adult Digenea are found within the parenchyma and consist of peripherally located vitellaria (yolk forming glands), 1 ovary and paired testes. Phyllodistomum are examples of adultstage digeneans in fish and parasitic in the urinary bladder of fish causing osmotic imbalance (Fig. 48). Vitellaria, when stained with H\&E, contain eosinophilic globules (i.e. yolk material). Mature sperm stained with H\&E are basophilic, elongate strands. Eggs can be found within the digenean, and the shells of mature eggs are often yellow to brown in colour. The ova are readily seen in H\&E- and PAS-stained preparations. The morphology of intact ova is used in identification of Digenea.

Cestodes. The Cestoda or tapeworms are endoparasitic with a wide geographic distribution, but show a high degree of host specificity. With few exceptions, all cestodes require at least 2 hosts. Often one of the intermediate hosts is an invertebrate (frequently an arthropod such as a copepod, amphipod, or isopod) that is

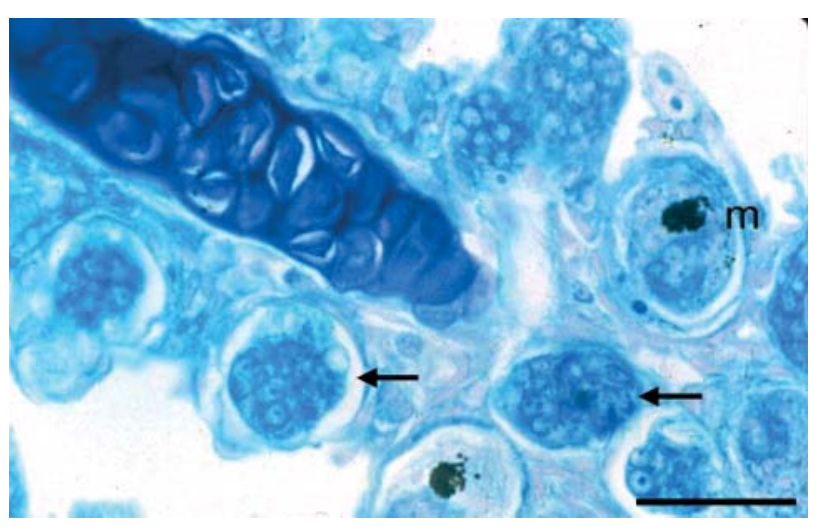

Fig. 47. Digenea. Embryonated eggs (arrows) and developing miracidia (m) of blood fluke Sanguinicola spp. in the gill of a rainbow trout Oncorhynchus mykiss. The miracidia have characteristic black eye spots, which are also visible in wet mounts. Adult Sanguinicola are occasionally visible in the branchial artery. May-Grünwald Giemsa. Scale bar $=30 \mu \mathrm{m}$ 


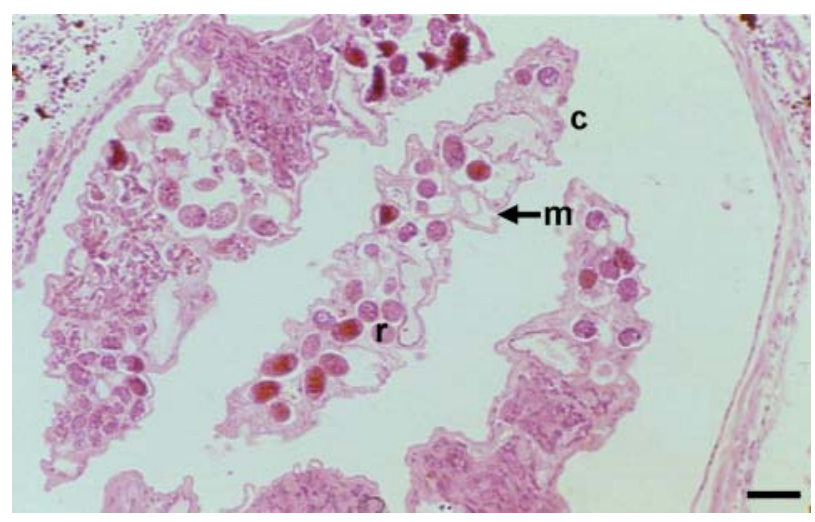

Fig. 48. Digenea. Distension of urinary bladder of rainbow trout Oncorhynchus mykiss attributed to infection with Phyllodistomum spp. Note thin cuticle (c), muscle layer beneath cuticle $(\mathrm{m})$ and reproductive organs (r). H\&E. Scale bar $=20 \mu \mathrm{m}$

eaten by another intermediate host or by the final host. Two life-cycle stages of cestodes are represented in fish; the adults inhabit the intestine and pyloric caeca, and plerocercoid larvae of the same or different cestode species are found in visceral organs and musculature.

Cestodes resemble trematodes in histological sections, but lack a digestive tract and nourishment is absorbed by the whole body surface. Some distinguishing features between the Trematoda and Cestoda are given in Table 2 .

The adult worm has a flattened, ribbon-like body (strobila), generally white in colour and often divided into individual proglottid segments, each containing a single set of reproductive organs; the exceptions are the unsegmented cestodes of the Orders Amphilinidea and Caryophyllidea. Each mature proglottid contains both male and female reproductive organs. The uterus appears as a cavity in the parenchyma of the worm and is usually filled with numerous eggs. The eggs from the proglottids are shed in the faeces of the host, and mature eggs (oncospheres) of cestodes can often be recognised by the presence of characteristic hooks in a

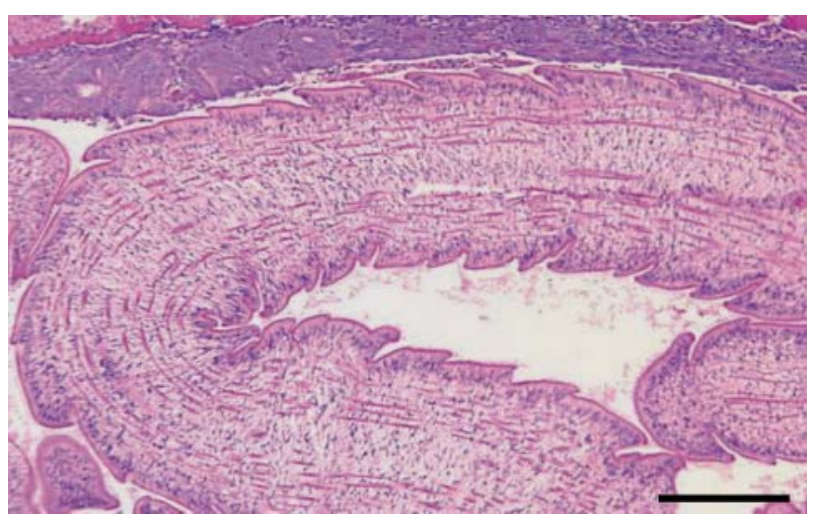

Fig. 49. Cestode. Eubothrium sp. in the intestinal tract of a sockeye salmon Oncorhynchus nerka. Both adults and larvae of Eubothrium may be present in the fish host. Absence of complete segmentation into proglottids with reproductive organs identifies this specimen as immature. Bands of longitudinal muscle deep in the parenchyma, and lack of a digestive tract help to distinguish cestodes from trematodes. H\&E. Scale bar $=100 \mu \mathrm{m}$

sphere. In some genera, a 'skirt' of parenchyma (called a velum) extends from each proglottid of the adult cestode and overlaps the next posterior one. When a velum is present, the proglottids are described as craspedote, and when it is absent they are described as acraspedote. In addition to subcuticular muscles located just beneath the cuticle (similar to trematodes), cestodes also possess longitudinal muscles deeper within in the parenchyma (Fig. 49), subtended by circular muscles that divide the parenchyma into an inner tube containing reproductive organs and an outer cortical zone. Excretory ducts open in the terminal proglottid.

Tapeworms have a holdfast organ (scolex), which may be acetabulate with 4 suckers, bothridiate with 4 bothridia (muscular holdfast organs), or bothriate with 2 bothria (holdfast grooves; Fig. 50). In histological sections suckers appear as muscular circles due to radial striations of the muscle fibres. Some cestode scolices may also be armed with hooks and spines or have a

Table 2. Key features used to distinguish parasites in the Class Trematoda and Cestoda

\begin{tabular}{|c|c|}
\hline Class Trematoda & Class Cestoda \\
\hline Do not posses calcareous corpuscles & Usually posses calcareous corpuscles \\
\hline Unsegmented & Mostly segmented body, ribbon-like \\
\hline Digestive tract present & No digestive tract \\
\hline $\begin{array}{l}\text { Attachment by oral and ventral suckers. The position } \\
\text { and relative size of the suckers are important characters }\end{array}$ & Attachment by scolex \\
\hline Thinner cuticle & Thicker layered cuticle with a basement membrane \\
\hline Muscle layers just beneath the cuticle & Muscle layers deep in parenchyma \\
\hline Extensive reproductive organs & Reproductive organs less well defined \\
\hline Presence or absence of body spines or papillae & \\
\hline Relative size, appearance and location of reproductive organs & Each proglottid contains a full set of reproductive organs \\
\hline
\end{tabular}


retractable rostellum or proboscis covered with fine hooks. The scolex also contains the rectangular 'brain', and 2 large major nerve trunks extend posteriorly along the entire length of the strobila. Posterior to the scolex of many cestodes is the neck, which is the most slender part of the body and is the germinative region producing proglottids.

A method for selective staining of hooks of scolices of tapeworms in histological sections was described by Sterba et al. (1989). The method is based on prestaining in haematoxylin, staining overnight in dilute polychrome blue and differentiated with tartrazine in cellosolve. The hooks stain blue, nuclei brown to brown-green and cell plasma yellow. The hooks stain brightly, which enables the identification of parasite remnants in granulomas and scars. The intensity of staining depends on the grade of maturity and sclerotization of hooks.

Both larval and adult cestodes have calcareous corpuscles, which measure 12 to $32 \mu \mathrm{m}$ in diameter, embedded within their parenchyma (Fig. 51). The precise function of these structures is unknown, but they are helpful for identification purposes in histological sections. Calcareous corpuscles appear basophilic to clear and sometimes have a concentric ringed appearance. Sometimes these corpuscles have been 'dissolved' during fixation or histological processing. In these cases, however, the parenchyma continues to conform to the shape of the corpuscles. Calcareous corpuscles are more numerous in the head and neck region of both the adult and larval cestode than in other regions of the parasite.

Cestode larvae are common in wild fish, and in histological sections they can often be seen encysted among the viscera and the musculature. These larvae may be cystic or solid in nature; the solid plerocercoid form occurs in fish. The plerocercoid is generally club-

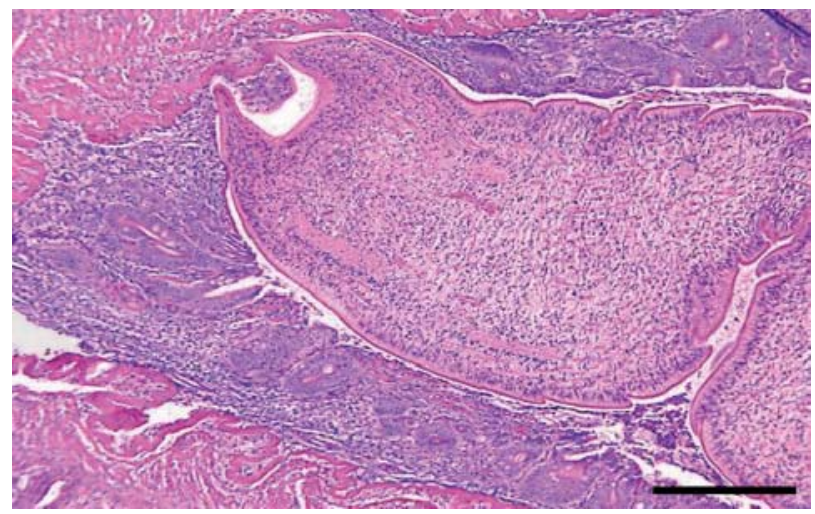

Fig. 50. Cestode. Scolex of Eubothrium sp. attached to the intestine of a sockeye salmon Oncorhynchus nerka. The scolex of Eubothrium has simple grooves (bothria) for attachment. High numbers of Eubothrium in salmonids can cause blockage of the intestinal tract. H\&E. Scale bar $=100 \mu \mathrm{m}$ shaped, with the adult holdfast invaginated at one end. In sections the body is filled with loose parenchyma tissue, and generally the worm does not show any prominent features unless the scolex is present. However, the plerocercoid is anatomically identical to the adult except for the absence of proglottidisation and reproductive organs.

Often no injury results from intestinal cestodes unless they are present in high numbers, but an inflammatory reaction may occur in association with mature worms and plerocercoid larvae that exert mechanical pressure on internal organs. Plercocercoids migrating in the visceral cavity can produce adhesions that are very damaging to fish, and migrating plerocercoids can even cause death when vital organs are severely injured. The large plerocercoids of Ligula intestinalis can cause great damage to small fish, even rupturing the body wall.

Nematodes. Nematodes are found in the intestinal tract, liver, pancreas and swim bladder of freshwater and marine fish. The Nematoda consist of many species of unsegmented roundworms that have a pseudocoelom and a fibre or threadlike body that is circular in cross-section (e.g. Anisakis, Capillaria, and Cystidiola). Members of the genus Anisakis (and a number of related genera) are parasites of the gastrointestinal tract of marine mammals. The parasites pass eggs in the host's faeces, and the eggs are ingested by a crustacean. The digestive tract within the body cavity is a 'tube within a tube' body plan, and is divided into an oral opening, mouth (buccal) capsule, oesophagus, intestine and rectum (Fig. 52). The hydrostatic skeleton (fluid-filled body cavity) allows for locomotion. When sectioned longitudinally (Fig. 52), nematodes usually show several characteristic features, including

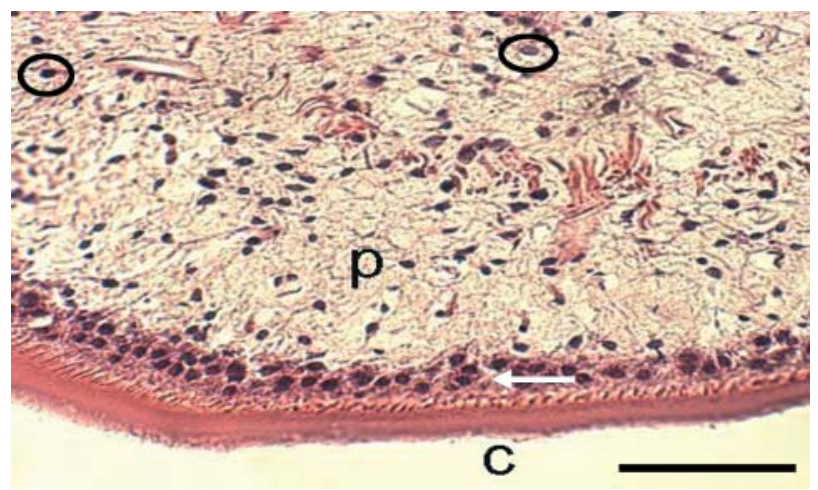

Fig. 51. Cestode. Diphyllobothrium dendriticum from a cutthroat trout Oncorhynchus clarki. Note the acellular integument (c), subcuticular cells (white arrow), the loose parenchyma (p), and the basophilic calcereous corpuscles (circles) within the parenchyma. Presence of calcereous corpuscles in the parenechyma of cestodes distinguishes them from trematodes (which do not have calcereous corpuscles). H\&E. Scale bar $=20 \mu \mathrm{m}$ 


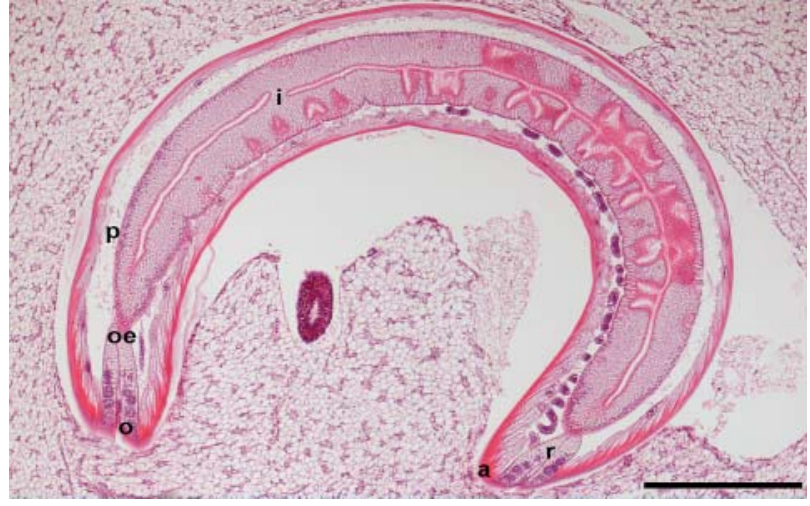

Fig. 52. Nematode. Longitudinal section of a nematode from a sand goby Pomatoschistus minutes showing the pseudocoelom ( $\mathrm{p}_{\text {; }}$ cavity between the body wall and the digestive tract). Digestive tract within the body cavity is a 'tube within a tube' body plan, divided into an oral opening (o), mouth capsule, oesophagus (oe), intestine (i), rectum (r), and anus (a). H\&E. Scale bar $=600 \mu \mathrm{m}$

an obvious acellular external cuticle. The cuticle is multi-layered and may be ornamented and have ridges. The anterior end of a nematode may show cuticular ornamentations around the mouth; these may be observed with careful sectioning. The hypodermis (also called the epidermis) is a thin cellular layer between the cuticle and the somatic musculature. The hypodermis is generally thinner than the somatic musculature, but in many nematodes, extensions of the hypodermis called lateral chords may protrude well into the pseudocoelom (Fig. 53). The body musculature of nematodes is composed of dense contractile elements and pale sarcoplasm, and is described as coelomyarian (Fig. 53) or platymyarian. Coelomyarian muscle cells appear U-shaped in cross-section and may extend well

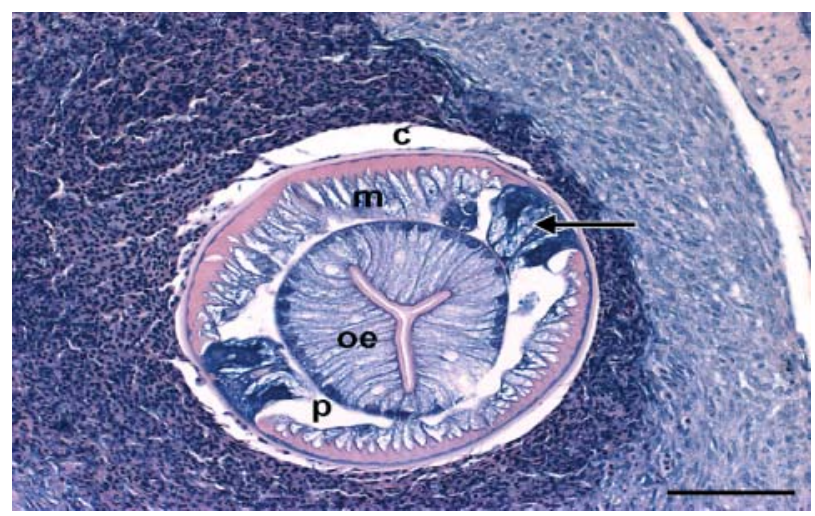

Fig. 53. Nematode. Cross-section showing a round body with an acellular external cuticle (c). Muscle cells (m) of the body musculature appear U-shaped (coelomyarian) in cross-section. Two prominent lateral chords of hypodermal tissue (arrow) extend from beneath the cuticle into the pseudocoelom (p). The central oesophagus (oe) has a typical triradiate (y-shaped) lumen. H\&E. Scale bar $=200 \mu \mathrm{m}$ into the pseudocoelom such that the body cavity is obscured. Platymyarian muscles cells are usually large and few, and lie flat on the hypodermis, rarely extending into the pseudocoelom.

The histological features of the digestive tract of nematodes can be helpful for identification. In crosssection, the oesophagus is usually recognised by its radial symmetry and triradiate lumen (Fig. 53), even though glandular tissue may be interspersed among the muscles. The type of epithelial cells that compose the intestine is useful for separating groups of nematodes. Types of cells range from very large multinucleate cells through cuboidal cells to tall columnar cells. The size and location of the intestinal epithelial cell nuclei can also be important characteristics for nematode identification, as can the presence or absence of microvilli bordering the intestinal lumen and the height of the microvillar layer. These characteristics are further described and illustrated in publications such as Chitwood \& Lichtenfels (1972).

The genital tracts of nematodes may be visible in histological sections; sexes are separate in most species, with females larger than males (Fig. 54). Adult males have a single genital tract consisting of a testis that produces sperm, which, in turn, is found in the vas deferens. Nematode sperm stained with H\&E appears small, oval, and eosinophilic with a basophilic nucleus. Female nematodes may have 1 or more genital tracts, consisting of ovaries that give rise to oviducts, which empty into uteri. The uteri contain developing eggs or embryos, and the distal part of the uteri, referred to as seminal receptacles, and may store sperm from previous copulations. Although some nematode species pro-

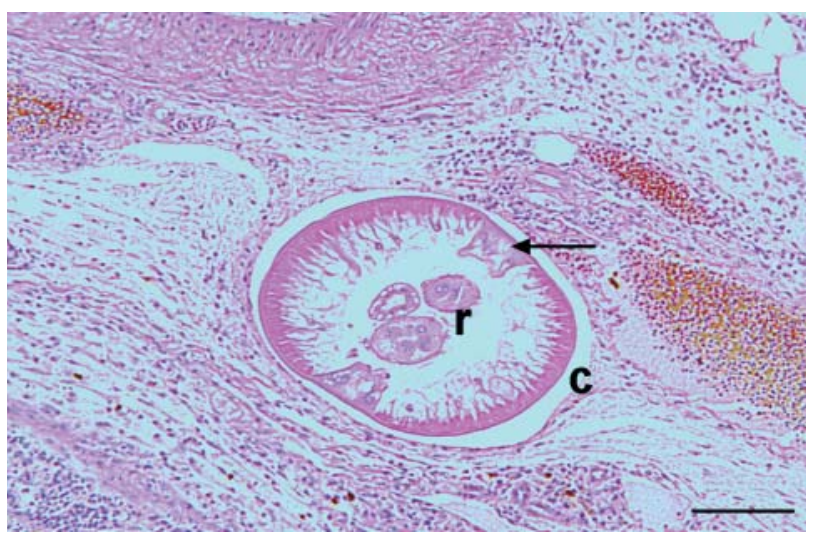

Fig. 54. Nematode. Unidentified nematode in the viscera of a lingcod Ophiodon elongatus. Prominent features include an acellular cuticle (c), 2 lateral chords of hypodermal tissue (upper right and lower left) extending from beneath the cuticle into the pseudocoelom, muscle tissue (with dense contractile elements and pale sarcoplasm) between the lateral chords (arrow), and a central intestine with cuboidal epithelium. The other 2 central structures may be reproductive (r). H\&E. Scale bar $=220 \mu \mathrm{m}$ 
duce larvae, most produce eggs. If ova are found, it may be possible to identify a species as these tend to have characteristic morphology. Fresh uncleaved or larvated eggs and associated polar plugs may also be observed by light microscopy.

In general, the pathology associated with nematode infestations in fish is variable but not extensive. A pronounced, encapsulating response may occur around the parasite, particularly in cases where the parasite is degenerating. In addition, migrating larvae cause granulomatous inflammation in many organs.

Acanthocephala. Acanthocephalans are a group of bilaterally symmetrical endoparasites that are parasitic among many species of freshwater and marine fish worldwide. Representatives belonging to the genera Acanthocephalus, Echinorhynchus, Metechinorhynchus and Pomphorhynchus are fairly common in salmonids. Principal characteristics of acanthocephalans include an elongate wrinkled body that is cylindrical and tapering at both ends in most species, and the presence of a protrusible, spined proboscis (Fig. 55) at the anterior end; a digestive tract is lacking. The body resembles a tube, with the body wall enclosing the pseudocoel (body cavity) in which are suspended the proboscis sheath and reproductive organs.

This group has an indirect life cycle with 1 or 2 intermediate hosts (one of which is an invertebrate). Fish serve as both second intermediate hosts and final hosts; sometimes larval and adult forms of a given species of acanthocephalan are present in the same fish host at the same time. The larval second intermediate stage encysts in the liver, spleen or mesentery of fish; the proboscis of encysted larvae is inverted. Adult parasites live in the intestine, and sexes of these oviparous parasites are separate (with females usually larger than males). Eggs, if present, are loose in the body cav-

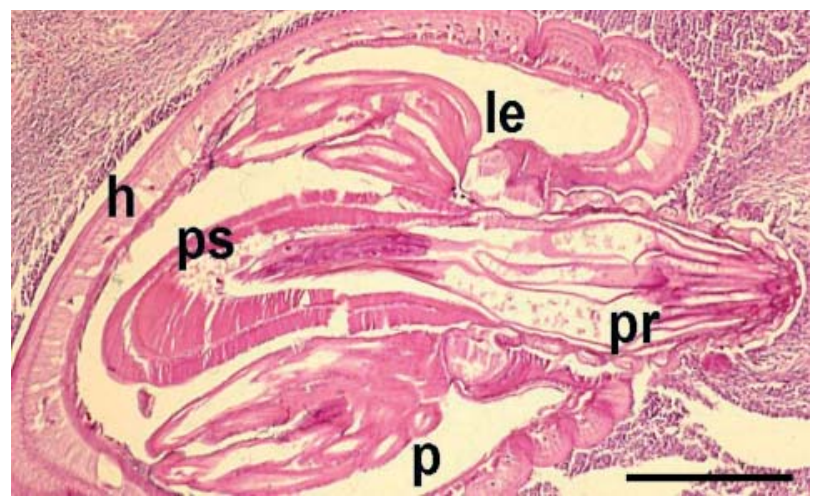

Fig. 55. Acanthocephala. Longitudinal section of the anterior portion female of an acanthocephalan in a fish intestine showing the proboscis with spines (pr), proboscis sheath (the sac into which the proboscis retracts; ps), the body wall with a thick hypodermis $(\mathrm{h})$ and the lemnisci (le; inner layers of the body wall which invaginate to form 2 diverticula that protrude into the pseudocoel, p). H\&E. Scale bar $=100 \mu \mathrm{m}$ ity (Fig. 55); there is no uterus. The ova are developed in 'egg balls' (Fig. 56) within the pseudocoelom and embryonated eggs are laid when mature.

These worms can be highly pathogenic to fish in culture, where they occur in high numbers. The armed retractable proboscis of the adult worm is embedded in the gut causing severe necrotic changes and haemorrhage within the mucosa, and a severe granulomatous reaction is associated with raised subserosal nodules.

Features in sections (in addition to the proboscis with its refractile spines) that can help to distinguish acanthocephalans from other metazoans include a body wall consisting of a relatively thin, non-rigid acellular cuticle and a very thick hypodermis consisting of several layers of fibres overlying thin bands of circular and longitudinal smooth muscle (Fig. 56). Distinctive lacunar channels, which appear as clear ovals or circles in the hypodermis in cross-sections of acanthocephalans, can often be observed. Another unique feature of acanthocephala is the sac-like projections called the lemnisci, which is found in the anterior portion of the worm in close association with the proboscis (Fig. 56), and associated with the eversion or retraction of the proboscis. H\&E staining can be used for routine histomorphology and Gomori's trichrome is useful for observing connective tissue that may surround the parasite.

Hirudinea (leeches). Leeches are annelids or segmented worms and the most highly developed helminths, with segmented bodies, a circulatory system, nephridia and a highly developed digestive system. Some may act as intermediate hosts for protozoan parasites, particularly parasites of fish such as species of trypanosomes.

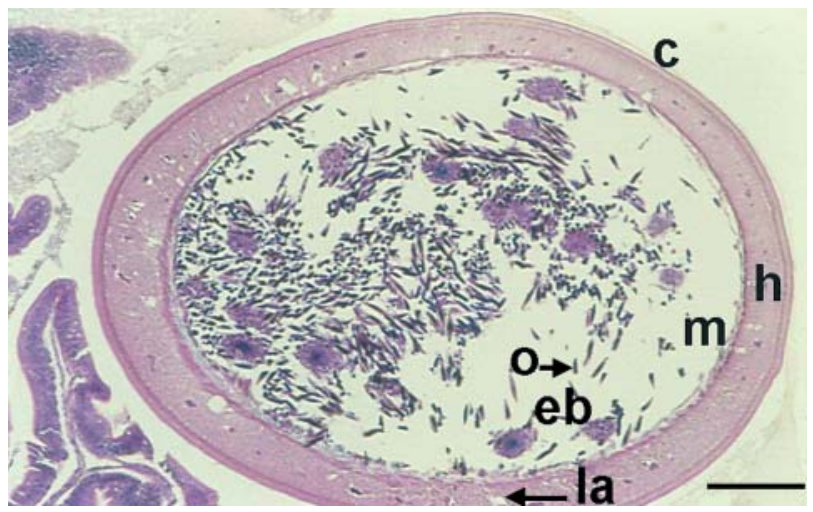

Fig. 56. Acanthocephala. Cross-section of a female acanthocephalan in the intestine of a fish. Visible features include a thin acellular cuticle (c), thick hypodermis (h) consisting of several layers of fibres and perforated at intervals by clear lacunar channels (la), and thin layers of somatic muscle (m) beneath the hypodermis. Acanthocephalans lack a digestive tract; ova (o) and the 'egg balls' (eb) from which they develop are visible within the body cavity (pseudocoelom). H\&E. Scale bar $=100 \mu \mathrm{m}$ 
Molluscs. Members of the Family Unionidae have an obligatory parasitic larval phase that affects freshwater fish, including salmonids. Glochidia attach to the gills and fins where they develop into juvenile mussels. In a similar manner, members of the Family Mytilidae release spat and these have occasionally been recorded developing on the gills of farmed fish.

Glochidiosis. The freshwater pearl mussel Margaritifera margaritifera is a member of the Family Unionidae and is resident in fast flowing, cool waters. In order to maintain the adult population upstream, glochidia are released annually. Glochidia are transported passively and clamp to the gill lamellae of resident fish using sharp 'teeth' (hooks) that enclose a portion of the lamellae in the mantle cavity. Encysted parasites occur to a lesser degree in the gill rakers and occasionally the pseudobranch. The escape of the mussels from their branchial cysts after metamorphosis to adult anatomy leaves open lesions that are subject to secondary infections. Cysts containing glochidia may grossly resemble metacercarial cysts, but contain a larval clam or mussel that can be recognised by its thin, bivalve chitinoid shell, which (in some species) has small hooks on its inner edge. A glochidium attached to secondary lamellae of a rainbow trout is shown in Fig. 57. H\&E staining is adequate for descriptive studies (Bruno et al. 1988). Preserved encysted glochidia often can be cleared satisfactorily for identification in a nematode-clearing solution such as lactophenol (Hoffman 1999).

Mussel spat. Nets and ropes of sea cages are colonised by a variety of marine organisms, and mussels are one of the more important and common 'fouling' agents. However, despite the close proximity of the fish to the nets, there is limited evidence showing

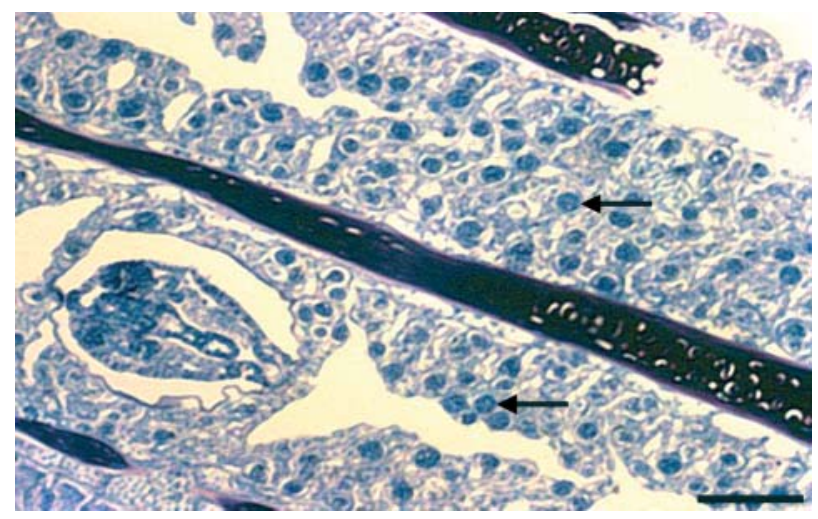

Fig. 57. Mollusc. Gill of a 5 mo old rainbow trout Oncorhynchus mykiss showing a single glochidium (larval freshwater mussel Margaritifera margaritifera) and numerous eggs of the blood fluke Sanguinicola sp. with developing embryos (arrows). Shell valves of the glochidium are clamped onto gill lamellar tissue, and the presence of the parasite has induced fusion of the tips of the lamellae. H\&E. Scale bar $=100 \mu \mathrm{m}$ direct involvement of these epifaunal species with farmed fish. In rare cases post-veliger larvae of the common blue mussel Mytilus edulis have been found attached to the gill lamellae of farmed Atlantic salmon several months after the fish have been transferred to seawater. Grossly, the affected fish appear thin, with a slightly raised opercular cavity and increased mucus (Bruno 1988). Post-veliger larvae are firmly attached and are grossly visible as white, circular bodies on the gill lamellae principally towards the lower half of each filament, and are clearly debilitating to farmed fish. An extensive hyperplasia may surround each larva (Fig. 58), with oedema, clubbing, necrosis and sloughing. An increase in eosinophilic granular cells can be recorded in the bulbous arteriosus as demonstrated by H\&E staining.

Crustacea. Several crustacean groups have evolved species to parasitism and examples of fish ectoparasites are found in the Branchiura, Copepoda and Isopoda. Parasitic crustacea are generally identified by gross examination, and only small sections of the parasites may be visible in histological sections. Features such as the chitinous exoskeleton, jointed appendages, and striated muscle help to identify these parasites as arthropods. Pathological changes caused by parasitic crustaceans are associated with an elongate cephalothorax present in adults, and the mechanical effects of feeding. The damage caused by feeding can be observed in histological sections as erosion of the epidermis and submucosal areas, and exposure of the underlying myotome with subepidermal oedema. H\&E staining is suitable to describe features of this group in tissue sections.

Copepods that are highly evolved to parasitism (e.g. Lernaeocera branchialis) do not have the classical crustacean features when attached to their hosts as adult females. On the definitive host, L. branchialis is haematophagous and attaches at the ventral part of

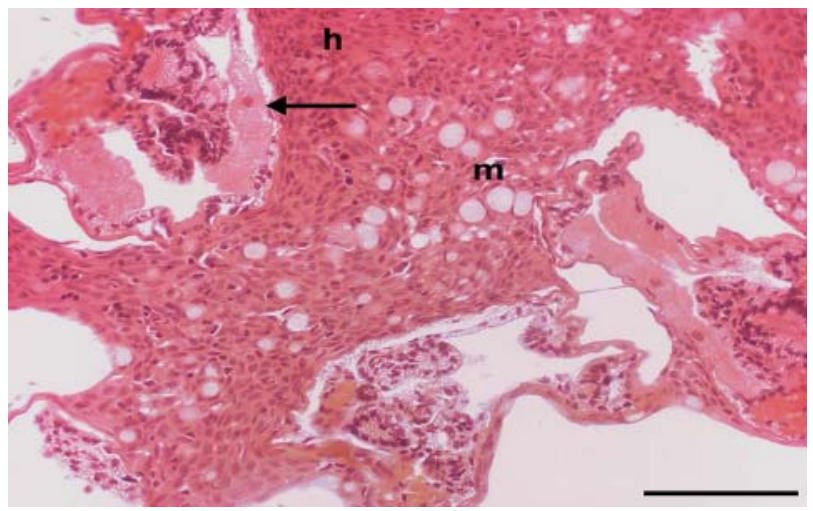

Fig. 58. Mollusc. Post-veliger mussel spat Mytilus edulis attached to secondary lamellae of Atlantic salmon Salmo salar (arrow). Note hyperplasia (h) and increased mucous cells (m). H\&E. Scale bar $=100 \mu \mathrm{m}$ 
the gill arch and burrows into the tissue of the host, eventually reaching the circulatory system where it feeds. The copepodid attaches to the end of the intermediate host gill lamellae, moults into the first chalimus stage and produces a bifurcate chitinous strand which enters the tip of the host gill filament, apparently via the perforations created by the claws, resulting in an intense local hyperplastic reaction with lamellar fusion (Fig. 59).

Argulus (Branchiura) attach to fish with the aid of 2 suction cup-like appendages (their first maxillae) and abundant little spines located over much of their underside. These lice have a long, slender preoral sting that they use to pierce the fish's skin and inject a toxin (or anticoagulant); then they use their mouth and mandibles to feed on blood, mucus, and tissue at the puncture site. Lernaea (Copepoda) infects all freshwater fish and is a serious problem in cyprinids. The parasite invades the skin, usually at the base of a fin, and ulcers produced by attachment of the parasite are slow to heal. The head develops into an anchor that holds the female in place. The female then develops egg sacs (2 fingerlike projections attached to the end of the body).

Salmon lice Lepeophtheirus salmonis (Copepoda) feed on host mucus, skin and blood, and when present in high numbers, cause serious damage to the skin with detrimental changes in physiological integrity, which can result in host death. A portion of the chitinous cuticle and striated muscle characteristic of Lepeophtheirus are visible in Fig. 60. Ceratothoa oestroides (Isopoda) is an example of a hermaphrodite parasite on a wide range of wild fish species. This parasite has become a threat to cage-reared fish facilities, where high fish density provides optimal conditions for transmission.

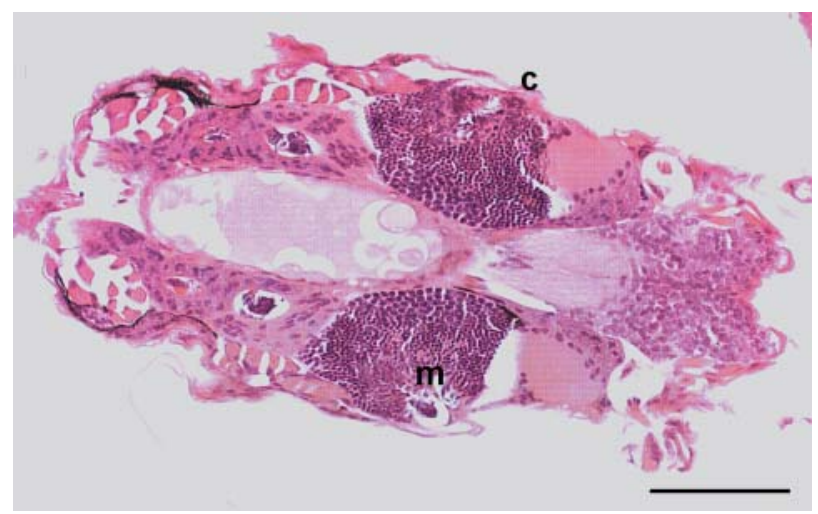

Fig. 59. Crustacea. Copepodid of Lernaeocera branchialis. The chalimus stage produces a bifurcate chitinous strand which enters the tip of the host gill filament causing an intense localised hyperplastic reaction with lamellar fusion. Chitinous cuticle (c) and striated muscle (m) are identified. H\&E. Scale bar $=100 \mu \mathrm{m}$

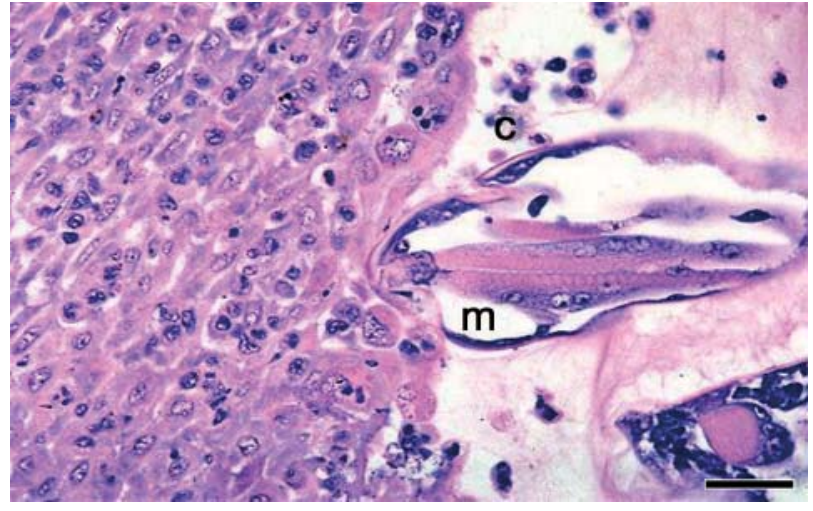

Fig. 60. Crustacea. Lepeophtheirus sp. attached to the skin of Atlantic salmon Salmo salar. A portion of the chitinous cuticle (c) and striated muscle (m), characteristic of arthropods, are clearly visible. H\&E. Scale bar $=50 \mu \mathrm{m}$

Acknowledgements. We thank Drs. I. Dyková for Figs. 5, 7, 12-17, 22, 26-28, 32, 34, 36, and 39, M. Kent for Fig. 21, T. Poppe for Fig. 30, B. MacConnell for Fig. 51, S. Feist for Fig. 52 and W. T. Yasutake for Figs. 2, 23, 25, 40, 47, and 57.

\section{LITERATURE CITED}

Abollo E, Novoa B, Figueras A (2005) SSU rDNA analysis of Kudoa rosenbuschi (Myxosporea) from the Argentinean hake Merluccius hubbsi. Dis Aquat Org 64:135-139

Adams M, Nowak BF (2001) Distribution and structure of lesions in the gills of Atlantic salmon (Salmo salar L.) affected with amoebic gill disease. J Fish Dis 24:535-542

Antonio DB, Andree KB, McDowell TS, Hedrick RP (1998) Detection of Myxobolus cerebralis in rainbow trout and oligochaete tissues by using a non-radioactive in situ hybridization (ISH) protocol. J Aquat Anim Health 10: 338-347

Arkush KD, Frasca Jr S, Hedrick RP (1998) Pathology associated with the rosette agent, a systemic protist infecting salmonid fish. J Aquat Anim Health10:1-11

Arkush KD, Mendoza L, Adkison MA, Hedrick RP (2003) Observations on the life stages of Sphaerothecum destruens n. g., n. sp., a mesomycetozoean fish pathogen formally referred to as the rosette agent. J Eukaryot Microbiol 50:430-438

Bartholomew JL, Yamamoto T, Rohovec JS, Fryer JL (1990) Immunohistochemical characterization of a monoclonal antibody against Ceratomyxa shasta. J Aquat Anim Health 2:68-71

Bruno DW (1988) The risk to farmed Atlantic salmon, Salmo salar L., from marine mussels growing on net cages. Bull Eur Assoc Fish Pathol 8:121-123

Bruno DW (2001) Dermocystidium sp., in Scottish Atlantic salmon, Salmo salar. Evidence for impact on fish in marine fish farms. Bull Eur Assoc Fish Pathol 21:209-213

Bruno DW, Poppe TT (1996) A colour atlas of salmonid diseases. Academic Press, London

Bruno DW, McVicar AH, Waddell IF (1988) Natural infection of farmed Atlantic salmon, Salmo salar L., parr by glochidia of the freshwater pearl mussel, Margaritifera margaritifera L. Bull Eur Assoc Fish Pathol 9:23-26 
Bruno DW, Collins RO, Morrison CM (1995) The occurrence of Loma salmonae (Protozoa:Microspora) in farmed rainbow trout, Oncorhynchus mykiss Walbaum, in Scotland. Aquaculture 133:341-344

Canning EU, Curry A, Feist SW, Longshaw M, Okamura B (1999) Tetracapsula bryosalmonae n. sp. for PKX organism, the cause of PKD in salmonid fish. Bull Eur Assoc Fish Pathol 19:203-206

Canning EU, Tops S, Curry A (2002) Ecology, development, and pathogenicity of Buddenbrockia plumatellae, Schröder, 1910 (Myxozoa, Malacosporea) (syn. Tetracapsula bryozoides) and establishment of Tetracapsuloides n. gen. for Tetracapsula bryosalmonae. J Eukaryot Microbiol 49:280-295

Cavalier-Smith T (1998a) A revised six-kingdom system of life. Biol Rev Camb Philos Soc 73:203-266

Cavalier-Smith T (1998b) Neomonada and the origin of animals and fungi In: Coombs GH, Vickerman K, Sleigh MA, Warre A (eds) Evolutionary relationships among protozoa. The Systematics Association, Spec Vol Ser 56. Kluwer Academic Publishers, Dordrecht, p 375-407

Cavalier-Smith T, Allsopp MTEP (1996) Corallochytrium, an enigmatic non-flagellate protozoan related to choanoflagellates. Eur J Parasitol 32:1-9

Chase JC, Dawson-Coates JA, Haddow JD, Stewart MH and 5 others (2001) Analysis of Kudoa thyrsites (Myxozoa: Myxosporea) spore antigens using monoclonal antibodies. Dis Aquat Org 45:121-129

Chitwood MB, Lichtenfels JR (1972) Identification of parasitic metazoa in tissue sections. Exp Parasitol 32:407-519

Clark G (1981) Staining procedures, 4th edn. Biological Stain Commission. Williams and Wilkins, Baltimore, MA

Cunningham CO (2002) Molecular diagnosis of salmonid diseases. Kluwer Academic Publishers, Dordrecht

Desser SS, Paterson WB (1978) Ultrastructural and cytochemical observations on sporogenesis of Myxobolus sp. (Myxosporida: Myxobolidae) from the common shiner Notropis cornutus. J Protozool 25:314-326

Dyková I, Lom J (1980) Tissue reactions to microsporidian infections in fish. J Fish Dis 3:265-283

Dyková I, Figueras A, Peric Z (2000) Neoparamoeba Page, 1987: light and electron microscopic observations on six strains of different origin. Dis Aquat Org 43:217-223

El-Matbouli M, Fischer-Scherl T, Hoffmann RW (1992) Present knowledge on the life cycle, taxonomy, pathology, and therapy of some Myxosporea spp. important for freshwater fish. Annu Rev Fish Dis 3:367-402

Feist SW (1997) Pathogenicity of renal myxosporeans of fish. Bull Eur Assoc Fish Pathol 17:209-214

Ferguson HW, (1989) Systemic pathology of fish. Iowa State University Press, Ames, IA

Franzen C, Müller A (1999) Molecular techniques for detection, species differentiation, and phylogenetic analysis of microsporidia. Clin Microbiol Rev 12:243-285

Gardiner CH, Poynton SL (1999) An atlas of metazoan parasites in animal tissues. Registry of Veterinary Pathology, Armed Forces Institute of Pathology, Washington, DC

Gardiner CH, Fayer R, Dubey JP (1998) An atlas of protozoan parasites in animal tissue. Registry of Veterinary Pathology, Armed Forces Institute of Pathology, Washington, DC

Herr RA, Ajello L, Taylor JW, Arseculeratne SN, Mendoza L (1999) Phylogenetic analysis of Rhinosporidium seeberi's 18S small-subunit ribosomal DNA groups this pathogen among members of the protoctistan Mesomycetozoa clade. J Clin Microbiol 37:2750-2754

Hoffman GL (1999) Parasites of North American freshwater fish. Comstock Publishing Associates (Cornell University Press), Ithaca, NY
Howard T, Carson J (1993) Verification that Paramoeba species are consistently associated with gill damage in fish affected with amoebic gill disease. In: Valentine P (ed) Seeking and solving. Proceedings of the Saltas Research and Development Review Seminar, Tasmania, 1993. Salmon Enterprises of Tasmania, Dover, TAS, p 69-80

Jones SRM, Prosperi-Porta G, Dawe SC, Barnes DP (2003) Distribution, prevalence and severity of Parvicapsula minibicornis infections among anadromous salmonids in the Fraser River, British Columbia, Canada. Dis Aquat Org 54:49-54

Jones S, Prosperi-Porta G, Dawe S, Taylor K, Goh B (2004) Parvicapsula minibicornis in anadromous sockeye (Oncorhynchus nerka) and coho (Oncorhynchus kisutch) salmon from tributaries of the Columbia River. J Parasitol 90:882-885

Karlsbakk E, Saether PA, Høstlund C, Fjellsøy KR, Nylund A (2002) Parvicapsula pseudobranchicola n.sp. (Myxozoa), a myxosporidian infecting the pseudobranch of cultured Atlantic salmon (Salmo salar) in Norway. Bull Eur Assoc Fish Pathol 22:381-387

Kent ML, Poppe TT (1998) Diseases of seawater netpenreared salmonid fish. Department of Fisheries and Oceans, Pacific Biological Station, Nanaimo, BC

Kent ML, Speare DJ (2005) Review of the sequential development of Loma salmonae (Microsporidia) based on experimental infections of rainbow trout (Oncorhynchus mykiss) and Chinook salmon (O. tshawytscha). Folia Parasitol (Praha) 52:63-68

Kent ML, Elliott DG, Groff JM, Hedrick RP (1989) Loma salmonae (Protozoa: Microspora) infections in seawater reared coho salmon Oncorhynchus kisutch. Aquaculture 80:211-222

Kent ML, Rantis V, Bagshaw JW, Dawe SC (1995) Enhanced detection of Enterocytozoon salmonis (Microspora), an intranuclear microsporean of salmonid fish, with the Warthin-Starry stain combined with hematoxylin and eosin. Dis Aquat Org 23:235--237

Kent ML, Khattra J, Hedrick RP, Devlin RH (2000) Tetracapsula renicola n. sp. (Myxozoa:Saccosporidae); the PKX myxozoan - the cause of proliferative kidney disease of salmonid fish. J Parasitol 86:103-111

Kent ML, Andree KB, Bartholomew JL, El-Matbouli M and 12 others (2001) Recent advances in our knowledge of the Myxozoa. J Eukaryot Microbiol 48:395-413

Lamas J, Bruno DW (1992) Observations on the ultrastructure of the attachment plate of Ichthyobodo sp., from Atlantic salmon, Salmo salar L., reared in the marine environment. Bull Eur Assoc Fish Pathol 12:171-173

Lom J, Arthur JR (1988) A guideline for the preparation of species descriptions in Myxosporea. J Fish Dis 12:151-156

Lom J, Dyková I (1992) Protozoan parasites of fish. Elsevier, Amsterdam

Lom J, Nilsen F (2003) Fish microsporidia: fine structural diversity and phylogeny. Int J Parasitol 33:102-127

Mendoza L, Taylor JW, Ajello L (2002) The class Mesomycetozoea: a heterogeneous group of microorganisms at the animal-fungal boundary. Annu Rev Microbiol 56:315-344

Morris DJ, Adams A, Richards RH (1997) Studies of the PKX parasite in rainbow trout via immunohistochemistry and immunogold electron microscopy. J Aquat Anim Health 9:265-273

Morris DJ, Adams A, Richards RH (2000) In situ hybridisation identifies the gill as a portal of entry for PKX (Phylum Myxozoa), the causative agent of proliferative kidney disease in salmonids. Parasitol Res 86:950-956

Muñoz P, Sitjà-Bobadilla A, Alvarez-Pellitero P (1998) Immunohistochemical characterization of a polyclonal 
antibody against Sphaerospora dicentrarchi (Myxosporea: Bivalvulida), a parasite from sea bass (Dicentrarchus labrax L.) (Teleostei: Serranidae). Parasitol Res 84:733-740

Nilsen F (2000) Small subunit ribosomal DNA phylogeny of microsporidia with particular reference to genera infecting fish. J Parasitol 86:128-133

Nilsen F (2003) Molecular phylogeny of microsporidia with emphasis on species infecting fish. Bull Scand Soc Parasitol 12-13:2002-2003

Noga EJ, Levy MG (1995) Dinoflagellida (Phylum Sarcomastigophora) In: Woo PTK (ed) Fish diseases and disorders, Vol 1. Protoxoan and metazoaninfections. CABI, Oxon, p 1-25

Nowak B, Elliott DG, Bruno DW (2002) The identification of parasites in fish tissue sections. Bull Eur Assoc Fish Pathol 22:173-177

Poynton SL, Sterud E (2002) Guidelines for species descriptions of diplomonad flagellates from fish. J Fish Dis 25: $15-31$

Ragan MA, Goggin CL, Cawthorn RJ, Cerenius L and 5 others (1996) A novel clade of protistan parasites near the animal-fungal divergence. Proc Natl Acad Sci USA 93: 11907-11912

Ribelin WE, Migaki G (eds) (1975) The pathology of fishes. University of Wisconsin Press, Madison, WI

Roberts RJ (2001) Fish pathology, 3rd edn. WB Saunders, London

Sawyer TK, Hnath JG, Conrad JF (1974) Thecamoeba hoffmani sp n (Amoebida: Thecamoebidae) from gills of fingerling salmonid fish. J Parasitol 60:677-682

Sawyer TK, Hoffman GL, Hnath JG, Conrad JF (1975) Infection of salmonid fish gills by aquatic amoebas (Amoebida: Thecamoebidae) In: Ribelin WE, Migaki G (eds) The pathology of fishes. University of Wisconsin Press, Madison, WI, p 143-150

Schachner O, Holzer A (2001) Gram staining and lectin binding properties of Myxosporea and Sporozoea. Biotech Histochem 75:15-22

Smothers JF, von Dohlen CD, Smith Jr LH, Spall RD (1994) Molecular evidence that myxozoan protests are metazoans. Science 265:1719-1721

Spanggaard B, Huss HH, Bresciani J (1995) Morphology of Ichthyophonus hoferi assessed by light and scanning electron microscopy. J Fish Dis 18:567-577

Sterba J, Milacek P, Vitovec J (1989) A new method for selective diagnostic staining of hooks of echinococci, cysticerci and tapeworms in histological sections. Folia Parasitol, Prague 36:341-344

Editorial responsibility: Otto Kinne (Editor-in-Chief), Oldendorf/Luhe, Germany
Sterud E, Simolin P, Kvellestad A (2003) Infection by Parvicapsula sp. (Myxozoa) is associated with mortality in seacaged Atlantic salmon Salmo salar in northern Norway. Dis Aquat Org 54:259-263

Summerfelt RC, Warner MC (1970) Incidence and intensity of infection of Plistophora [sic] ovariae, a microsporidian parasite of the golden shiner, Notemigonus crysoleucas. In: Snieszko SF (ed) A symposium on diseases of fish and shellfish. Spec Publ No 5, American Fisheries Society, Washington, DC, p 142-160

Thoeson JC (ed) (1994) Suggested procedures for the detection and identification of certain finfish and shellfish pathogens, 4th edn. Fish Health Section, American Fisheries Society, Bethesda, MA

Van de Peer Y, Ben Ali A, Meyer A (2000) Microsporidia: accumulating evidence that a group of amitochondriate and suspectedly primitive eukaryotes are just curious fungi. Gene 246:1-8

Whipps CM, Grossel G, Adlard RD, Yokoyama H, Bryant MS, Munday BL, Kent ML (2004) Phylogeny of the multivalvulidae (Myxozoa: Myxosporea) based on comparative ribosomal DNA sequence analysis. J Parasitol 3:618-622

Wittrock DD, Bruce CS, Johnson AD (1991) Histochemistry and ultrastructure of the metacercarial cysts of blackspot trematodes Uvulifer ambloplitis and Neascus pyriformis. J Parsitol 17:454-460

Woo PTK, Poynton SL (1995) Diplomonadida, Kinetoplastida and Amoebida (Phylum Sarcomastigophora). In: Woo PTK (ed) Fish diseases and disorders, Vol 1. Protozoan and metazoan infections. CABI, Wallingford, p 27-96

Woo PTK, Bruno DW, Lim SHL (eds) (2002) Diseases and disorders of finfish in cage culture. CABI, Oxon

Yasutake WT, Elliott DG (2003) Epizootiology and histopathology of Parvicapsula sp. in coho salmon Oncorhynchus kisutch. Dis Aquat Org 56:215-221

Yokoyama H, Inoue D, Sugiyama A, Wakabayashi H (2000) Polymerase chain reaction and indirect fluorescent antibody technique for the detection of Kudoa amamiensis (Multivalvula: Myxozoa) in yellowtail Seriola quinqueradiata. Fish Pathol 35:157-162

Young CA, Jones S (2005) Epitopes associated with mature spores not recognized on Kudoa thyrsites from recently infected Atlantic salmon smolts. Dis Aquat Org 63:267-271

Zilberg, D, Munday BL (2000) Pathology of experimental gill disease in Atlantic salmon (Salmo salar L.) and the effect of pre-maintenance of fish in seawater on the infection. J Fish Dis 23:401-407

Submitted: January 19, 2004; Accepted: March 28, 2006 Proofs received from author(s): June 7, 2006 